\title{
Fiscal Multipliers and Financial Crises
}

\author{
Miguel Faria-e-Castro * \\ New York University \\ January, 2017 \\ JOB MARKET PAPER \\ Click here for the latest version
}

\begin{abstract}
What is the impact of an extra dollar of government spending during a financial crisis? How important was U.S. fiscal policy during the Great Recession? I develop a macroeconomic model of fiscal policy with a financial sector that allows me to study the effects of fiscal policy tools such as government purchases and transfers, as well as of financial sector interventions such as bank recapitalizations and credit guarantees. Solving the model with nonlinear methods allows me to show how the linkages between household and bank balance sheets generate new channels through which fiscal policy can stimulate the economy, and study the state dependent effects of fiscal policy. I combine the model with data to assess the impact of the fiscal policy response during the financial crisis and Great Recession. My main findings are that: (i) the fall in consumption would have been $50 \%$ worse in the absence of fiscal interventions; and (ii) transfers to households and bank recapitalizations yielded the largest fiscal multipliers.
\end{abstract}

${ }^{*}$ I am extremely grateful to Thomas Philippon, Virgiliu Midrigan and Jaroslav Borovička for their guidance and advice during this project. I also thank Stephen Ayerst, Regis Barnichon, Jess Benhabib, Vadim Elenev, Mark Gertler, Dan Greenwald, Debbie Lucas, Joseba Martinez, Steven Pennings, Diego Perez, Thomas Sargent, Pedro Teles, Stijn Van Nieuwerburgh, Venky Venkateswaran, and Gianluca Violante for their very helpful comments, insights and suggestions. Finally, I thank all seminar participants at Banco de Portugal, Cambridge, Cornell, European Central Bank, Federal Reserve Board, FRB St Louis, FRB San Francisco, Georgetown, Indiana Kelley, LBS, LSE, Minnesota, MIT Sloan, Notre Dame, Nova SBE, NYU, NYU Stern, UT Austin McCombs, as well as participants at the 10th Meeting of the Portuguese Economic Journal and EconCon 2016 (Princeton) for questions and comments that helped me improve the paper. Contact: miguel. castro@nyu.edu 


\section{Introduction}

The recent global financial crisis and subsequent Great Recession led to renewed interest in fiscal policy by both policymakers and academics. As the use of conventional monetary policy to fight the recession became constrained by factors such as the zero lower bound in the U.S. or a system of fixed exchange rates in the eurozone, governments around the world relied on extraordinary fiscal stimulus packages to achieve macroeconomic stabilization. These packages included standard fiscal policy tools: public purchases of goods and services and social transfers or tax rebates to households, both of which have been extensively studied in macroeconomics. However, this period also saw unprecedented amounts of fiscal resources being committed to interventions in the financial sector. As a concrete example, the American Recovery and Reinvestment Act of 2009 (ARRA, the "Obama stimulus") consisted of outlays equivalent to 2.5\% of GDP at its peak, allocated to conventional fiscal policy tools. The Troubled Asset Relief Program (TARP), the umbrella program for most of the U.S. Treasury's financial sector interventions, involved outlays of over $6 \%$ of GDP in the fourth quarter of 2008 alone - twice as large as the ARRA.

In this paper, I study the effects of these different tools in the context of a quantitative assessment of the U.S. discretionary fiscal policy response to the financial crisis and Great Recession. I find that these interventions were very important to stabilize the economy: in their absence, the fall in aggregate consumption would had been one-third worse. In particular, I find that transfers and equity injections in the financial sector were the most important tools to achieve this goal, but with different redistributive implications.

To arrive at these results, I combine data with a model of fiscal policy, which I use as a measurement device to estimate shocks. I extend the workhorse New Keynesian model, the common framework to study fiscal multipliers, along several dimensions, including heterogeneous agents, incomplete markets, a financial sector, and equilibrium default. These ingredients provide a role for traditional fiscal tools such as purchases and transfers, as well as for financial sector interventions such as equity injections and credit guarantees. In the model, borrower households finance housing purchases with long-term debt. A financial sector supplies this credit, raising short-term deposits from savers. This sector is subject to a leverage constraint, which binds when capital is low, hampering intermediation. Both borrowers and banks can default on their debts, and this depends on leverage in each sector. Financial crises are modeled as exogenous shocks that raise the number of borrower defaults. This causes banks to post losses and reduce lending, affecting negatively borrower disposable income and private consumption.

The interaction between household and financial sector balance sheets augments the standard Keynesian channels through which conventional fiscal tools, purchases and transfers, operate. ${ }^{1}$ By raising borrower disposable income, fiscal policy also raises house prices. This reduces household leverage, relaxing borrowing constraints directly and reducing the number of defaults. In turn,

\footnotetext{
${ }^{1}$ Standard channels arise from the combination of monopolistic competition and nominal rigidities as outlined in Woodford (2011). These channels are complemented by the presence of non-Ricardian agents, who have a higher marginal propensity to consume out of current income (MPC), as described in Galí et al. (2007).
} 
banks post fewer losses and are able to lend more at lower rates, further raising current disposable income for borrowers. The government can also intervene directly in the financial sector. Bank recapitalizations directly facilitate the expansion of bank intermediation, by relaxing their constraints and moderating the financial accelerator. Guarantees on bank debt lower their funding costs, providing an implicit recapitalization. This operates through precautionary motives, and the government can stimulate the economy even without spending any resources in equilibrium.

Whether the constraints faced by borrowers and banks bind, and whether they are expected to bind, is very important to determine the effectiveness of different types of fiscal tools. This state dependence cannot be captured using standard solution techniques based on log-linearization around a steady state. For this reason, I solve the model with nonlinear methods. This allows me to capture the strongly nonlinear ways in which these policies interact, and study how their effects vary with the state of the economy.

I calibrate the model to the U.S., and use it to assess the fiscal policy response to the financial crisis of 2007-08 and the subsequent Great Recession. I assemble a comprehensive dataset of the fiscal policy response, which includes the Economic Stimulus Act of 2008 (the Bush tax rebates), the Troubled Asset Relief Program and the American Recovery and Reinvestment Act of 2009 (the Obama stimulus), among others. I map this data into the fiscal policy tools considered in the model, and apply a particle filter to the calibrated model in order to estimate sequences of policy-invariant structural shocks that allow the model to match the path of aggregate consumption and a measure of credit spreads in the data. By taking into account the fiscal policy response, this procedure estimates the sequences of structural shocks that allow me to study fiscal policy counterfactuals. Conceptually, the structural shocks are obtained by "inverting" the model and retrieving the sequences of shocks that allow the model to match some endogenous observable variables. Given that the model is nonlinear, this is not a trivial task, and I estimate conditional distributions for the shocks using a particle smoother. Armed with these distributions, I then ask the following question: how much worse would the Great Recession have been in the absence of discretionary fiscal interventions?

I find that fiscal interventions played an important role: aggregate consumption would have fallen by $1 / 3$ more in the absence of a fiscal policy response. I decompose the contribution of the different tools, and find that social transfer programs and bank recapitalizations had the largest effect on aggregate consumption. The former had the largest impact, by transferring resources from Ricardian savers to constrained borrowers. While bank recapitalizations had a smaller aggregate impact, they were much closer to generating a Pareto improvement, to the extent that they benefitted both savers (who own the banks) and borrowers (who benefit from being able to better smooth consumption at lower costs) alike. Finally, I use the estimated sequences of shocks to estimate time-varying fiscal multipliers for different policy tools in the U.S. I find that the fiscal multiplier for government purchases is remarkably stable and smaller than one. The fiscal multipliers for transfers and bank recapitalizations were very high at the peak of the crisis, but very low and even negative during periods of expansion.

This finding highlights the importance of analyzing the effects of fiscal policy across the state 
space. The effects of transfers vary so much due to two main economic forces: first, borrowing constraints are relaxed during expansions, which lowers the marginal propensity to consume out of current income (MPC) for borrowers. Second, transfers sustain house prices, which reduces default rates. This, in turn, reduces losses for banks and helps relax their leverage constraint. This, in turn, allows them to lend more and at lower rates. The strength of this second effect depends both on borrower MPC and on how tight the leverage constraint is for banks: for this reason it is particularly strong when the economy is in a recession and the financial sector is undercapitalized. Bank recapitalizations operate mainly through this second channel: they raise current lending and lower the cost of funds, thus raising borrower disposable income. While their aggregate impact is weaker, since they are a less direct way of raising borrower disposable income, their redistributive consequences are less stark, as they also benefit savers who own the financial sector.

Relation to the Literature This paper contributes to the evaluation of fiscal policy during the Great Recession, providing the first model-based comprehensive assessment of both conventional tools and financial sector interventions. ${ }^{2}$ Drautzburg and Uhlig (2015) study conventional fiscal policy during this period, in the context of a New Keynesian model; I extend their analysis by including a financial sector. This allows me to study the impact of conventional policy through this sector, as well as non-conventional fiscal tools that are targeted at intermediaries. Since these interventions draw on the same fiscal resources as traditional tools (taxpayer dollars), it makes sense to evaluate them using the same set of criteria that account for the stabilizing effects of these policies on the macroeconomy. This approach has been pioneered by Lucas (2016), who argues that the effective amount of stimulus provided by fiscal policy tends to be severely underestimated due to the omission of programs such as credit guarantees, particularly during severe downturns.

This work also contributes to the on-going debate about the effectiveness of the policy response to the Great Recession, especially in terms of its composition. Mian and Sufi (2014), for example, argue that the U.S. government devoted too many resources to supporting the financial sector at the onset of the financial crisis, while disregarding the situation of over indebted homeowners who were in the process of deleveraging. Several prominent policymakers have disagreed, defending the crucial role played by the financial sector in intermediating resources and ensuring that household deleveraging be undertaken in an orderly and controlled fashion (i.e. Geithner, 2015). The model I develop contributes to formalizing and quantifying these arguments: I find that transfers to borrowers were very important in preventing the drop in household spending, but that financial sector support was also important and with different redistributive consequences.

Several authors have explored the state dependence of fiscal multipliers for purchases and transfers in recent research: Auerbach and Gorodnichenko (2012) study multipliers in recessions and expansions for the U.S., and find spending multipliers of about 0.5 in expansions and 1.5-2 dollars in recessions. Ramey and Zubairy (2016) estimate smaller numbers, about 0.6 for the purchases multiplier, but they still find that spending multipliers tend to depend on the state of the econ-

\footnotetext{
${ }^{2}$ Blinder and Zandi (2015) perform a similar exercise, using a macroeconometric model.
} 
omy. My model-based estimates are consistent with those found by these authors, and larger in recessions than in expansions. ${ }^{3}$

Recent research on fiscal policy has been increasingly concerned with the impact of government transfers to households. Oh and Reis (2012) document that a large part of the conventional fiscal stimulus during the Great Recession was composed of social transfers (mainly Medicaid and unemployment insurance), and analyze the effectiveness of transfers and government purchases for macroeconomic stabilization in an Aiyagari-Bewley model with nominal rigidities. Kaplan and Violante (2014) further develop this argument, using data from the Survey of Consumer Finances and a structural model to show that the liquidity of household asset portfolios matters for their marginal propensity to consume out of current income and, therefore, for the consumption response to tax rebates. Unlike these studies I do not consider a full-blown Aiyagari-Bewley heterogeneous agents model, but I draw on their findings to motivate the introduction of a limited type of heterogeneity in my model in the tradition of Campbell and Mankiw (1989): I consider two types of households who differ in their preferences and access to financial assets. Savers are permanently unconstrained and act in a manner that is fully consistent with Ricardian Equivalence, accounting for the fact that current fiscal deficits are future tax liabilities. Borrowers, on the other hand, face a borrowing constraint and are non-Ricardian. Unlike most of the literature, I do not assume that these agents are permanently constrained, and thus their marginal propensity to consume out of current income varies depending on the state of the economy. I also improve on existing work by considering the role that transfers they play in the interaction between the household and financial sectors. In my model transfers reduce default rates by borrowers and help keep the financial system well-capitalized. Through this novel channel, this results in lower lending spreads and enables the flow of credit between different types of agents. ${ }^{4}$

My paper also contributes to the literature on fiscal interventions in the financial sector. Philippon (2010) models the interaction between household and bank balance sheets in a static setting, and evaluates the relative merits of transferring resources to households or banks, finding that the latter are preferable. I find that, for the purpose of macroeconomic stabilization, this may change with the state of the economy, in particular depending on which constraints bind and which sector has the highest level of leverage. Several papers have analyzed the impact of interventions such as bank bailouts on private incentives, and their implications for moral hazard and excessive risktaking in the financial sector: Farhi and Tirole (2012), Jeanne and Korinek (2013) and Chari and Kehoe (2016) all study how, in one way or another, the expectation of future transfers in states of the world in which there is a financial crisis may raise the likelihood that such crisis materializes in the first place. While such anticipation effects exist in my model, they are not the focus of my analysis. Financial crises are exogenous events in my model, even though the state of the economy (in particular household and bank leverage) matters for how severe the crisis is. This literature

\footnotetext{
${ }^{3}$ For other model-based treatments of the state dependence of fiscal multipliers, see Canzoneri et al. (2016) and Mertens and Ravn (2014).

${ }^{4}$ Galí et al. (2007) first emphasized that the effects of fiscal policy could be amplified in borrower-saver models. See also Mehrotra (2014) and Pennings (2016) for recent studies that use this device to study the impact of transfers.
} 
tends to focus on optimal policy from an ex-ante perspective, while I am interested in analyzing the ex-post effects of fiscal interventions. ${ }^{5}$

Structure The rest of the paper is organized as follows: section 2 describes the model and defines the equilibrium. Section 3 presents the calibration and explains some of the mechanisms in the model, emphasizing the interactions between the balance sheets of the different sectors. Section 4 describes the menu of fiscal policies available to the government, and how their effects vary with the state of the economy. In section 5 I conduct the main quantitative exercise of this work, which consists of evaluating fiscal policy during the Great Recession. Section 6 concludes.

\section{Model}

In this section I develop a dynamic general equilibrium model with nominal rigidities and financial crises that can be used as a laboratory to study different types of fiscal interventions. The model is set up in discrete and infinite time, $t=0,1,2, \ldots$. The economy is populated by five types of agents: households, who can be either borrowers or savers, financial firms (commercial banks), a corporate sector consisting of intermediate goods producers and final goods retailers, a central bank, and a fiscal authority.

The structure of the model is summarized in Figure 1: borrowers differ from savers to the extent that they derive utility from housing services and can finance housing purchases by borrowing in long-term debt. Banks intermediate funds between savers and borrowers, and they run a maturity mismatch as they fund their long-term loans with one-period deposits. Both borrowers and savers supply their labor to monopolistically competitive producers of intermediate goods, who in turn supply a representative retailer of final goods. Borrowers can default on their payments to the bank, and banks can default on their deposit payments to savers. The central bank sets the policy rate using a standard Taylor Rule. The overall structure is reminiscent of models developed by Iacoviello (2015) and Landvoigt (2016).

There are two exogenous shocks in the model: a total factor productivity (TFP) shock to the production function, and a credit risk shock that affects the rate at which borrowers default on their debt payments. Markets are incomplete, and all financial contracts take the form of risky debt (except for government debt, which is safe).

\footnotetext{
${ }^{5}$ Kollmann et al. (2013), Prestipino (2014) and Bianchi (2016) also analyze equity injections in the context of dynamic stochastic models. In these models, financial intermediaries allocate savings from depositors to investors/producers, unlike in my model where banks intermediate credit between households with different marginal propensities to consume in a way that is more similar to Cúrdia and Woodford (2010).
} 

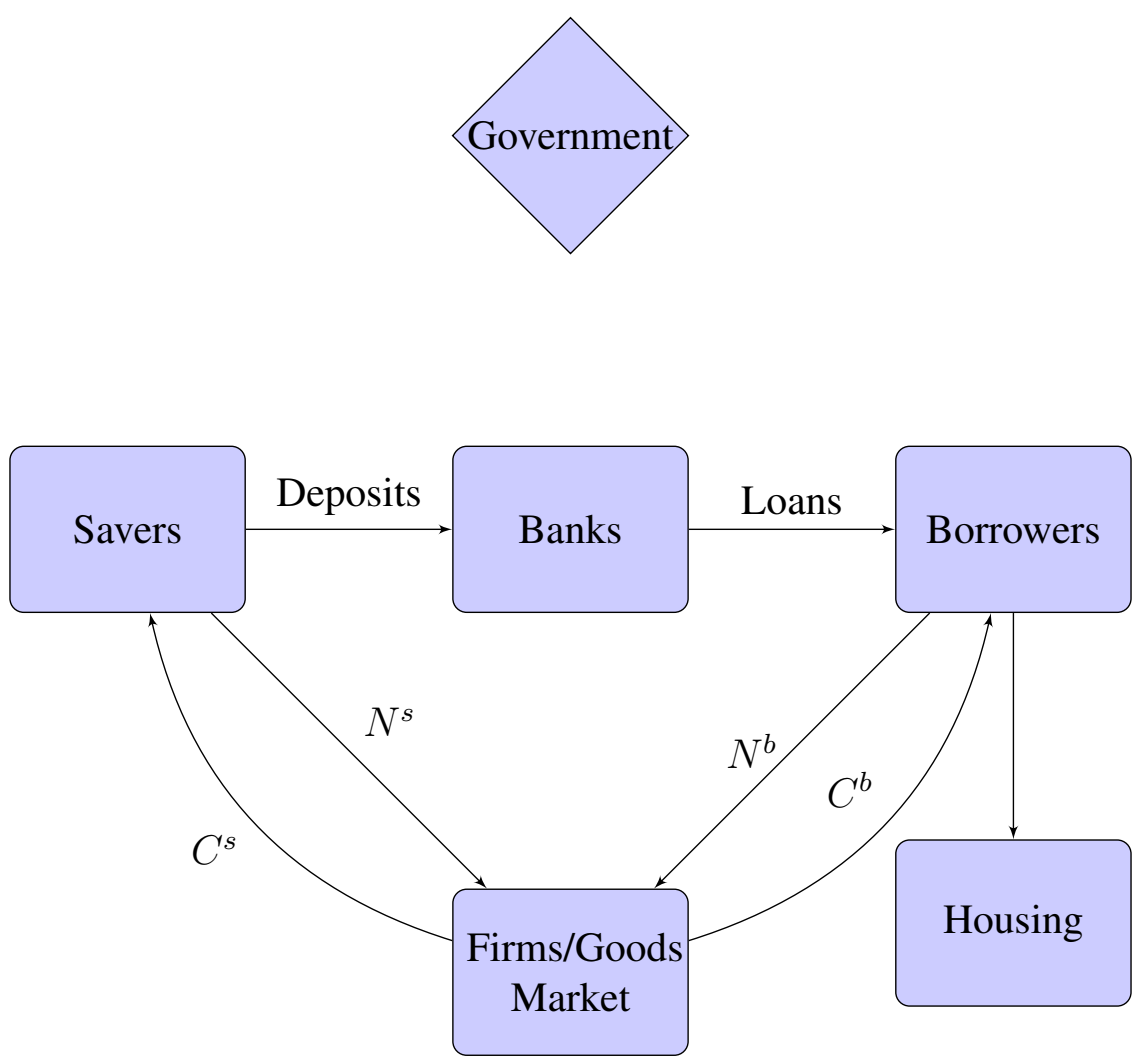

Figure 1: Structure of the Model

\subsection{Environment}

I now describe each type of agent in more detail, focusing on preferences, technology and market structure.

\subsubsection{Household Preferences}

There are two types of households, borrowers and savers, indexed by $i=\{b, s\}$ and in measures $\chi$ and $1-\chi$, respectively. Households differ in terms of the preferences and the type of financial assets they have access to. Savers can invest in short-term bank deposits and government debt, while borrowers can own houses and borrow in long-term debt. Savers own all firms and banks in the economy.

I assume that household preferences differ in two dimensions: borrowers derive utility from houses, and are less risk-averse than savers. Instantaneous utility is defined over streams of con- 
sumption $C_{t}^{i}$, labor $N_{t}^{i}$, and housing $h_{t}^{i}$, and is given by

$$
u_{t}^{i}=\log \left(C_{t}^{i}\right)-\frac{\left(N_{t}^{i}\right)^{1+\varphi}}{1+\varphi}+\xi^{i} \log \left(h_{t}^{i}\right)
$$

Logarithmic preferences over consumption implicitly set the elasticity of intertemporal substitution to one; $\varphi$ is the inverse of the Frisch elasticity of labor supply, and $\xi^{i}$ is the preference parameter for housing. I assume that $\xi^{b}>0=\xi^{s}$, so that savers do not derive any utility from housing services. Instantaneous utility is otherwise equal for both types.

Following Rudebusch and Swanson (2012), I assume that households value these streams of utility according to a modified Epstein-Zin specification given by

$$
V_{t}^{i}=u_{t}^{i}+\beta\left[\mathbb{E}_{t}\left(V_{t+1}^{i}\right)^{1-\alpha^{i}}\right]^{1 /\left(1-\alpha^{i}\right)}
$$

where $\alpha^{i}$ is a risk-aversion parameter. These preferences allow me to consider differences in riskaversion, while keeping the elasticity of intertemporal substitution constant across agent types. I assume that $\alpha^{b}<\alpha^{s}$, savers are more risk-averse than borrowers. It is worth noting that contrary to what is common in the literature, borrowers and savers do not differ according to their degree of patience.

\subsubsection{Savers}

Savers maximize utility (1) subject to a sequence of budget constraints of the type,

$$
P_{t} C_{t}^{s}+Q_{t}^{d} P_{t} D_{t}+Q_{t} P_{t} B_{t}^{g}=(1-\tau) P_{t} w_{t} N_{t}^{s}+Z_{t}^{d} P_{t-1} D_{t-1}+P_{t-1} B_{t-1}^{g}+P_{t} T_{t}+\Gamma_{t}
$$

where $D_{t}$ are real deposits, $B_{t}^{g}$ is real public debt, $Q_{t}$ is the price of debt (the inverse of the nominal interest rate), $w_{t}$ is the real wage, $\tau$ is a linear tax on labor, $T_{t}$ are lump-sum taxes (or transfers) from the government, and $\Gamma_{t}$ are net profits and transfers from the corporate and financial sectors. $Z_{t}^{d}$ is the payoff per unit of deposits, only realized at $t$ due to the possibility of bank failure and liquidation, as explained below. Savers maximize utility subject to a sequence of budget constraints of the type above. Their first-order conditions are standard and consist of asset pricing conditions for deposits, for government debt (the Euler Equation) and an intratemporal labor supply condition. ${ }^{6}$ It is useful to define the saver's stochastic discount factor for real payoffs,

$$
\Lambda_{t, t+1}^{s} \equiv \beta\left\{\frac{V_{t+1}^{s}}{\left[\mathbb{E}_{t}\left(V_{t+1}^{s}\right)^{1-\alpha^{s}}\right]^{1 /\left(1-\alpha^{s}\right)}}\right\}^{-\alpha^{s}} \frac{C_{t}^{s}}{C_{t+1}^{s}}
$$

\footnotetext{
${ }^{6}$ All equilibrium conditions, including the saver's optimality conditions, are reported in Appendix A.1.
} 


\subsubsection{Borrowers}

Borrowers derive utility from housing services and borrow in long-term debt to finance house purchases.

Household Debt Contracts Banks offer long-term debt contracts to borrowers. Each debt contract has a face value of one dollar and a price of $Q_{t}^{b}$. I assume that debt contracts have stochastic maturity: every period, a (one dollar) contract matures with probability $\gamma \in[0,1]$. When the debt contract matures, the borrower can choose whether to repay the bank or default. In the latter case, the bank seizes the housing assets that were pledged as collateral (i.e. the house gets foreclosed). The borrower enters the period with total (nominal) debt balances of $P_{t-1} \bar{B}_{t-1}^{b}{ }^{7}$ By the law of large numbers a fraction $\gamma$ of this stock of debt matures, and is either repaid or defaulted on. End-of-period debt balances can be written as

$$
P_{t} \bar{B}_{t}^{b}=P_{t} L_{t}+(1-\gamma) P_{t-1} \bar{B}_{t-1}^{b}
$$

where $L_{t} \geq 0$ corresponds to new loans that are contracted in the current period. The stochastic maturity structure allows us to summarize household debt using a single state variable. This approach is reminiscent of the modeling of long-term debt as geometrically decaying perpetuities as in Woodford (2001). ${ }^{8}$ In this context, $\gamma$ can be seen as the average (inverse) maturity of debt, with the limiting case of $\gamma=1$ corresponding to short-term, one-period debt contracts.

Default and Foreclosures To obtain partial default in equilibrium while keeping the model environment tractable, I assume a family construct for the borrower. ${ }^{9}$ The borrower household enters period $t$ with an outstanding debt balance $\bar{B}_{t-1}^{b}$ and some stock of housing $h_{t-1}$. At the beginning of the period, the borrower household is divided into a continuum of members indexed by $i \in[0,1]$. Each of these members receives an equal share of the debt balance and housing, $\left(\bar{B}_{t-1}^{b}, h_{t-1}\right)$, and a housing quality shock $\nu_{t}(i)$. This is an iid shock drawn from a distribution $F_{t}^{b}[0,+\infty)$ and satisfying $\mathbb{E}_{t}\left[\nu_{t}(i)\right]=1, \forall t$. This shock affects the quality and resale value of this member's housing stock. Letting $p_{t}^{h}$ denote the real price of houses in terms of the final consumption good, member $i$ 's housing stock is worth $\nu_{t}(i) p_{t}^{h} h_{t-1} \cdot{ }^{10}$

As described above, a fraction $\gamma$ of member $i$ 's outstanding debt balance matures every period. Given the resale value of housing, each member can thus choose to repay its maturing debt balances, or default and let the bank seize her housing assets. The cost of default is the loss of

\footnotetext{
${ }^{7} \mathrm{I}$ use the upper bar to simplify notation. Since there are a mass $\chi$ of borrwers, the aggregate level of debt is $B_{t-1}^{b}=\bar{B}_{t-1}^{b} / \chi$.

${ }^{8}$ The implications for default are different, however. For another treatment of long-term debt with stochastic maturity see Paul (2016).

${ }^{9}$ Similar approaches are adopted by Jeske et al. (2013), Landvoigt (2016) and Elenev et al. (2016).

${ }^{10}$ This housing quality shock can alternatively be interpreted as a housing depreciation shock. What is important is technological, affecting the house's exchange rate for final goods, and not a preference shock.
} 
this housing collateral. Let $\iota(\nu) \in\{0,1\}$ denote the default choice by member with house quality shock $\nu$. This indicator function is equal to one if this member defaults on her debt repayments, and zero otherwise. After default and repayment decisions are made, members reconvene in the borrower household who then takes all relevant decisions for the current period (including the states for the following period).

Budget and Borrowing Constraints Once individual members have made their default decisions, they are regrouped in the borrower household who centrally takes all static and intertemporal decisions. The borrower household chooses consumption, labor supply, new borrowing, new housing as well as the default rules for each individual member. ${ }^{11}$ The budget constraint, written in real terms, is

$C_{t}^{b}+\gamma \frac{\bar{B}_{t-1}^{b}}{\Pi_{t}} \int\left[1-\iota_{t}(\nu)\right] \mathrm{d} F_{t}^{b}+p_{t}^{h} h_{t}=(1-\tau) w_{t} N_{t}^{b}+Q_{t}^{b} L_{t}+p_{t}^{h} h_{t-1} \int \nu\left[1-\gamma \iota_{t}(\nu)\right] \mathrm{d} F_{t}^{b}-T_{t}+T_{t}^{b}$

where $T_{t}^{b}$ are lump-sum transfers from the government. New borrowing $L_{t}$ is defined in (3).

The borrower family is subject to two additional constraints. The first is a borrowing constraint, stating that new debt contracted this period cannot exceed a fraction of the total housing stock that is acquired in the current period,

$$
L_{t}=\bar{B}_{t}^{b}-\frac{\bar{B}_{t-1}^{b}}{\Pi_{t}}(1-\gamma) \leq \mathrm{m} p_{t}^{h} h_{t}
$$

The second constraint is a no-prepayment constraint, effectively imposing that new borrowing be positive,

$$
L_{t}=\bar{B}_{t}^{b}-\frac{\bar{B}_{t-1}^{b}}{\Pi_{t}}(1-\gamma) \geq 0
$$

Optimality The borrower household chooses $\left(C_{t}^{b}, L_{t}, N_{t}^{b}, h_{t},\left\{\iota_{t}(\nu)\right\}_{\nu \in[0,+\infty)}\right)$ to maximize (1) subject to (4), (5) and (6). It can be shown that the optimal default rule is static and given by a threshold rule: the borrower optimally defaults on all debt repayments for which $\nu<\nu_{t}^{*}$, where this threshold satisfies

$$
\nu_{t}^{*}=\frac{\bar{B}_{t-1}^{b}}{\prod_{t} p_{t}^{h} h_{t-1}}
$$

This default rule is very intuitive and reminiscent of limited liability for the members of the borrower household. Each member decides to repay maturing debt if the value of the collateral exceeds that of the debt repayment, and defaults otherwise. In equilibrium, default is positive and partial and the rate of defaults fluctuates with household leverage, which in turn depends on equilibrium

\footnotetext{
${ }^{11}$ This arrangement is thus implicitly equivalent to one where borrower family members are identical agents with access to a full set of contingent claims that allow them to hedge any idiosyncratic risks within the group.
} 
objects such as the house price. Another relevant optimality condition is the asset pricing equation for housing, which takes the form

$$
p_{t}^{h}=\frac{\frac{\xi}{h_{t}} C_{t}^{b}+\mathbb{E}_{t}\left\{\Lambda_{t, t+1}^{b} p_{t+1}^{h}\left[1-\gamma\left(1-\Psi_{t+1}^{b}\left(\nu_{t+1}^{*}\right)\right)\right]\right\}}{1-\lambda_{t}^{b} \mathrm{~m}}
$$

where $\lambda_{t}^{b}$ is the Lagrange multiplier on the borrowing constraint (5), and $\Lambda_{t, t+1}^{b}$ is the borrower's stochastic discount factor for real payoffs, defined analogously to (2). $\Psi_{t+1}^{b}\left(\nu_{t+1}^{*}\right)$ is a partial expectation for the house quality shock, defined as

$$
\Psi_{t}^{b}\left(\nu_{t}^{*}\right) \equiv \int_{\nu_{t}^{*}}^{\infty} \nu \mathrm{d} F_{t}^{b}(\nu)
$$

Condition (8) highlights the fact that housing markets are segmented, and only borrowers price houses. Through the first and second terms, the utility "dividend" from housing services and the continuation value, respectively, borrower consumption has a first order impact on house prices. This will be crucial for the transmission mechanisms of fiscal policy in this model.

\subsubsection{Corporate Sector}

The corporate sector consists of final goods retailers and intermediate goods producers. Final goods retailers are perfectly competitive and employ a continuum of intermediate goods varieties indexed by $k \in[0,1]$ to produce the final good using a Dixit-Stiglitz aggregator with constant elasticity of substitution $\varepsilon$

$$
Y_{t}=\left[\int_{0}^{1} Y_{t}(k)^{\frac{\varepsilon}{\varepsilon-1}} \mathrm{~d} k\right]^{\frac{\varepsilon-1}{\varepsilon}}
$$

There is a continuum of intermediate goods producers, each producing a different variety $k$. All firms are owned by the savers and have access to a linear production technology in labor,

$$
Y_{t}(k)=A_{t} N_{t}(k)
$$

where $A_{t}$ is an exogenous (aggregate) TFP shock. Given the CES technology assumption, each of these firms faces a demand schedule of the type

$$
Y_{t}(k)=\left[\frac{P_{t}(k)}{P_{t}}\right]^{-\varepsilon} Y_{t}
$$

I assume that firms are subject to menu costs for changing their prices. These real menu costs follow a standard quadratic functional form of the type

$$
d\left[P_{t}(k), P_{t-1}(k)\right] \equiv \frac{\eta}{2} Y_{t}\left[\frac{P_{t}(k)}{P_{t-1}(k)} \Pi^{-1}-1\right]^{2}
$$


where $\Pi$ is the inflation target set by the central bank ${ }^{12}$, and $\eta$ is the menu cost parameter. Appendix A.2 presents the details on the firm's problem. It shows that the first-order condition for an individual price setting firm $k$ combined with the assumption of a symmetric equilibrium yields a standard (nonlinear) Phillips Curve that related inflation to aggregate output,

$$
\eta \frac{\Pi_{t}}{\Pi}\left(\frac{\Pi_{t}}{\Pi}-1\right)+\varepsilon\left[\frac{\varepsilon-1}{\varepsilon}-\frac{w_{t}}{A_{t}}\right]=\eta \mathbb{E}_{t}\left[\Lambda_{t, t+1}^{s} \frac{Y_{t+1}}{Y_{t}} \frac{\Pi_{t+1}}{\Pi}\left(\frac{\Pi_{t+1}}{\Pi}-1\right)\right]
$$

\subsubsection{Financial Sector}

The modeling of the financial sector follows Gertler and Kiyotaki (2010), but with some important differences. Banks engage in maturity transformation by borrowing in short-term deposits and lending in long-term debt. Crucially, and contrary to the original reference, banks' balance sheets feature a fixed-income maturity mismatch, which exposes them to interest rate risk. While their assets are nominal fixed-income contracts, they are exposed to downside risk as borrowers may choose to default in their debt. The model is therefore able to capture the two most important risk factors to which modern commercial banks are exposed (Begenau et al., 2015). I assume that banks hold perfectly diversified portfolios of household debt, and this credit risk is systemic. Beyond this source of aggregate risk, I also assume that banks are exposed to idiosyncratic asset quality shocks. If a bank receives a sufficiently low asset quality shock it may be unable to repay all of its depositors in the current period, in which case it fails and its remaining assets are liquidated.

There is a continuum of banks indexed by $j \in[0,1]$; these banks are wholly owned by savers. Bank $j$ enters the period with a portfolio of debt securities $b_{j, t-1}$ and deposits $d_{j, t-1}$. Each deposit entitles its owner to a unit repayment, while each debt security yields a systemic payoff of $Z_{t}^{b}$. Furthermore, the bank receives shock $u_{j, t} \sim F^{d}$ on its asset portfolio. This means that (nominal) earnings at the beginning of the period are

$$
P_{t} e_{j, t}=u_{j, t} Z_{t}^{b} P_{t-1} b_{j, t-1}-P_{t-1} d_{j, t-1}
$$

Banks that are unable to fully repay their depositors default. This means that $\exists u_{j, t}^{*}$ such that the bank defaults if and only if $u_{j, t}<u_{j, t}^{*}$, where

$$
u_{j, t}^{*}=\frac{d_{j, t-1}}{Z_{t}^{b} b_{j, t-1}}
$$

The default threshold is equal to leverage divided by the aggregate return on the bank's assets. This means that periods of high household default, when $Z^{b}$ is low, may also trigger waves of bank default, and this is more likely when bank leverage is high.

I assume that due to contractual frictions that are left unmodeled, banks are forced to pay out a constant fraction $1-\theta$ of their earnings as dividends every period. Thus $\theta \in[0,1]$ is the fraction

\footnotetext{
${ }^{12}$ Costs are set-up in such a way that it is free to adjust to keep up with inflation.
} 
of earnings that are retained as (book) capital. To fund their activities, banks face a flow of funds or balance sheet constraint, expressed in real terms as

$$
Q_{t}^{b} b_{j, t}=\theta e_{j, t}+Q_{t}^{d} d_{j, t}
$$

The bank also faces a leverage constraint, which constrains the market value of its assets not to exceed the ex-dividend market value of the bank. Let $V_{j, t}\left(e_{j, t}\right)$ denote the real market value of the bank at the beginning of the period, before dividends are paid. The ex-dividend value of the bank is then given by

$$
\Phi_{j, t}\left(e_{j, t}\right) \equiv V_{j, t}\left(e_{j, t}\right)-(1-\theta) e_{j, t}
$$

The constraint imposes that this value must always exceed a fraction $\kappa$ of the market value of the bank's assets,

$$
\Phi_{j, t}\left(e_{j, t}\right) \geq \kappa Q_{t}^{b} b_{j, t}
$$

This constraint effectively caps the amount of lending that banks can offer every period. Banks seek to maximize the present discounted value of their dividends. The bank's problem, conditional on having survived the earnings shock this period, is then

$$
V_{j, t}\left(e_{j, t}\right)=\max _{b_{j, t}, d_{j, t}}\left\{(1-\theta) e_{j, t}+\mathbb{E}_{t}\left[\int_{u_{j, t+1}^{*}}^{\infty} \frac{\Lambda_{t, t+1}^{s}}{\Pi_{t+1}} \max \left\{0, V_{j, t+1}\left(e_{j, t+1}\right)\right\} \mathrm{d} F^{d}\right]\right\}
$$

Banks solve (13) subject to the law of motion for earnings (10), the flow of funds constraint (11), and the capital requirement (12). A detailed derivation of the bank's problem can be found in Appendix A.3. In the appendix, I show that $\Phi_{j, t}\left(e_{j, t}\right)=\Phi_{j, t} \theta e_{j, t}$, where $\Phi_{j, t}$ can be interpreted as the marginal value of a dollar of earnings for the bank. Letting $\mu_{j, t}$ denote the Lagrange multiplier on the leverage constraint, we can write the solution to the bank's problem as

$$
\mathbb{E}_{t}\left\{\frac{\Lambda_{t, t+1}^{s}}{\Pi_{t+1}}\left(1-\theta+\theta \Phi_{j, t+1}\right)\left[\Psi^{d}\left(u_{j, t+1}^{*}\right) \frac{Z_{t+1}^{b}}{Q_{t}^{b}}-\frac{1-F^{d}\left(u_{j, t+1}^{*}\right)}{Q_{t}^{d}}\right]\right\}=\kappa \mu_{j, t}
$$

where $\Psi^{d}\left(u_{t}^{*}\right) \equiv \int_{u_{t}^{*}}^{\infty} u \mathrm{~d} F^{d}(u)$ is a partial expectation term. This asset pricing condition highlights three potential sources of excess returns: binding constraints in the present, through $\mu_{j, t}$; bank default/limited liability through $\Psi^{d}, F^{d}$; and future binding constraints through $\Phi_{j, t+1}$. This last term comes from the envelope condition and is given by

$$
\Phi_{j, t}=\frac{\mathbb{E}_{t}\left\{\frac{\Lambda_{t, t+1}^{s}}{\Pi_{t+1}}\left(1-\theta+\theta \Phi_{j, t+1}\right)\left[1-F^{d}\left(u_{j, t+1}^{*}\right)\right]\right\}}{Q_{t}^{d}\left(1-\mu_{j, t}\right)}
$$


Aggregation and Bank Entry Since the shocks $u_{j, t}$ are iid across banks and time, condition (15) does not depend on any bank specific variable. This means that $\Phi_{j, t} \equiv \Phi_{t}, \forall j$. The appendix shows that the bank's problem is homogeneous of degree one in the level of current earnings $e_{j, t}$. Thus all banks take decisions that are proportional to their level of current earnings. Since all banks take proportional portfolio decisions, this also means that $\left(u_{j, t}^{*}, \mu_{j, t}\right) \equiv\left(u_{t}^{*}, \mu_{t}\right), \forall j$. While banks receive idiosyncratic shocks, they are able to readjust their portfolios every period such that there is no cross-sectional variation in ratios. This allows for simple aggregation of the banking system and, in particular, allows us to focus the analysis on a representative bank whose earnings correspond to aggregate earnings for the banking system.

Aggregate earnings $P_{t} E_{t}$ are comprised of earnings of surviving banks $P_{t} E_{t}^{s}$ plus earnings of new banks $P_{t} E_{t}^{n}$. Earnings for surviving banks are given by

$$
P_{t} E_{t}^{s}=P_{t-1} \int_{u_{t}^{*}}^{\infty}\left[u_{j, t} Z_{t}^{b} b_{j, t-1}-d_{j, t-1}\right] \mathrm{d} F^{d}(u)=P_{t-1}\left\{\Psi^{d}\left(u_{t}^{*}\right) Z_{t}^{b} B_{t-1}^{b}-\left[1-F^{d}\left(u_{t}^{*}\right)\right] D_{t-1}\right\}
$$

where I have used the fact that $u_{j, t}$ shocks are iid across banks. Since a fraction $F^{d}\left(u_{t}^{*}\right)$ of existing banks fails every period, I assume that an equal mass of banks enter the market. Each of those banks is given a set-up transfer equal to $\frac{\varpi}{F^{d}\left(u_{t}^{*}\right)} Q_{t}^{b} P_{t-1} B_{t-1}$, implying that

$$
P_{t} E_{t}^{n}=\varpi Q_{t}^{b} P_{t-1} B_{t-1}
$$

and thus real aggregate bank earnings evolve as

$$
E_{t}=\Pi_{t-1}^{-1}\left\{\Psi^{d}\left(u_{t}^{*}\right) Z_{t}^{b} B_{t-1}^{b}-\left[1-F^{d}\left(u_{t}^{*}\right)\right] D_{t-1}+\varpi Q_{t}^{b} B_{t-1}\right\}
$$

Asset Returns Let $\lambda^{b}, \lambda^{d}$ denote resource costs of default on household debt and deposits, respectively. Consider a bank that enters the period with a stock of debt securities worth $B_{t-1}^{b}$. Every period, a fraction $\gamma$ of these securities mature (given our assumption of perfect diversification), of which a fraction $1-F_{t}^{b}\left(\nu_{t}^{*}\right)$ are repaid, and the remaining ones default and yield the value of foreclosed housing. I assume that banks cannot hold housing assets, and must immediately resell these houses in the housing market. ${ }^{13}$ The remaining fraction of debt securities $1-\gamma$ remains outstanding and can be resold in the debt securities market at price $Q_{t}^{b}$. The payoff per dollar of debt securities is therefore given by

$$
Z_{t}^{b} \equiv(1-\gamma) Q_{t}^{b}+\gamma\left[1-F_{t}^{b}\left(\nu_{t}^{*}\right)+\left(1-\lambda^{b}\right) \frac{1-\Psi_{t}^{b}\left(\nu_{t}^{*}\right)}{\nu_{t}^{*}}\right]
$$

Similarly, for bank deposits, we define the unit return as $Z_{t}^{d}$, which can be written as

$$
Z_{t}^{b}=1-F^{d}\left(u_{t}^{*}\right)+\left(1-\lambda^{d}\right) \frac{1-\Psi^{d}\left(u_{t}^{*}\right)}{u_{t}^{*}}
$$

\footnotetext{
${ }^{13}$ These houses are bought by the borrowers, who are the only agents that can hold them intertemporally.
} 


\subsubsection{Housing}

As previously explained, I assume that the housing market is segmented: borrowers are the only agents that derive utility from housing services, and the only agents that are allowed to hold housing assets intertemporally. This assumption is useful to generate larger movements in house prices, as these are determined using the borrower's stochastic discount factor. Movements in house prices are important in determining equilibrium default rates, and generate pecuniary externalities through the borrowing constraint. ${ }^{14}$ Foreclosed houses that are held by the banks are immediately resold back to the borrowers. For simplicity, I also assume that the supply of housing is fixed and normalized to $\chi, h_{t}=\chi, \forall t$. This assumption, coupled with the fact that $\mathbb{E}_{t}(\nu)=1, \forall t$ means that the total, quality-adjusted supply of housing in the economy is equal to $\chi$ at every point in time, $h_{t} \int \nu \mathrm{d} F_{t}^{b}(\nu)=\chi, \forall t .^{15}$

\subsubsection{Government}

The government consists of separate and independent monetary and fiscal authorities.

Monetary Policy The central bank conducts conventional monetary policy by following a standard Taylor Rule, through which the policy interest rate $Q_{t}^{-1}$ responds to deviations of output and inflation from their targets,

$$
Q_{t}^{-1}=\bar{Q}^{-1}\left[\frac{\Pi_{t}}{\overline{\bar{\Pi}}}\right]^{\phi_{\Pi}}\left[\frac{Y_{t}}{\bar{Y}}\right]^{\phi_{Y}}
$$

where $\bar{Y}, \bar{Q}$ are the steady state values of output and the nominal interest rate. Since I depart from the standard representative agent framework, it is not obvious what optimal monetary policy should look like outside of a standard linear-quadratic framework as pointed out by McKay and Reis (2016). While acknowledging this, I nevertheless choose the above Taylor Rule so as to remain as close to the existing literature as possible.

Fiscal Policy Fiscal policy is conducted by a fiscal authority that is in charge of spending, taxation and discretionary fiscal interventions. The government's budget constraint is

$$
P_{t-1} B_{t-1}^{g}+P_{t} G_{t}+\sum_{\omega \in \Omega} \operatorname{Net}^{\operatorname{Costs}_{\omega}}=\tau P_{t} Y_{t}\left[1-d\left(\Pi_{t}\right)\right]+P_{t} T_{t}+Q_{t} P_{t} B_{t}^{g}
$$

On the left-hand side we have expenditures: maturing debt, government purchases of the final goods, and net costs of extraordinary fiscal measures $\omega \in \Omega$. On the right-hand side we have

\footnotetext{
${ }^{14}$ This assumption of market segmentation has also been used by Garriga et al. (2015) and Greenwald (2016), for example.

${ }^{15}$ This normalization is chosen to simplify algebra and the derivation of the aggregate resource constraints, but is easily relaxed - the model can be easily extended to handle aggregate shocks to the average quality of housing.
} 
sources of revenue: income taxes, lump-sum taxes and bond issuances. Income taxes are levied on corporate profits and labor income, which can be shown to be equal to total output net of menu costs.

Since the focus of this paper is the analysis of extraordinary fiscal policy measures, I try to keep the rest of fiscal policy as simple as possible: I assume that both income taxes $\tau$ as well as government spending during normal times are fixed, thus $G_{t}=\bar{G}$ in the absence of extraordinary measures. In order to satisfy the intertemporal budget constraint, I allow lump-sum taxes to respond to deviations of public debt from its steady state level according to a simple fiscal rule of the form

$$
T_{t}=\phi_{T}\left(\log B_{t-1}^{g}-\log \bar{B}^{g}\right)
$$

where $\bar{B}^{g}$ is the steady state level of public debt and $\phi_{T}$ is the speed of adjustment: as discussed later in the calibration section, this parameter will be set to a small number so that large changes in fiscal outlays or revenues are mostly absorbed by public debt in the short-run.

\subsection{Equilibrium}

Equilibrium is defined in the standard way: it consists of allocations, prices and policies such that (i) all agents choose allocations and optimize given prices and policies, (ii) prices clear markets given allocations and policies, (iii) policies satisfy the government's budget constraint. A full list of the model's equilibrium conditions is provided in Appendix A.1.

For reference, the aggregate resource constraint is given by

$$
C_{t}+G_{t}+\lambda^{b} \gamma \chi p_{t}^{h}\left[1-\Psi_{t}^{b}\left(\nu_{t}^{*}\right)\right]+\lambda^{d} Z_{t}^{b} \frac{B_{t-1}^{b}}{\Pi_{t}}\left[1-\Psi^{d}\left(u_{t}^{*}\right)\right]=Y_{t}\left[1-\frac{\eta}{2}\left(\frac{\Pi_{t}}{\Pi}-1\right)^{2}\right]
$$

where $Y_{t} \equiv A_{t} N_{t}$ is gross output, $C_{t} \equiv \chi C_{t}^{b}+(1-\chi) C_{t}^{s}$ is aggregate consumption and $N_{t} \equiv$ $\chi N_{t}^{b}+(1-\chi) N_{t}^{s}$ are aggregate hours. Throughout, I focus on the fiscal multiplier of fiscal policies over GDP, which I define as total consumption by the private and public sectors (or absorption),

$$
G D P_{t}=C_{t}+G_{t}
$$

The difference between GDP and output are the resource costs of household default, bank default, and price-setting.

\section{Model Analysis and Calibration}

Before discussing the effects of fiscal policy, I use this section to present the calibration, describe the solution method, and discuss some of the positive aspects of the model. 


\subsection{Calibration}

The period in the model is a quarter. Most parameters are chosen so that the model's steady state matches moments of the U.S. economy and financial system in the early 2000's, prior to the 2007 financial crisis. The model has several parameters, which I group into four broad categories: standard macro, policy, household finance, and banking parameters. The calibration is summarized in Table 1.

Standard Macro Parameters These are the standard parameters related to preferences and technology that are chosen to be in line with the large literature on New Keynesian models. The discount factor is set at $\beta=0.99$ to generate an annualized real interest rate of $4 \%$ at the deterministic steady state. ${ }^{16}$ The inverse Frisch elasticity of labor supply is set to be $\varphi=1$, which is an average value in macroeconomic models, especially given the absence of any sort of labor market frictions or wage rigidities. The elasticity of substitution across varieties is set at $\varepsilon=6$, implying an average mark-up of $20 \%$ at the steady state. To choose the Rotemberg menu cost parameter, I set $\eta$ such that the slope of a linearized Phillips Curve would coincide with that of a Calvo-type model where the probability of readjusting the price every period is equal to $25 \%$. This corresponds to a "Calvo parameter" of 0.75 , a standard value in macroeconomic models that implies that prices are adjusted once a year on average. This procedure yields $\eta=58.25$.

Policy Parameters I assume standard values for the Taylor Rule parameters, $\phi_{\Pi}=1.5$ and $\phi_{Y}=0.5 / 4$. I assume that the Central Bank pursues an annualized inflation target of $2 \%$.

For fiscal policy flows, I assume standard targets as percentages of steady state output. I set $\bar{G}$ to be $20 \%$ of steady state GDP, which is an average number for the U.S.. The value of $\bar{B}^{g}$, the steady state level of public debt, matters greatly for determining the tax rate, as $\bar{\tau}$ emerges as the rate that balances the government's budget in steady state, while taking into account the costs of rolling over the stock of debt (as I assume that lump-sum taxes/transfers are zero at steady state). In my model all public debt needs to be rolled over at a quarterly frequency. Using a standard target of $70 \%$ of annual GDP would imply a high value $4 \times 70 \%=280 \%$ of quarterly GDP, which would in turn imply very high tax rates. Before the financial crisis, the average (marketvalue weighted) maturity of U.S. Federal debt was of 20 quarters (60 months). Thus, in any given quarter, the government rolls over approximately $280 \% / 20=14 \%$ of quarterly GDP in public debt. I therefore set $\bar{B}^{g}$ to be $14 \%$ of steady state GDP. At the steady state, these values imply an income tax rate of $24.17 \%$, which is higher than the US (15.9), but reflects the absence of any other taxes in the model. I assume that the fiscal policy rule parameter is $\phi_{T}=0.05$, consistent with the estimates of Leeper et al. (2010). This low number ensure that lump-sum taxes/transfers move slowly, and most short-term public finance adjustments are absorbed by government debt.

\footnotetext{
${ }^{16}$ Given that the model will be solved nonlinearly, precautionary motives imply that the interest rate is lower than $4 \%$ at the stochastic steady state.
} 
Household Finance and Borrowers The model features a set of non-standard parameters related to household finance that I choose to match pre-crisis moments of the U.S. economy. The parameter on the borrowing constraint is chosen to generate a ratio of household debt to GDP of $80 \%$, the value in the early 2000's. This is low compared to the value of household debt to GDP at the height of the housing boom, but this is accounted for by the fact that household debt is procyclical and this period will be treated as an expansion. This implies $\mathrm{m}=0.2030$. The preference parameter for housing is chosen to match an aggregate loan-to-value ratio of $80 \%$, a very stable feature of the U.S. economy between the early 1990's and the financial crisis of 2007; this yields $\xi=0.0347$, which is a value in line with that chosen in other similar models. The credit risk distribution $F_{t}^{b}$ is assumed to be Beta, with time-varying dispersion and a constant mean equal to one. The distribution is thus characterized by a single time-varying parameter, $\sigma_{t}^{b}$. The Beta assumption implies that we have closed form expressions for the distribution function and partial expectation that appear in the equilibrium conditions,

$$
\begin{aligned}
& F_{t}^{b}\left(\nu_{t}^{*}\right)=\left[\frac{\sigma_{t}^{b} \nu_{t}^{*}}{\sigma_{t}^{b}+1}\right]^{\sigma_{t}^{b}} \\
& \Psi_{t}^{b}\left(\nu_{t}^{*}\right)=1-\left[\frac{\sigma_{t}^{b} \nu_{t}^{*}}{\sigma_{t}^{b}+1}\right]^{\sigma_{t}^{b}+1}
\end{aligned}
$$

I assume that $\sigma_{t}^{b}$ follows a two-state Markov chain, with a high and low risk states, $\sigma_{t}^{b} \in\left\{\sigma^{b, \text { crisis }}, \sigma^{b \text {,normal }}\right\}$. The transition probability matrix is

$$
\mathbf{P}^{b}=\left[\begin{array}{cc}
0.80 & 0.20 \\
0.005 & 0.995
\end{array}\right]
$$

This means that crises are infrequent, but relatively persistent. The economy has an unconditional probability of being in a crisis of $2.44 \%$. To choose the values of the states, I target a steady-state, low risk, non-performing loan rate of $2 \%$. This yields $\sigma^{b \text {,normal }}=12.9280$. I set $\sigma^{b \text {,crisis }}$ to $40 \%$ of that value, which implies that if the steady state economy were to suddenly enter the crisis state, the default rate would be $10 \%$ caeteris paribus. These probabilities also imply that the economy spends, on average, two years in a financial crisis, consistent with the estimates by Jordà et al. (2016). Finally, I set $\lambda^{b}=0.3$, which is in line with the evidence on losses given default for U.S. bank secured loan portfolios in Ross and Shibut (2015).

One crucial parameter is the fraction of borrowers, $\chi$, which I pick to ensure that the model is able to replicate the estimates of Parker et al. (2013) and Broda and Parker (2014) of the impact of the 2008 Bush tax rebate on aggregate consumption. I choose $\chi$ to ensure that, given the state of the economy in 2008, a transfer to borrowers of the same magnitude as the tax rebates (relative to GDP) have the same impact on aggregate consumption: a $1.3 \%$ increase in the second quarter of 2008 and a $0.6 \%$ increase in the third. Setting $\chi=0.45$ achieves the desired effect, and this number is also broadly consistent with the fraction of borrowers estimated and/or calibrated by 
other authors based on different datasets and targets. Using 2001 Survey of Consumer Finances (SCF) data, Kaplan and Violante (2014) estimate that between $17.5 \%$ and 35\% are hand-to-mouth in the United States. While this number is lower than mine, borrowers in the model will not behave as hand-to-mouth when their borrowing constraint is not binding. Broda and Parker (2014) estimate that around $40 \%$ of households in the U.S. are liquidity constrained, based on Nielsen survey data. Finally, Elenev et al. (2016) use several waves of the SCF to estimate the fraction of the population with a negative fixed income positions, and arrive at $47 \%$, a number similar to mine.

Banking I set $\gamma=1 / 4$, which implies a maturity gap of 1 year, lower than the evidence uncovered by English et al. (2014). $\theta=0.9$ is set to match an average payout rate of $10 \%$ for large U.S. commercial banks. The initial transfer to starting banks is set at $\lambda=0.0105$. This ensures that the bank constraint does not bind at the steady state, and that the deterministic steady state spread on debt securities reflects only credit risk. The distribution for bank idiosyncratic shocks is a generalized Beta with support $[\underline{u}, \bar{u}]$ and given by

$$
F^{d}(u)=\frac{u^{\sigma^{d}}-\underline{u}^{\sigma^{d}}}{\bar{u}^{\sigma^{d}}-\underline{u}^{\sigma^{d}}}
$$

I set $\sigma^{d}=1, \underline{u}=0.91, \bar{u}=1.09$. This ensures that the mean asset quality shock is equal to one, and that the probability of bank default is zero at the deterministic steady state. The leverage constraint parameter is chosen to match a leverage ratio of around 10 for large U.S. commercial banks, $\kappa=0.1$. 


\begin{tabular}{|c|c|c|c|}
\hline Parameter & Description & Value & Target \\
\hline \multicolumn{4}{|c|}{ Standard Parameters } \\
\hline$\beta$ & Discount factor & 0.99 & Annualized real interest rate of $4 \%$ \\
\hline$\varphi$ & Frisch elasticity & 1 & Standard \\
\hline$\varepsilon$ & Micro ES across varieties & 6 & $20 \%$ mark-up in SS \\
\hline$\eta$ & Rotemberg Menu Cost & 58.25 & Prices adjusted once every four quarters \\
\hline \multicolumn{4}{|c|}{ Policy Parameters } \\
\hline$G$ & SS Govt. Spending & $0.2 \times Y$ & $20 \%$ for the U.S. \\
\hline $\bar{B}^{g}$ & SS Govt. Debt & $0.14 \times Y$ & Avg. debt maturity of 20 months and $70 \%$ of annual GDP \\
\hline $\bar{\Pi}$ & Trend Inflation & $1.02^{0.25}$ & $2 \%$ for the U.S. \\
\hline$\phi_{\Pi}$ & Taylor Rule - Inflation & 1.5 & Standard \\
\hline$\phi_{Y}$ & Taylor Rule - Output & $0.5 / 4$ & Standard \\
\hline$\phi_{\tau}$ & Fiscal Rule & 0.05 & Leeper et al. (2010) \\
\hline \multicolumn{4}{|c|}{ Borrower Parameters } \\
\hline$\chi$ & Fraction of borrowers & 0.45 & Response of Consumption to ESA2008 in Parker et al. (2013) \\
\hline$\widehat{\alpha^{b}}$ & Risk-aversion for borrower & 2 & \\
\hline $\mathrm{m}$ & Borrowing constraint & 0.2030 & Household debt to GDP of $80 \%$ \\
\hline$\xi$ & Housing preference & 0.0347 & Loan to value of $80 \%$ (SCF) \\
\hline$\sigma^{b}$ & House quality parameter & 12.928 & NPL/Total loans of $2 \%$ \\
\hline$\lambda^{b}$ & Loss given default & 0.3 & FDIC data \\
\hline \multicolumn{4}{|c|}{ Banking Parameters } \\
\hline$\alpha^{s}$ & Risk-aversion for saver & 4 & \\
\hline$\gamma$ & Duration of debt & 0.25 & Maturity gap of 1 year \\
\hline$\theta$ & Retained earnings & 0.9 & Payout rate of $10 \%$ \\
\hline$\kappa$ & Leverage constraint & 0.10 & Book leverage of 10 \\
\hline$\varpi$ & Transfer to new banks & 0.0105 & Lending spread of $2 \%$ annualized \\
\hline \multicolumn{4}{|c|}{ Shock Parameters } \\
\hline$\rho_{a}$ & Persistence of TFP & 0.926 & Utilization-adj. TFP for Consumption, Fernald (2012) \\
\hline$\sigma_{a}$ & SD of TFP Innovations & 0.0040 & Utilization-adj. TFP for Consumption, Fernald (2012) \\
\hline$\sigma^{b, \text { risky }}$ & House quality during crises & 5.171 & NPL rate of $10 \%$ during crises \\
\hline $\operatorname{Pr}\left(\operatorname{crisis}_{t} \mid \operatorname{crisis}_{t-1}\right)$ & Crisis persistence & 0.8 & Jordà et al. (2016) \\
\hline
\end{tabular}

Table 1: Summary of the Calibration

\subsection{Model Solution}

One important object of the analysis in this paper is the state dependence of the effects of different fiscal policy tools. For this reason, traditional solution methods such as a first-order approximation around a deterministic steady state are not sufficient. For example, credit guarantees have an impact mostly through precautionary motives, which would not adequately be captured by solution techniques that disregard higher order terms. Furthermore, the model features two occasionally binding constraints which influence this state dependence. For that reason, higher order approximation methods do not suffice either. To capture these nonlinearities and precautionary motives, I use global solution methods. In particular, I use a collocation-based method that combines time iteration (Judd et al., 2002) with multilinear interpolation.

The occasionally binding constraints, for the banks and the borrowers, pose technical chal- 
lenges. For this reason, I opt to use multilinear interpolation as opposed to global shape-preserving methods (such as higher order splines or Chebyshev polynomials). The reason is that multilinear interpolation is more flexible at dealing with the strong nonlinearities that occur in the points of the state space where constraints start (and stop) binding. ${ }^{17}$ The model is solved by discretizing the state space, approximating the minimal set of variables needed to compute the equilibrium in a functional space, and updating these approximated guesses using time iteration. The computational details of the solution method as well as robustness and accuracy checks regarding the numerical solution can be found in Appendix B.1.

\subsection{Technology Shock}

To understand the model's dynamics, it is instructive to first look at the response of the economy's variables to a standard technology shock. Figure 2 plots Generalized Impulse Response Functions (GIRF) of macroeconomic and financial variables to a one standard deviation TFP shock. Variables are expressed in percentage deviations from their stochastic steady state value, which is also used as the starting point for the impulse. ${ }^{18}$ Details on how these GIRF are generated can be found in Appendix B.3.

GDP responds positively to a TFP shock, as normal in this class of models. Importantly, since borrowers have a higher marginal propensity to consume out of their disposable income, and labor incomes rises, their consumption increases relatively more in response to a TFP shock. As the final panel illustrates, this effect is complemented by lower spreads on their borrowing. Lending spreads fall for two main reasons: first, as borrower consumption increases and house prices rise, the default rate falls. This results in a fall of credit risk, leading to lower spreads. Second, and as explained before, banks run a maturity mismatch and are thus exposed to interest rate risk. As inflation falls and the central bank lowers interest rates, this raises bank profits. As banks are now better capitalized, and the likelihood of their leverage constraint binding in the future falls, the excess premium they demand on lending also falls.

\subsection{Financial Crises}

What do financial crises look like in the model? I define a crisis as any period of high credit risk, when $\sigma_{t}^{b}=\sigma^{b \text {,crisis }}$. This essentially acts as an exogenous shock to borrower default risk: as the house quality distribution is hit by a mean-preserving spread, the default rate rises for the same level of household leverage $\nu_{t}^{*}$. This causes immediate losses for banks through reduced debt

\footnotetext{
${ }^{17}$ The key disadvantage of multilinear interpolation with respect to these other methods is that it is typically worse at extrapolation. I address this concern by choosing grids for the endogenous states that minimize extrapolation.

${ }^{18}$ I use the term "stochastic steady state" in the sense of the risky steady state of Coeurdacier et al. (2011), which is the point to which the economy converges in the absence of exogenous innovations, even when agents expect that these might occur. It differs from the non-stochastic steady state to the extent that it features precautionary behavior by the agents.
} 

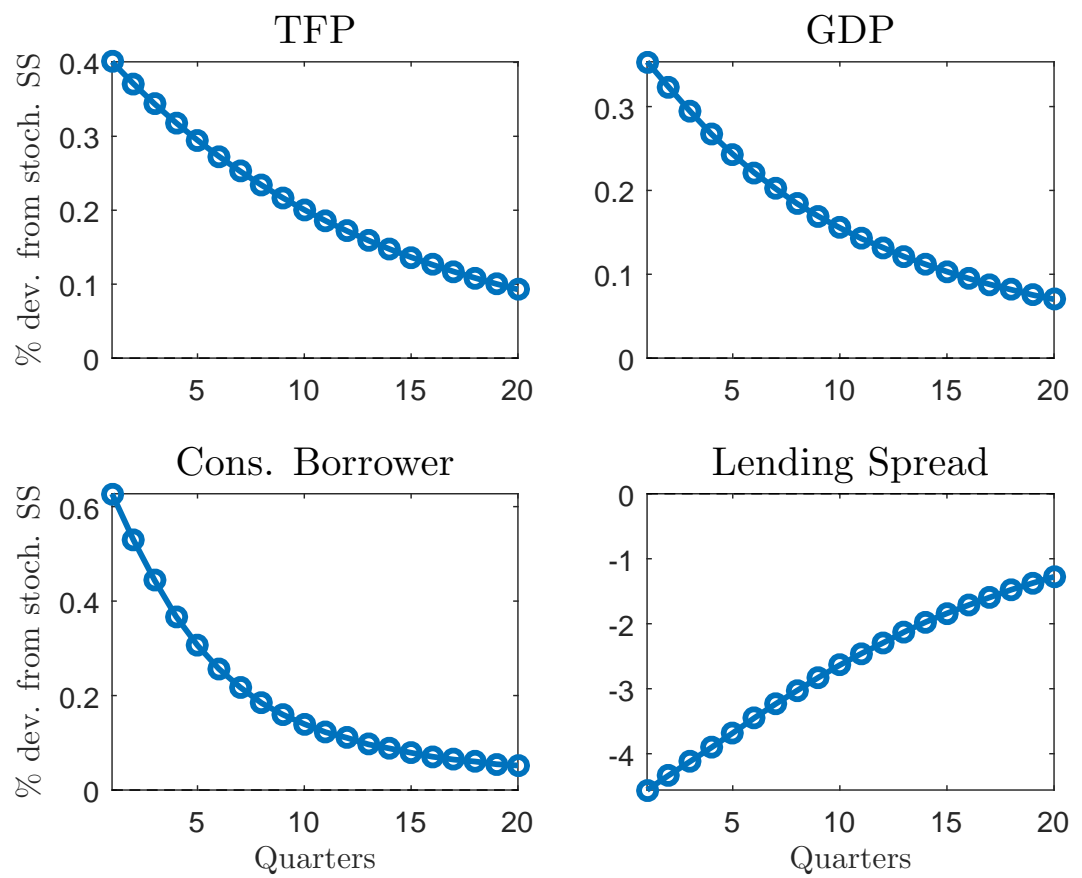

Figure 2: Generalized Impulse Response Functions to TFP shock.

repayments in the current period. Further losses are caused by a financial accelerator effect that arises from the interaction between the banks' leverage constraint and the fact that debt is longterm. If current losses are large enough to make banks' constraint bind, spreads rise further and this is achieved by falling prices of debt securities. Since debt is long-term, this triggers capital losses. As the current payoff on debt securities falls, banks might start defaulting, which further erodes bank capital by decreasing the price of deposits $Q_{t}^{d}$.

For borrower households, a financial crisis has offsetting effects on disposable income. On one hand, the rise in the number of defaults raises disposable income, since the household no longer has to pay part of its new debt. On the other hand, the supply of new credit may be disrupted for two reasons: first, a persistent credit risk shock raises borrowing rates; second, if bank losses are large enough to trigger the financial accelerator, this not only further disrupts prices but also quantities of debt. Thus a financial crisis can result in no new debt being issued as bank capital is depleted. If the latter effect dominates the former, borrower consumption falls. If this fall is large enough, it may trigger a collapse in aggregate demand, which in turn results in lower labor income and further reduces disposable income for the borrower. These effects are amplified whenever the borrower is constrained, since these will be the states when its marginal propensity to consume is higher, and thus aggregate demand is more dependent on fluctuations of borrower consumption.

Figure 3 plots the behavior of the model around financial crises. I simulate the model for a long period of time (100,000 periods), and extract all sequences of periods where the economy 

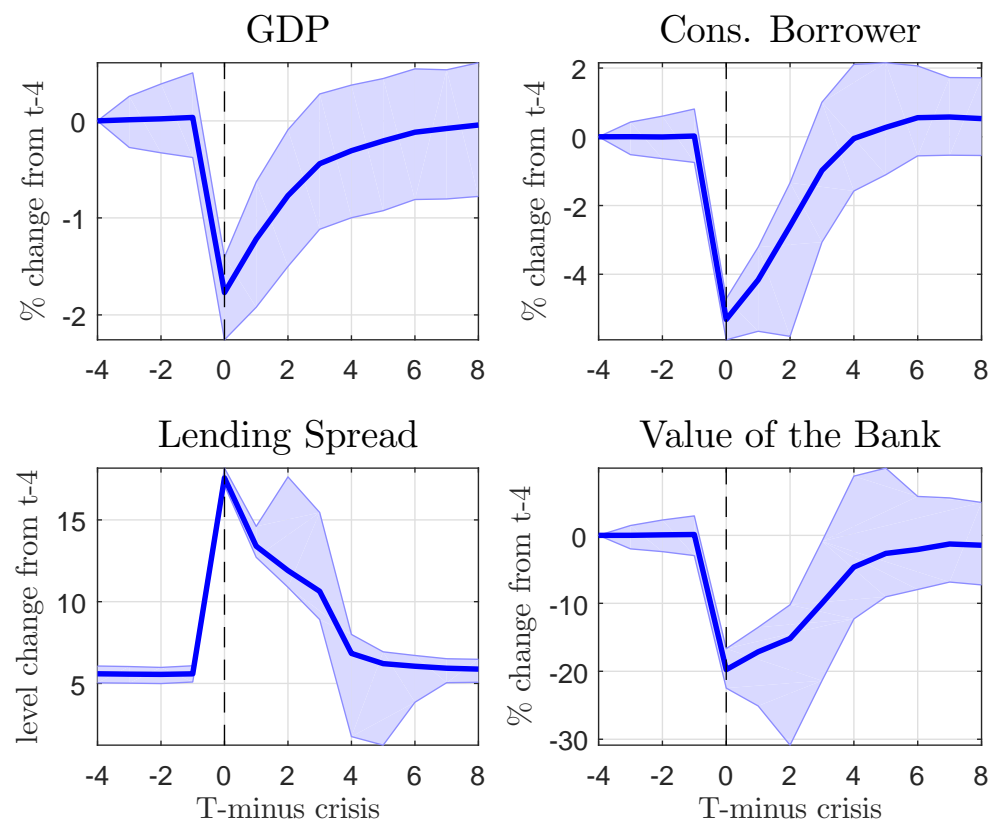

Figure 3: Typical Financial Crisis. The horizontal axis plots time minus initial period of the crisis. The vertical axis measures the variable in $\%$ deviations from its value at $t-4$, four quarters before the beginning of the crisis. Solid blue line is the median behavior, and shaded areas are the interquartile range after a long simulation of the model. 
enters a crisis. I then plot the median behavior in solid blue lines along with the interquartile range as a shaded area. As the figure shows, bank value drops sharply as defaults soar. The increase in credit risk, along with the financial accelerator that is triggered by bank losses, causes spreads to rise considerably. As banks cut back their lending and spreads rise, net borrowing falls and this impacts negatively borrower income. As borrowers cut back their consumption, collateral values fall, which leads to a further increase in borrower default and constraints the ability to borrow. The fall in borrower consumption also triggers aggregate demand externalities, and GDP falls. In the end, borrower consumption falls by over $5 \%$ and GDP falls by almost $2 \%$. Saver consumption (not shown) moves very little on impact, and falls over time. This is related to two opposing effects: on the one hand, banks suffer losses and this results in a loss of financial wealth that triggers a negative wealth effect, as shown in the final panel. On the other hand, faced with a recession, the central bank lowers interest rates, which has a positive effect on saver consumption. ${ }^{19}$

\section{Fiscal Policy and State Dependence}

In this section, I describe the effects of the different fiscal tools considered, and how these change with the state of the economy. I consider four main tools of discretionary fiscal policy: government purchases $G_{t}$, targeted transfers to borrowers $T_{t}^{b}$, equity injections in banks $s_{t}^{k}$, and credit guarantees to bank deposits $s_{t}^{d}$. I show that conventional fiscal policy, in the form of purchases and transfers, affects aggregate demand through the well-known Keynesian channels, and that these are augmented by a novel channel that depends on the interaction between borrower and bank balance sheets.

Stochastic Structure for Policies Throughout, I treat fiscal policies as exogenous shocks as it is standard in the macroeconomics literature. An analysis of optimal fiscal policy is beyond the scope of this paper. ${ }^{20}$

For the purpose of describing the effects of fiscal policy on the economy, I model discretionary policies as unexpected and transitory shocks. Denoting each policy instrument by $\omega_{t} \in$ $\left\{G_{t}, T_{t}^{b}, s_{t}^{k}, s_{t}^{d}\right\} \equiv \Omega_{t}$, I assume the following vector of states and transition matrix,

$$
\omega_{t}=\left[\omega_{t}^{\text {normal }}, \omega_{t}^{\text {crisis }}\right]^{T} \quad \text { and } \quad \mathbf{P}^{p}=\left[\begin{array}{cc}
.995 & .005 \\
.99 & .01
\end{array}\right]
$$

\footnotetext{
${ }^{19}$ This effect actually masks two implicit effects: first, there is the standard direct positive effect through the Euler Equation. Second, a fall in interest rates lowers the cost of funding for banks and raises their value, thus mitigating the early negative effect of loss in financial wealth.

${ }^{20}$ I assume that fiscal policies are purely exogenous shocks and do not follow fiscal rules for several reasons. First and foremost, I do so for simplicity, as this assumption allows me to better distill the effects of a purely exogenous perturbation in the economy. Second, this paper is about the effects of discretionary fiscal policies which are typically less expected and likely to follow fiscal rules in the same manner as automatic stabilizers do. Nevertheless, the model can easily accommodate fiscal rules through which policies depend on the current state of the economy. This extension is currently work in progress.
} 
That is, each policy instrument follows a two-state Markov process, with the first state being a "normal" value and the second a "crisis" one. The normal value is equal to a constant value of $20 \%$ of steady state GDP for government spending, and zero for all other instruments. The crisis value is set to be of a magnitude equivalent to the size of the interventions conducted by the U.S. government during the Great Recession (see section 5 for more details). Crisis policies are very unexpected and transitory.

\subsection{Fiscal Multipliers}

The nonlinear nature of the model as well as the state dependent effects of fiscal policy make it conceptually hard to define the fiscal multiplier. In this model, the fiscal multiplier for policy is a function of the states of the economy, $\mathbb{S}_{t} \equiv\left(D_{t-1}, B_{t-1}^{b}, B_{t-1}^{g}, A_{t}, \sigma_{t}^{b}, \Omega_{t}\right)$, which I denote by $\mathcal{M}^{\omega}\left(\mathbb{S}_{t}\right)$. Throughout, I focus on long-term discounted multipliers as defined in Mountford and Uhlig (2009)

$$
\mathcal{M}^{\omega}\left(\mathbb{S}_{t}\right)=\frac{\sum_{t=1}^{T} \prod_{j=1}^{t} Q_{j}\left(\mathrm{GDP}_{t}^{\text {Stimulus }}-\mathrm{GDP}_{t}^{\text {No Stimulus }}\right)}{\sum_{t=1}^{T} \prod_{j=1}^{t} Q_{j}\left(\text { Spending }_{t}^{\text {Stimulus }}-\text { Spending }_{t}^{\text {No Stimulus }}\right)}
$$

where Spending is defined as the left-hand side of the government budget constraint in (16). This type of fiscal multiplier is also called the integral multiplier by Ramey and Zubairy (2016). Conceptually, the fiscal multiplier compares the difference between GDP conditional on the policy being activated and the counterfactual GDP that the economy would experience in the absence of the policy. This difference is scaled by the additional fiscal spending that is generated by this intervention. The basic version of the multiplier, also called the impact multiplier, computes this measure only for the period when the policy is enacted (the impact period). This measure is imperfect for several reasons, the chief being that it does not account for the full path taken by macroeconomic variables in response to the policy. While an increase in government purchases can have a stabilizing impact in the short-run, the increased tax burden may depress demand in the long-run, a factor emphasized by Drautzburg and Uhlig (2015) in their analysis of the ARRA stimulus. Other policies may have delayed effects that would not be fully captured by measuring only the response of the variables on impact (i.e. productive public investment, not considered in this paper). By taking into account the paths of both GDP and spending over $T$ periods, the longrun multiplier addresses these concerns, while using the risk-free interest rate to discount future outcomes. ${ }^{21}$ While I focus on long-term discounted multipliers, other measures of fiscal multipliers are straightforward to compute: besides impact multipliers, another common measure for the impact of fiscal policy is the "maximum response" of a variable (i.e., the peak of the IRF).

\footnotetext{
${ }^{21}$ It is not obvious which interest rate should be used to discount future periods in this context, if whether the interest rate given policy or the rate in the absence of policy. I choose the former, and always evaluate multipliers using the path of interest rates given that the policy has been enacted. Quantitatively, this does not make a big difference.
} 
To compute fiscal multipliers, I follow a procedure similar to that used to compute Generalized Impulse Response Functions and described in Appendix B.3: given an initial set of states, $\mathbb{S}_{0}$, I simulate the economy for several different paths of the exogenous shocks, with and without the policy being activated. I then take the median difference of these paths as my measure of impact on the outcome variable (GDP and Spending).

\subsection{Government Purchases}

Government purchases are the canonical instrument of macroeconomic stabilization, and their impact on output has been thoroughly studied both theoretically and empirically. ${ }^{22}$ Purchases can help stabilize output due to to a combination of nominal rigidities, monopolistic competition and incomplete markets. Since some agents are constrained in their consumption smoothing decisions, they are not Ricardian and their MPC out of current income (wage plus net borrowing) is high. As the government demands more goods, some firms are unable to raise their prices. As mark-ups are positive, they raise quantities produced, which involves an increase of the real wage. This increase of current disposable income then raises private consumption due to the high MPC of borrowers, in a Keynesian channel that has been studied by Galí et al. (2007).

In this model, the strength of these effects can vary according to the state of the economy. While borrowers are never fully Ricardian even when unconstrained, due to the anticipation that constraints may bind, their MPC will be lower in regions where the borrowing constraint does not bind, hampering the effectiveness of this type of fiscal policy. ${ }^{23}$

The interlinkages between the household and financial sectors generate, however, a new transmission mechanism that augments the traditional one: the collateral-default channel. This arises from the interaction between the pecuniary externality caused by the borrowing constraint, the structure of the default decision, and banks' pricing of debt securities. Since housing markets are segmented, houses are priced with the borrower's stochastic discount factor: this implies that current borrower consumption has a first-order effect on the value of collateral. By expanding borrower disposable income, especially when this agents has a high MPC, the government also raises collateral values. This has two effects: the direct effect is a relaxation of the borrowing constraint, allowing for an increase in net borrowing and further raising current income. The indirect effect is a fall in the number of defaults. This raises profits for the bank, and helps relaxing its constraint (and/or reduce its likelihood of binding). This, in turn, lowers lending spreads and expands intermediation capacity. Thus the bank can lend more and at lower rates, again raising current income

\footnotetext{
${ }^{22}$ This literature is too large to be reviewed here. For recent theoretical and empirical analyzes see Woodford (2011) and Nakamura and Steinsson (2014), respectively.

${ }^{23} \mathrm{My}$ treatment thus differs from most of the literature on fiscal policy and heterogeneous agents models nonRicardian agents as either hand-to-mouth agents that have no access to financial markets and exogenously consume their disposable income, or borrowers for whom the borrowing constraint is always binding and thus have a constant MPC. Exceptions are typically full-blown Aiyagari-Bewley models as in Kaplan and Violante (2014) or McKay and Reis (2016).
} 

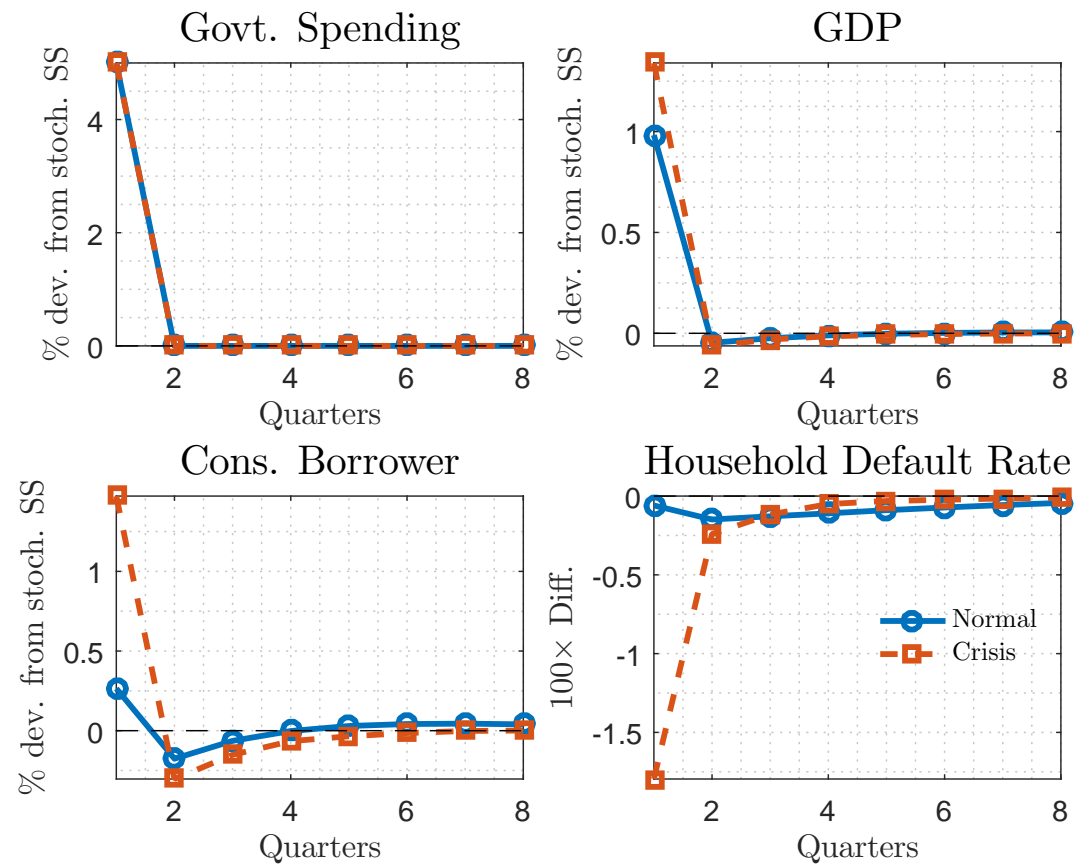

Figure 4: GIRF to Government Purchases, Crisis and Non-Crisis

for the borrower. This channel is also state dependent: during expansions, the central bank raises rates in response to an increase in government spending. Due to their exposure to interest rate risk, this lowers the value of the bank, partly undoing this channel.

Figure 4 plots the GIRF's of government spending, GDP, borrower consumption and the default rate in response to a shock to government purchases equal to $1 \%$ of steady state output (or $5 \%$ of steady state government purchases). These GIRF's are obtained by taking the median path of an economy that suffered the fiscal policy shock vis-à-vis one that experienced the same path of exogenous shocks save for the policy ones. Each panel has two GIRF's: the blue line with circles corresponds to a shock to government purchases starting from the stochastic steady state, with low risk. The orange line with squares corresponds to a shock to government purchases in an economy that starts from the stochastic steady state and just received a high risk shock. Thus the state dependent effects of fiscal policy are represented by the differences between the two lines in each panel. A rise in government purchases has a positive impact on GDP and borrower consumption, and this impact is larger when the economy is experiencing a financial crisis, since borrowers are more constrained and have a higher MPC. The collateral-default channel is much stronger during a crisis, as illustrated by the much larger impact on default rates in the fourth panel.

State Dependent Fiscal Multipliers The previous analysis shows that the model is able to generated larger fiscal multipliers for government purchases in recessions than in expansions. This 

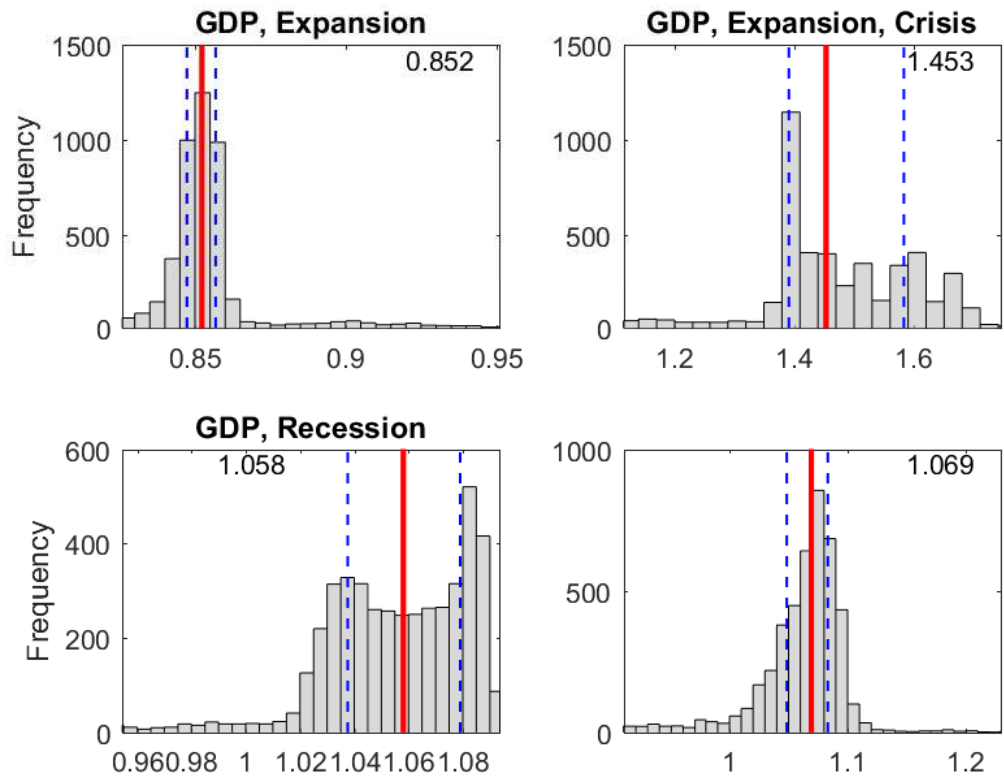

Figure 5: Distribution of Fiscal Multipliers of Government Purchases, purchase shock equal to $1 \%$ of steady state GDP. Solid vertical line is median, dashed vertical lines are first and third quartiles.

is consistent with the empirical evidence in Auerbach and Gorodnichenko (2012) and Ramey and Zubairy (2016): while these authors disagree regarding the size of the fiscal multiplier of government purchases, both studies agree that these tend to be larger during times of slack (i.e., recessions). The model is able to generate state dependence in this same direction due to the two mechanisms described above: the standard Keynesian/MPC effect, augmented with the collateraldefault channel. To illustrate this, I compute distributions for fiscal multipliers when the economy is either in an expansion or in a recession, and is hit by a government purchases shock. To obtain a "typical" expansion (recession), I proceed as follows: I start the economy from the stochastic steady state, and hit it with a sequence of four positive (negative) TFP shocks, each equal to $\sigma_{a}$. I then take this fourth period of a consecutive expansion (recession) as a starting point to study the economy. Notice that this is different than simply starting the economy at the stochastic steady state and hitting it with a positive (or negative) TFP shock, the reason being that my procedure accounts for the fact that the endogenous states behave differently during expansions and recessions. This is particularly important in this model, as a TFP expansion induces agents to increase their leverage and thus make the economy more exposed to a financial crisis.

Starting from a typical TFP expansion (recession), I then simulate the economy for several different paths of shocks, both with a government purchases shock and without. This allows me to compute a fiscal multiplier for each particular realization of the shocks, from where we can obtain a distribution of fiscal multipliers. I consider four regimes: expansion, expansion with a credit risk 
shock, recession and recession with a credit risk shock. These distributions are the four panels of Figure 5: the red solid line is the median, the blue dashed lines are the first and third quartile, and the median is reported as the number in the upper right corner of each panel. The left panels measure fiscal multipliers in the absence of a financial crisis, and show that the model is able to generate purchase multipliers lower than one (0.85) during expansions, and higher than one (1.06) during recessions. For reference, the Congressional Budget Office estimates the fiscal multiplier on government purchases to be between 0.5 and 2.5 (CBO, 2011) Moving to the right column, where the same exercise is performed, but simultaneously hitting the economy with a negative credit shock at the initial period, one sees that multipliers under a financial crisis are always greater, which is not surprising to the extent that a financial crisis is a "demand-driven" recession in the model. What is more interesting is that fiscal multipliers are the highest when the economy enters a financial crisis during a TFP expansion. The reason is that this is, in some sense, the worst kind of recession: during a TFP expansion, both households and banks expand their leverage considerably. Thus the credit risk shock hits exactly when the economy is the most vulnerable. Given that the recession is particularly deep, and aggregate demand is depressed, government purchases have the potential to generate large multipliers, often above 1.5 as shown in the histogram.

\subsection{Transfers to Borrowers}

The second type of conventional fiscal tool I consider is a targeted transfer to the borrower household, $T_{t}^{b}$. These transfers subsume a wide variety of fiscal programs that consisted on the direct or indirect transfer of resources towards agents whose marginal propensity to consume out of current income was likely to be high. These range from the tax rebates in the spirit of the Economic Stimulus Act of 2008 to the homeowner relief programs started under TARP (the Hardest Hit Fund, Home Affordable Modification Program, etc.). The transfer follows the same process as described before for purchases in (17). The states are $[0,0.028 \times \bar{Y}]$, zero and $2.8 \%$ of steady state GDP. This makes the transfer shock comparable to the total amount spent with the ESA 2008 tax rebates, and corresponds to an increase of about $6 \%$ of steady state government spending.

The mechanism through which transfers operate is in many ways similar to purchases: as the government transfers directly resources to agents with high MPC, aggregate demand expands and this triggers a Keynesian multiplier. The collateral-default channel is also present in the case of transfers: by raising disposable income and borrower consumption, the house price rises and this expands borrowing capacity and reduces credit risk at the same time. Figure 6 illustrates these effects: since the collateral-default channel is now more direct, GDP is more sensitive during periods of crisis, with the difference in response being much greater than for the case of purchases.

State Dependent Fiscal Multipliers Several recent articles look at the effectiveness of transfer versus spending multipliers (Oh and Reis, 2012; Mehrotra, 2014; Pennings and Giambattista, 2015). On a related note, several other authors have looked at the relationship between targeted 

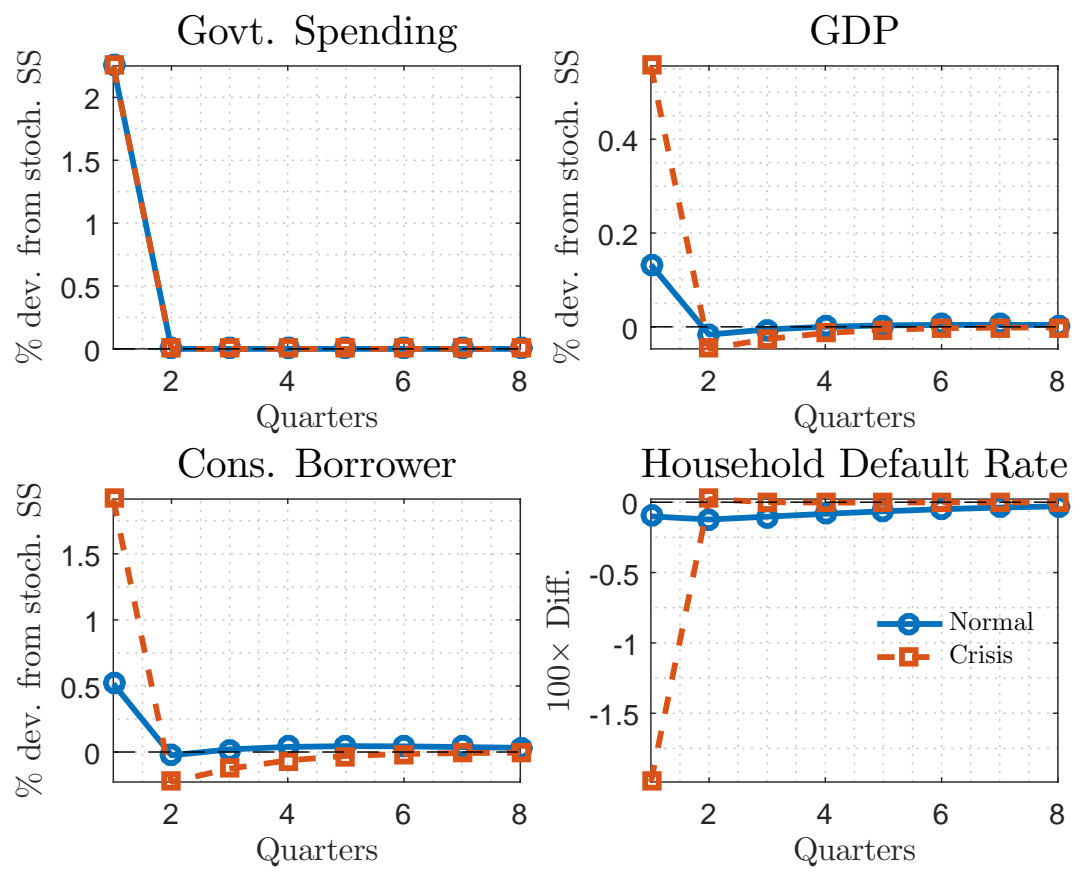

Figure 6: GIRF to Transfers, Crisis and Non-Crisis

transfers and marginal propensities to consume (Kaplan and Violante, 2014), which has obvious consequences for the effectiveness of these policies for the purpose of output stabilization. It is typically difficult to generate transfer multipliers that are as large as spending multipliers, the reason typically being that increases in government purchases generate negative wealth effects that induce agents to expand their labor supply, while transfers to borrowers reverse that negative income effect and induce transfer recipients to work less. This effect is also present in this model, and indeed transfer multipliers tend to be smaller than those for government purchases.

Figure 7 computes fiscal multiplier distributions in expansions and recessions. While these multipliers are consistently smaller than one, a similar pattern emerges: they are larger in recessions and, conditional on the state of the economy, larger in financial crises. In particular, they can exceed one during financial crises that are triggered after a period of expansion.

A final point is related to the size dependence of the effects of transfers: the above experiment considers a relatively large transfer to borrowers. Very large transfers are expected to generate smaller effects (per dollar spent) than smaller transfers, the reason being that borrowers' MPC falls very rapidly as soon as they become unconstrained. A transfer that is small enough so as to keep borrowers constrained will have a larger impact (again, per dollar spent) than a larger one that allows the constraint to stop binding. To illustrate this point, Figure 8 repeats the previous exercise but for a much smaller transfer, equal to $0.5 \%$ of steady state GDP. As explained, the effect per dollar spent (i.e. the fiscal multiplier) becomes much larger. 

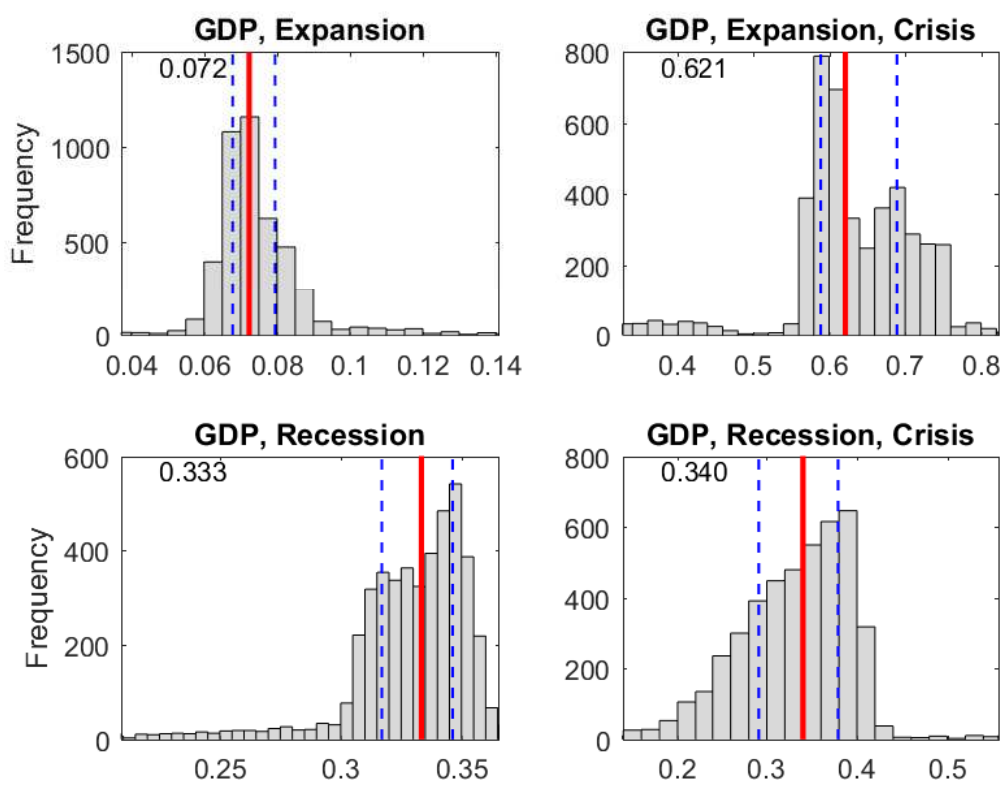

Figure 7: Distribution of Fiscal Multipliers for Transfers, transfer equal to 2.8\% of steady state GDP. Solid vertical line is median, dashed vertical lines are first and third quartiles.

\subsection{Equity Injections}

I model equity injections as a transfer from the government to the banks. ${ }^{24}$ These are pro-rata subsidies to book equity of surviving banks: a bank with book equity $\theta e_{j, t}$ receives a subsidy equal to a proportion $s_{t}^{k}$ of its retained earnings. The fact that subsidies are proportional to equity allows us to retain aggregation in the banking system and keep the model tractable. This affects banks in two ways: first, it provides them with additional funds for investing, and reduces their need to borrow

$$
Q_{t}^{b} b_{j, t}=\left(1+s_{t}^{k}\right) \theta e_{j, t}+Q_{t}^{d} d_{j, t}
$$

second, this affects directly the marginal value of earnings, helping relax the bank's constraint and moderate the financial accelerator that it generates

$$
\Phi_{t}=\left(1+s_{t}^{k}\right) \frac{\mathbb{E}_{t}\left\{\frac{\Lambda_{t+1}^{s}}{\Pi_{t+1}}\left(1-\theta+\theta \Phi_{t+1}\right)\left[1-F^{d}\left(u_{t+1}^{*}\right)\right]\right\}}{Q_{t}^{d}\left(1-\mu_{t}\right)}
$$

\footnotetext{
${ }^{24}$ See Prestipino (2014) and Bianchi (2016) for similar treatments. The most notable equity injection program under TARP was the Capital Purchase Program, which involved the purchase of preferred equity and warrants in commercial and investment banks. The reason I do not model bank recapitalizations as equity holdings of the government is technical, as to avoid the proliferation of state variables.
} 

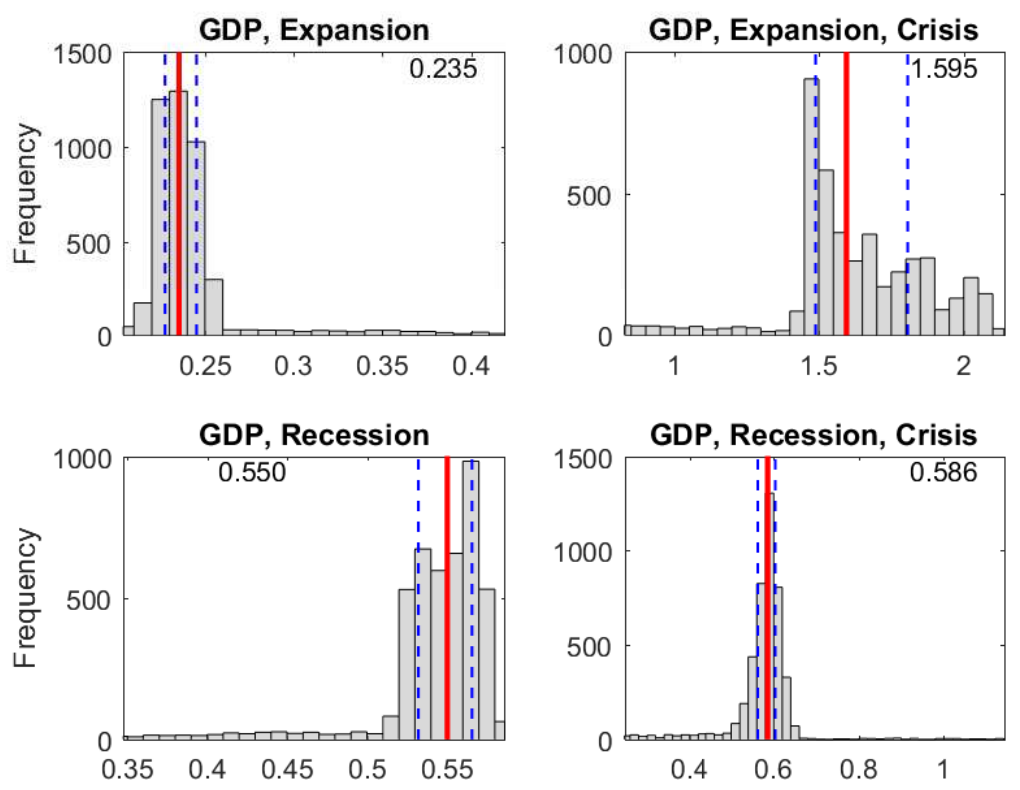

Figure 8: Distribution of Fiscal Multipliers of Transfers, Smaller Transfer, transfer equal to $1 \%$ of steady state GDP. Solid vertical line is median, dashed vertical lines are first and third quartiles.

The first effect, which is more direct, reduces bank leverage both by reducing their borrowing and raising the value of their assets. As a result, the number of bank defaults falls and their cost of borrowing stabilizes. This, in turn, sustains bank earnings and thus mitigates spreads. The second effect comes from the fact that the subsidy is proportional, and thus an extra dollar of earnings is particularly valuable in the states of the world where the government attributes this subsidy.

Since banks are owned by the savers, bank recapitalizations should be mostly effective when the leverage constraint binds. In practice, they will have an effect even when this constraint does not bind due to precautionary motives. In the absence of these, bank recapitalizations would be largely ineffective when constraints do not bind. The reason is that they would involve the transfer of resources to an unconstrained agent, and raising these resources involves taxing potentially constrained agents (borrowers). When banks are unconstrained, they simply reduce their borrowing and do not expand their lending. This deleveraging is, naturally, positive due to precautionary reasons, but this is not a first order effect. Bank recapitalizations only have first-order effects when banks are constrained, in which case they allow banks to sustain their lending. Through the financial accelerator, then, spreads do not have to rise by as much. This helps maintain the flow of credit and sustain aggregate demand, particularly if borrowers are constrained. One reason why bank recapitalization may be particularly effective at restoring aggregate demand is due to the fact that banks are leveraged: for each dollar injected into a bank, the bank lends out $x$ dollars, where $x$ is the leverage ratio. On the other hand, this is only effective as long as borrowers are constrained 

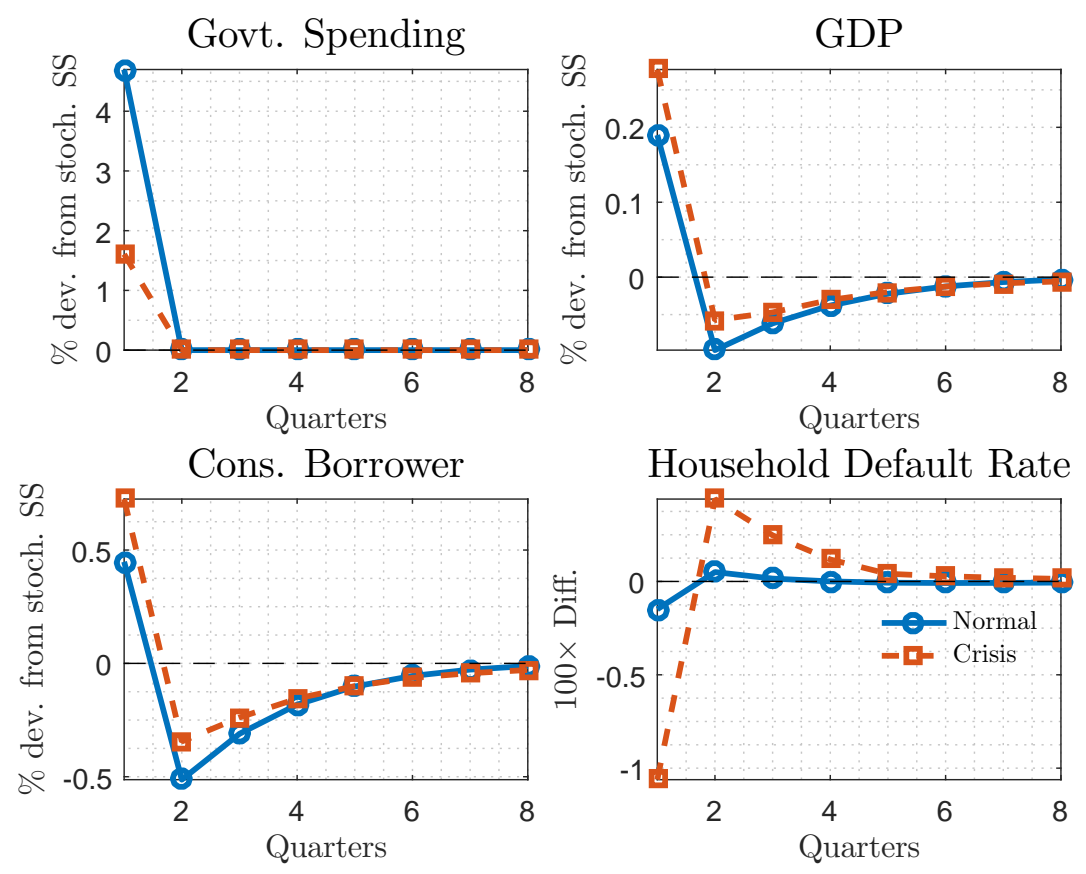

Figure 9: GIRF to Bank Recaps, Crisis and Non-Crisis

(i.e. as long as they want to borrow more); if borrowers are not constrained, they will not borrow more with a bank recap, and the positive effect will operate only through the price of debt.

Figure 9 plots the response of the economy to a $13 \%$ equity injection, during normal and crisis times. This number is chosen so that it corresponds to net fiscal spending equal to $1 \%$ of GDP at the steady state, thus making the scale comparable to that of the interventions analyzed above. First, since the transfer is proportional, and bank equity is depressed during crises, the effective amount of spending is much lower during a financial crisis. This is consistent with the notion that recapitalization programs are particularly cost effective during financial crises, when bank stocks are "cheap". Government spending is less than half during a crisis, but GDP expands by more. Borrowers benefit from expanded lending, and at lower costs. House prices jump on impact and the default rate falls.

State Dependent Fiscal Multipliers Figure 10 plots the distribution of multipliers for bank recapitalizations depending on the state of the economy. These multipliers are relatively low and, in particular, they are negative during a TFP expansion. This reflects the notion that the state of the economy is crucial for gauging the effectiveness of fiscal policy tools such as bank recapitalizations: when banks are unconstrained, these are a very poor tool of stabilization, as they involve a transfer from agents that are potentially constrained (borrowers) to agents that are unconstrained. 

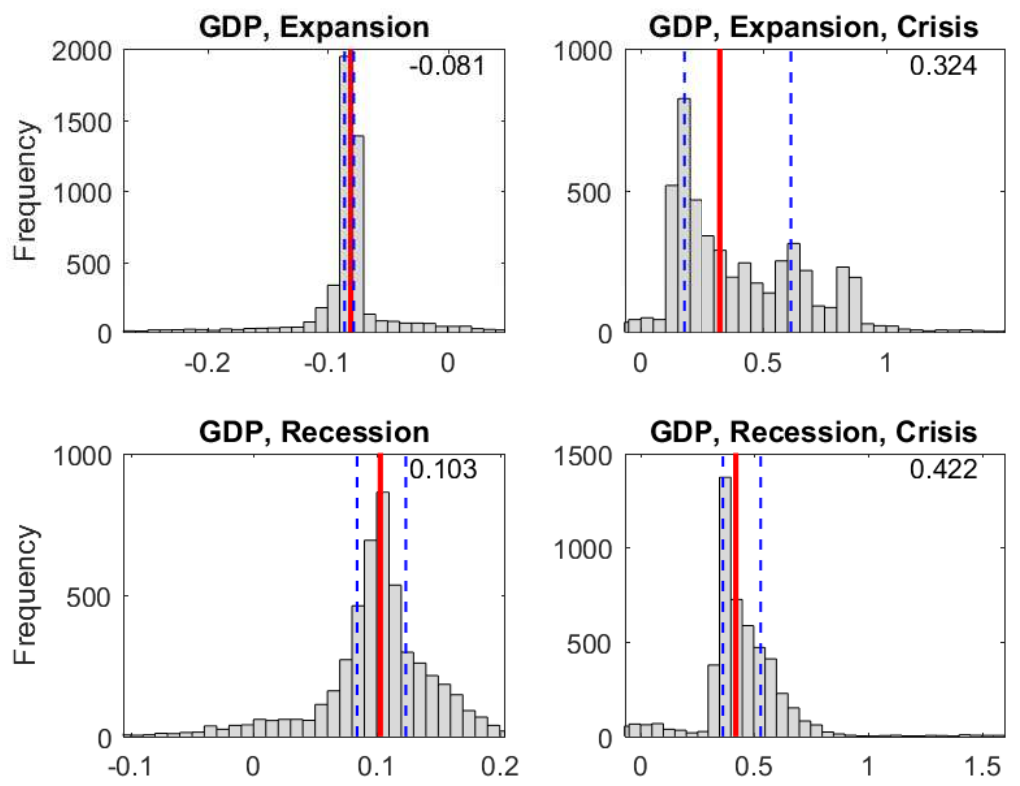

Figure 10: Distribution of Fiscal Multipliers of Bank Recaps, equity subsidy of 13\%. Solid vertical line is median, dashed vertical lines are first and third quartiles.

Philippon (2010) also studies the relative merits of transfers to borrowers versus bank recapitalizations, and concludes that recapitalizing banks tends to be more efficient in a static setting featuring debt overhang. A comparison of this figure with figure 7 provides an analogous comparison, in a fully dynamic and stochastic setting. In the absence of a financial crisis, transferring resources to borrowers is strictly preferred for the aforementioned reasons. When the economy enters a financial crisis, however, it depends, and it may be preferable to bail out banks in some states of the world. This depends on whose constraints bind (and how intensely these constraints bind), and it ultimately becomes a quantitative question.

\subsection{Credit Guarantees}

The final fiscal instrument that I consider are credit guarantees on bank deposits. These work as follows: at $t$, the government commits to guarantee a fraction $s_{t}^{d}$ of all deposit repayments due by banks at $t+1$. The return on deposits from the household's point of view becomes

$$
Z_{t+1}^{d}=s_{t}^{d}+\left(1-s_{t}^{d}\right)\left[1-F^{d}\left(u_{t+1}^{*}\right)+\left(1-\lambda^{d}\right) \frac{1-\Psi^{d}\left(u_{t+1}^{*}\right)}{u_{t+1}^{*}}\right]
$$

I assume that the government effectively purchases the deposit, so that it receives the liquidation value of the bank in case the deposit fails. This is a realistic assumption given the current bank 
resolution procedures enforced by the FDIC. This policy acts primarily through precautionary motives, and it can be a very effective tool of stabilization: by making the return on deposits more certain, the government closes the spread between the bank borrowing cost and the policy rate. This, in turn, means that banks can borrow more at the same cost, and thus finance a larger pool of assets. Thus this reduction in the cost of borrowing for banks can be passed through onto borrowers. Furthermore, by reducing the costs of borrowing, the government contributes to reducing bank leverage, which reduces the probability of default in the next period, and further reduces borrowing costs.

The crucial point regarding credit guarantees is that their announcement (and commitment) can have such stabilizing effects so as to generate large nonlinearities regarding the effective amount that is spent in equilibrium. Net fiscal costs at $t$, from guarantees announced at $t-1$ are given by

$$
\text { Net Fiscal Costs } \operatorname{Cos}_{t-1}^{d} \times \frac{D_{t-1}}{\Pi_{t}}\left[F^{d}\left(u_{t}^{*}\right)-\left(1-\lambda^{d}\right) \frac{1-\Psi^{d}\left(u_{t}^{*}\right)}{u_{t}^{*}}\right]
$$

When the government announces $s_{t-1}^{d}$, bank borrowing $D_{t-1}$ falls, contributing to a fall in defaults in the following period, $u_{t}^{*} \downarrow$. If this impact is large enough, an interesting non-monotonicity can arise: a larger program of credit guarantees can result in lower equilibrium spending. As the government commits to guaranteeing a larger fraction of bank debt, the economy stabilizes and less banks default in equilibrium. This is a logic similar to the one used to justify the role of emergency lending facilities and other lender-of-last-resort type interventions during financial crises.

Figure 11 plots the response of macro and financial variables to a 5\% transitory credit guarantee during normal and crisis times. The first thing to notice is that credit guarantees involve zero government spending in normal times, since the number of bank defaults is zero at the stochastic steady state. Importantly, there is still a small positive effect on GDP and borrower consumption, attributable to the precautionary effects described above. While no banks default at the stochastic steady state, the probability of default is not zero as there is a positive (but small) probability of entering either a financial crisis and/or a very severe TFP recession in which banks default in equilibrium. ${ }^{25}$ Credit guarantees operate by affecting the return on deposits in these states of the world; this reduces banks' cost of funding. Since banks are unconstrained, this reduction in the cost of funding is partially passed through onto borrowers as lower costs of lending. Borrower consumption expands on impact due to lower borrowing costs, and then falls below steady state. The reason is that the guarantee in this experiment is transitory, while credit risk is not: by sustaining credit, this policy effectively prevents deleveraging.

Fiscal Multipliers of Credit Guarantees The above analysis demonstrates that it is not obvious how to apply the concept of fiscal multiplier to credit guarantees. In the absence of a financial crisis, the government does not spend any resources with the credit guarantee, while still generating

\footnotetext{
${ }^{25}$ This is consistent with the observation in the data that, in the years preceding the financial crisis, CDS spreads were not zero even though no bank failures were observed.
} 

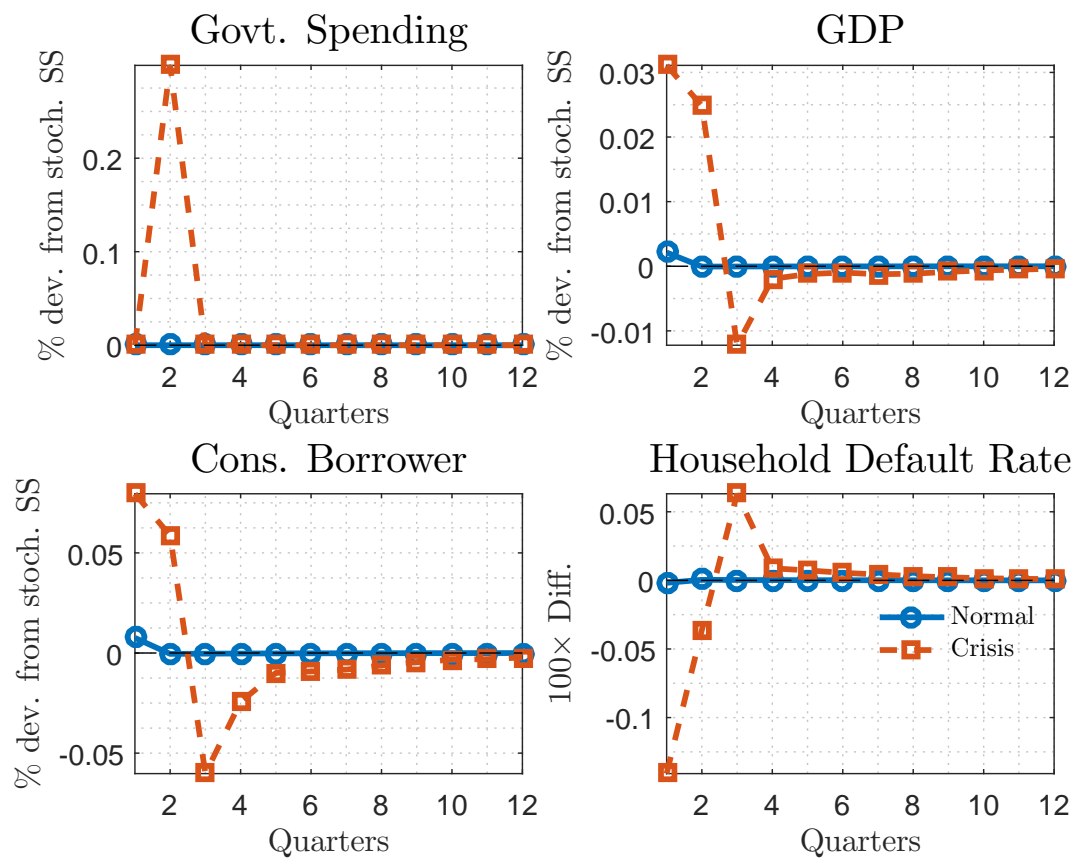

Figure 11: GIRF to Credit Guarantee, Crisis and Non-Crisis

a small but positive impact on GDP and consumption due to precautionary motives. This implies that the ex-post multiplier, that is, the multiplier computed with the effective amount spent with the guarantees, is infinity. Lucas (2016) provides a detailed discussion of this issue, acknowledging the deep measurement problem that is faced by researchers and policymakers when trying to assess the macroeconomic impact of government guarantee programs. Since these are contingent liabilities for the government, it is more sensible to adopt a fair-value approach to the cost of these guarantees instead of directly measuring the effective outlays (as this approach would generate infinite fiscal multipliers in many cases); this approach accounts for the market risk of these programs.

The CBO computes fair-value subsidy estimates every year for a range of different government credit programs in the U.S.. The models used to compute these subsidy estimates are mostly based on measured of the interest rate spread between guaranteed and non-guaranteed debt contracts with otherwise similar characteristics (for example, the spread between jumbo and agency-conforming loans for the case of mortgages). An estimate of the total subsidy can then be computed as the product of this spread by the total amount of guaranteed debt outstanding. This approach is conceptually similar to the one used by the CBO and is straightforward to implement in this model. Starting from the expression for the fiscal multiplier (18), I replace the term Spending ${ }_{t}^{\text {Stimulus }}-$ Spending $_{t}^{\text {No Stimulus }}$ with an estimate of the total subsidy per dollar of debt, obtained as

$$
\text { Fair Value }_{t}^{\text {Stimulus }}=\left(Q_{t}^{d, \text { Guaranteed }}-Q_{t}^{d, \text { Non-Guaranteed }}\right) \times D_{t}^{\text {Stimulus }}
$$

A more sophisticated calculation would take into account the value of debt that would be issued by 

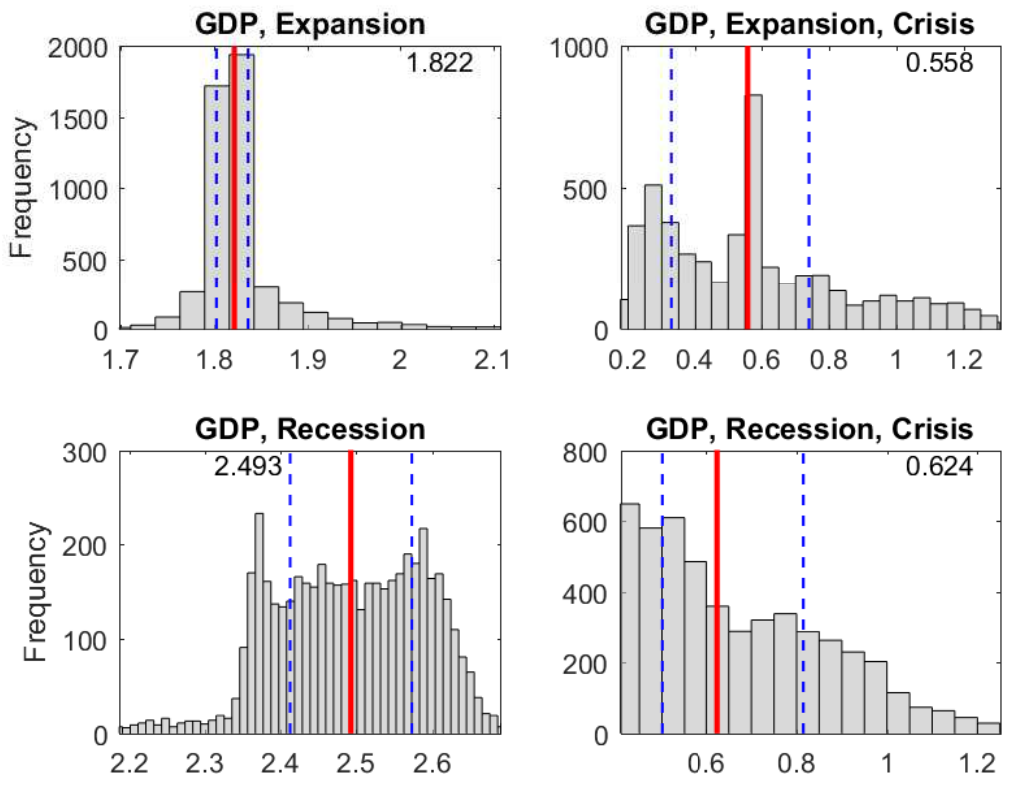

Figure 12: Distribution of Fiscal Multipliers of Bank Credit Guarantees, for a guarantee of 5\%. Solid vertical line is median, dashed vertical lines are first and third quartiles. Number reported is the median.

the banks in the absence of the government policy. I adopt the above calculation because it is more transparent and has a very natural interpretation. Since all credit programs are blanket guarantees in the model (i.e. they apply to all banks), the price of non-guaranteed bank debt is a counterfactual object that can be computed as

$$
Q_{t}^{d, \text { Non-Guaranteed }}=\mathbb{E}_{t} \frac{\Lambda_{t+1}^{s}}{\prod_{t+1}}\left[1-F^{d}\left(u_{t+1}^{*}\right)+\left(1-\lambda^{d}\right) \frac{1-\Psi^{d}\left(u_{t+1}^{*}\right)}{u_{t+1}^{*}}\right]
$$

Distributions for long-run fiscal multipliers computed using this approach are reported in Figure 12. The fair-value fiscal multipliers of a 5\% transitory credit guarantee are very large and positive, exceeding 2 during recessions. Multipliers computed using this approach fall substantially during periods of high risk, as the implicit subsidy then becomes non-trivial. The multipliers of credit guarantees are, nevertheless, comparable to those of direct recapitalizations, suggesting that this is a very cost-effective manner of recapitalizing the banking system. 


\section{Quantitative Analysis: Fiscal Policy during the Great Reces- sion}

In this section, I conduct the main quantitative exercise of the paper. Using the model as a measurement device, I assess the effectiveness of U.S. fiscal policy during the recent financial crisis and subsequent Great Recession. I first collect data on the different discretionary fiscal policies enacted by the U.S. government during this period. Using these observed sequences of policies, I use a particle filter to estimate the sequences of structural shocks that allow the model to replicate the observed data on aggregate consumption and a measure of credit spreads in the data. Importantly, these shocks are estimated by accounting for the policy response, and so are truly invariant to fiscal policy. I use these shocks and the model to conduct counterfactual experiments. First, I answer the following question: what would have the Great Recession looked like in the absence of a fiscal policy response? Second, I perform a decomposition by turning off one policy at a time. This allows us to measure the contribution of each policy tool towards macroeconomic stabilization. Finally, I present and discuss a byproduct of this analysis: a time series of state-dependent fiscal multipliers for different policy tools. These multipliers are informative regarding what combinations of policies are more effective at different points in time.

\subsection{Data and Measurement}

The first step in the procedure is to use the structural model to measure the sequences of shocks experienced by the U.S. economy during the financial crisis. The model admits two types of exogenous states: structural non-policy shocks $\mathcal{Z}_{t} \equiv\left(a_{t}, \sigma_{t}^{b}\right)$ and fiscal policy shocks $\Omega_{t} \equiv$ $\left(G_{t}, T_{t}^{b}, s_{t}^{k}, s_{t}^{d}\right)$. I collect data on $\left\{\Omega_{t}\right\}_{t=0}^{T}$ directly, and then estimate $\left\{\mathcal{Z}_{t}\right\}_{t=0}^{T}$ using the model and data on macroeconomic and financial time series. To this end, I use a particle filter. While technically complex, the procedure is conceptually simple, and equivalent to asking the following question: given the series of fiscal policies, what are the sequences of shocks that allow the model to match observed data on consumption and spreads? Intuitively, I invert the model to extract the sequence $\left\{\mathcal{Z}_{t}\right\}_{t=0}^{T}$ that allows the model to replicate the sequences of two observables (aggregate consumption and credit spread), given $\left\{\Omega_{t}\right\}_{t=0}^{T}$.

\subsubsection{Standard Data Series}

For the observable variables, I use data on aggregate consumption and a measure of credit spreads.

Consumption Since there is no investment in the model, I use aggregate consumption as the main macroeconomic variable to target. Real aggregate consumption should be the data counterpart of $C_{t}=\chi C_{t}^{b}+(1-\chi) C_{t}^{s}$. I use quarterly real personal consumption expenditures from 
the St. Louis FRED database (series code: PCECC96). I detrend this series using a standard Hodrick-Prescott filter.

Credit Spreads I define credit spreads in the model as they are typically computed in the data: as the difference in yield between one lending security and the risk-free government bond

$$
\operatorname{spread}_{t}^{b}=\frac{1}{Q_{t}^{b}}-\frac{1}{Q_{t}}
$$

Given that the bulk of lending from banks to households is comprised of mortgages, the natural data counterpart to $\operatorname{spread}_{t}^{b}$ would be a mortgage-backed security (MBS) spread. One problem, however, is that most mortgage-backed securities are insured by government-sponsored enterprises such as Fannie Mae or Freddie Mac, and are thus mostly reflective of prepayment, liquidity and other types of risk other than credit. The ideal counterpart to this object in the data would be a nonagency MBS spread, which is not easy to construct. ${ }^{26}$ For this reason, I use the spread between the Moody's seasoned BAA corporate bond yield over the 10 year Treasury yield (FRED series BAA10Y). This series is more likely to capture the time-varying credit risk in the economy that is faced by financial institutions. The series for the BAA spread and detrended consumption (in $\%$ deviations from its trend) are plotted in figure 13.

\subsubsection{Fiscal Policies}

While the previous data series are standard, the mapping of observed fiscal measures onto the four policies considered in the model requires some further work. I compile a list of discretionary fiscal policy measures undertaken by the U.S. Government and its agencies during the Great Recession and map each of these measures into one of the model's policies. The general classification is based on the following criteria:

1. $G_{t}$ : policies that consist of direct purchases of goods and services by the government.

2. $T_{t}^{b}$ : policies that involve direct transfers to households; tax rebates, cuts and/or incentives; incentive payments and program funding directed at homeowners; creditor relief and support.

3. $s_{t}^{k}$ : equity injections and transfers to the financial sector.

4. $s_{t}^{d}$ : credit and/or asset guarantees; emergency lending facilities aimed at the financial sector.

Most of the policies I focus on were implemented and funded directly by the U.S. Treasury under one of the three large pieces of legislation concerning fiscal policy: the Economic Stimulus Act

\footnotetext{
${ }^{26}$ Technically, the correct object would be the spread between non-agency and agency MBS, as the latter is likely to include adjustments for all types of risk other than credit risk.
} 

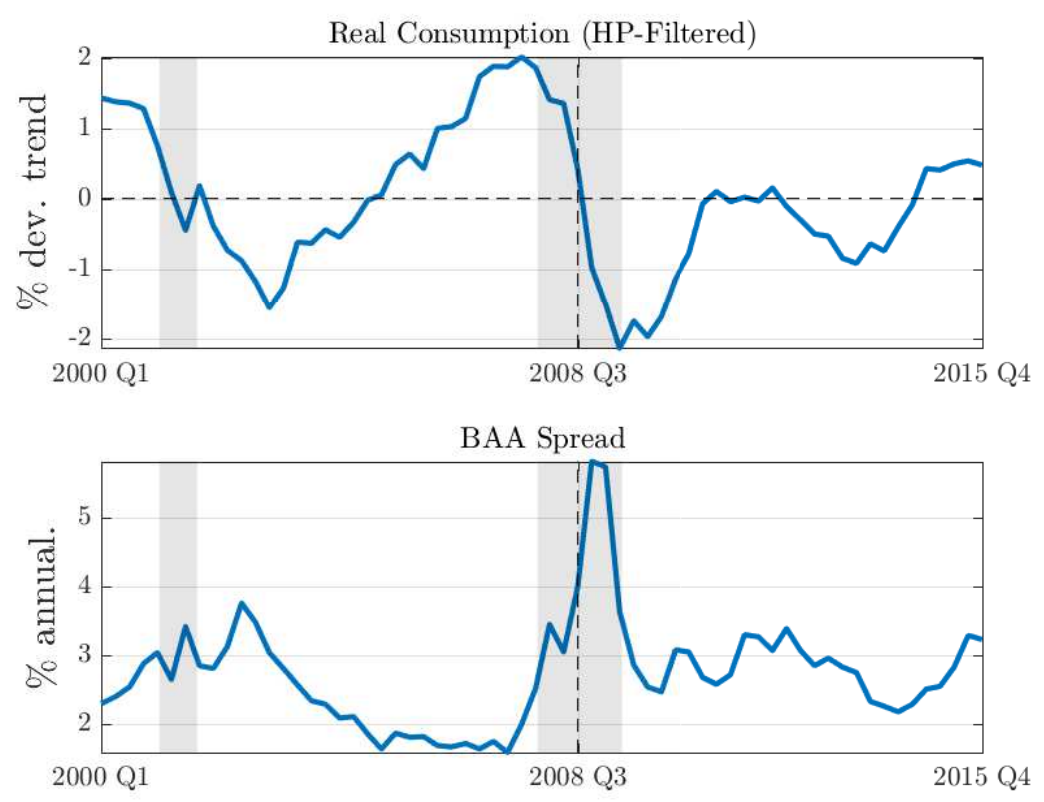

Figure 13: Annualized BAA spread over 10-year Treasury and detrended real consumption. Sample: 2000Q1-2015Q4. Lehman Brothers failure highlighted (2008Q3). Source: St. Louis FRED.

of 2008 (February 2008, the "Bush Rebate"), the Emergency Economic Stabilization Act of 2008 (October 2008, included the Troubled Asset Relief Program, TARP), and the American Recovery and Reinvestment Act of 2009 (February 2009, the "Obama Stimulus"). Additionally, I consider policies enacted by independent government agencies and corporations for which the U.S. Treasury is ultimately liable, such as the Federal Deposit Insurance Corporation (FDIC) ${ }^{27} \mathrm{I}$ describe the data collection procedure in more detail in Appendix $\mathrm{C}$, and table 2 provides a summary of the policies considered.

Mapping Fiscal Policy Data to the Model Figure 14 plots the resulting data series, normalized by US GDP in the first quarter of 2007 (annualized). The vertical dashed line corresponds to the third quarter of 2008, the quarter of the run on and subsequent failure of Lehman Brothers. The bulk of traditional fiscal policy consisted of transfers, which exceeded 2\% of GDP immediately before Lehman (through the ESA tax rebates), as well as in the beginning of 2009 (mainly Medicaid transfers triggered by the ARRA). The magnitude of fiscal interventions in the financial sector, through equity injections and asset guarantees, exceeded that of traditional fiscal policy. Equity injections reached 6\% of GDP in the last quarter of 2008, as the Capital Purchase Program of TARP

\footnotetext{
${ }^{27}$ The Federal Reserve also engaged in extensive quasi-fiscal policies during this period; an extension that considers these is currently work in progress.
} 


\begin{tabular}{|c|c|c|c|}
\hline Instrument & Description & Policies & Sources \\
\hline$G$ & Govt. Purchases & $\begin{array}{l}\text { ARRA: consumption expenditures, gross investment, } \\
\text { transfers and grants to state and local govts. net of } \\
\text { Medicaid and Education. }\end{array}$ & BEA \\
\hline$T^{b}$ & Transfers & $\begin{array}{l}\text { ESA: tax rebates. ARRA: losses in current tax re- } \\
\text { ceipts (incl. Making Work Pay), current transfer pay- } \\
\text { ments (incl. unemployment extension), Medicaid and } \\
\text { Education transfers to state govts. TARP: Making } \\
\text { Home Affordable (incl. HAMP), transfers to Federal } \\
\text { Housing Agency, Hardest Hit Fund. }\end{array}$ & BEA, US Treasury \\
\hline$s^{k}$ & Equity Injections & $\begin{array}{l}\text { TARP: Capital Purchase Program, Community De- } \\
\text { velopment Capital Initiative, Targeted Investment Pro- } \\
\text { gram (BofA and Citi), Investment in AIG, equity in- } \\
\text { jections in Fannie Mae and Freddie Mac. }\end{array}$ & US Treasury \\
\hline$s^{d}$ & Guarantees & $\begin{array}{l}\text { TARP: Asset Guarantee Program, Term } \text { Asset- } \\
\text { Backed Securities Loan Facility, Citigroup. } \\
\text { Temporary Liquidity Guarantee Program. }\end{array}$ & FDIC, Fed, US Treasury \\
\hline
\end{tabular}

Table 2: Summary of Fiscal Policies considered. Underlined acronyms stand for the umbrella programs: ESA is the Economic Stabilization Act of 2008, ARRA is the American Recovery and Reinvestment Act of 2009, TARP is the Troubled Asset Relief Program of 2008. 
was implemented. The value of assets guaranteed by the government also exceeded $4 \%$ of GDP through the year 2009.

In order to map these series to the model, I target the size of the interventions relative to (steady state) GDP. For government spending and transfers this is straightforward. For equity injections and credit guarantees, I extract series for $\left(s_{t}^{k}, s_{t}^{d}\right)$ that correspond to the same amount of effective and potential outlays as a percentage of GDP as observed in the data. ${ }^{28}$

As in the previous section, I abstract from fiscal rules and treat each policy as an exogenous shock. Each policy then corresponds to an extra state variable in the model. For computational reasons, and in order to keep the dimensionality of the state space tractable, I follow the previous approach and treat each policy intervention as a two-state Markov process, where the first state is the "normal" one, corresponding to no discretionary policy, and the second state corresponds to a "crisis" mode. I assume the following general stochastic structure for policy $\omega_{t}$,

$$
\omega_{t}=\left[\omega^{\text {normal }}, \omega^{\text {crisis }}\right]^{T} \quad \text { and } \quad \mathbf{P}^{\omega}=\left[\begin{array}{cc}
.995 & .005 \\
1-p^{\omega} & p^{\omega}
\end{array}\right]
$$

While stark, this structure captures the essence of the fact that these policies are extremely unconventional and thus unexpected. I set $s_{t}^{k}, T_{t}^{b}, s_{t}^{d}$ to zero in the default state, and $G_{t}$ is set to a constant value that is chosen to be equal to $20 \%$ of GDP at steady state. I estimate $\left(\omega^{\text {crisis }}, \mu^{\omega}\right)$ using maximum likelihood and a Hamilton filter over the sample period 2000Q1-2015Q4. Since my sample period is short and does not include any other financial crises, I exogenously calibrate the probability of the policy being activated, and estimate the probability of exiting the policy regime. The estimation procedure is not trivial to the extent that it is equivalent to estimating the parameters of a hidden Markov model. The resulting estimates are in Table $3{ }^{29}$

\begin{tabular}{lcccc} 
& $G_{t} / Y$ & $T_{t}^{b} / Y$ & $s_{t}^{k}$ & $s_{t}^{d}$ \\
\hline \hline$p^{\omega}$ & 0.929 & 0.75 & 0.50 & 0.917 \\
$\omega^{\text {crisis }}$ & $0.35 \%$ & $2.08 \%$ & $15.96 \%$ & $1.01 \%$ \\
Max. value & $0.62 \%$ & $2.86 \%$ & $21.66 \%$ & $1.74 \%$ \\
\hline
\end{tabular}

Table 3: Maximum likelihood estimates for fiscal policy shock processes

\footnotetext{
${ }^{28}$ For equity injections, I assume that the observed data series measure $x_{t}^{k}=\frac{s_{t}^{k} \theta \bar{E}}{Y}$, where variables with bars are steady state values, and obtain $s_{t}^{k}$ by inverting that expression. Similarly, for credit guarantees, I assume that the measured series is $x_{t}^{d}=\frac{s_{t}^{d} \bar{D}}{Y}$.

${ }^{29}$ A detailed description of the procedure, which is based on Hamilton (1989), can be found in appendix D. Figure A.3 in the Appendix plots the time series for each policy along with the discretized counterparts.
} 


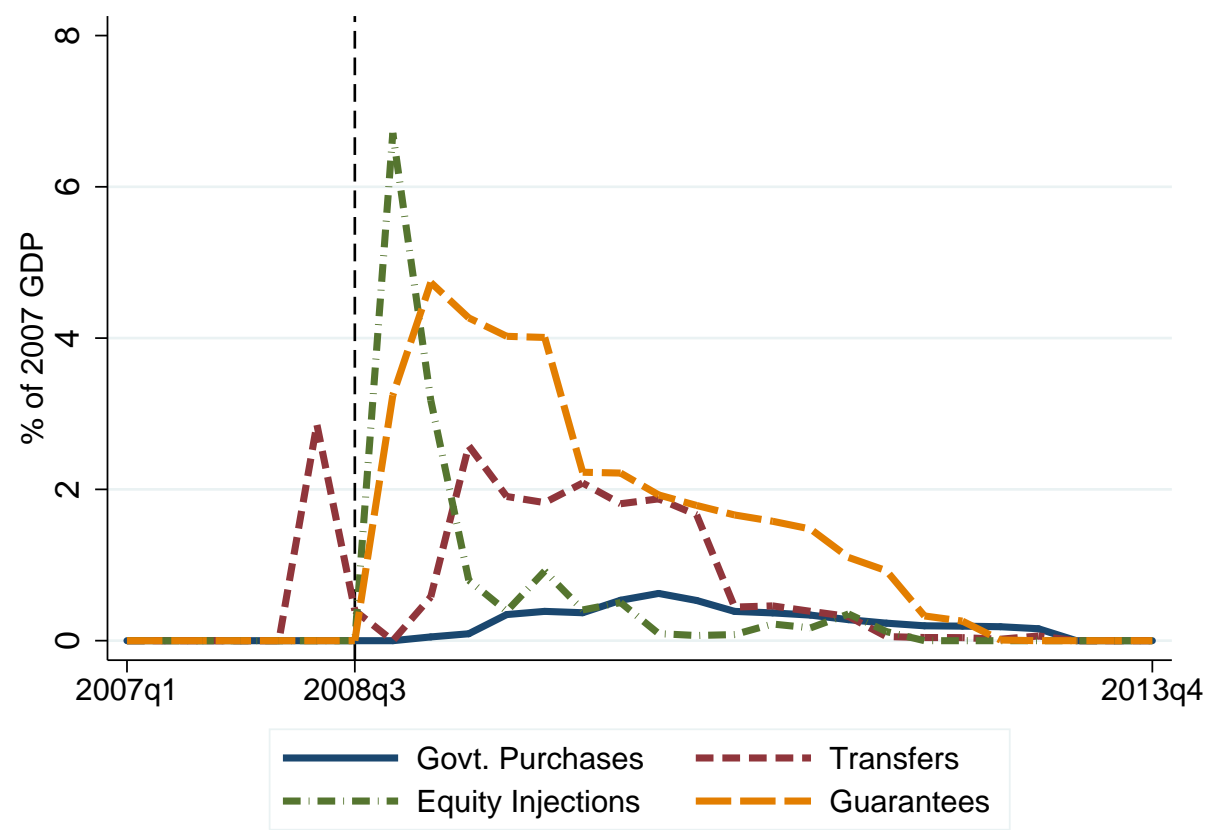

Figure 14: Discretionary fiscal policy measures enacted during the Great Recession, normalized by 2007Q1 US GDP. Sources: BEA, US Treasury, FDIC, own calculations.

\subsubsection{Measuring the Structural Shocks}

Armed with the sequences of policies and the calibrated model, I use a particle smoother as described in Fernández-Villaverde and Rubio-Ramírez (2007) to extract sequences of conditional densities for the structural shocks that allow the model to match the observed paths for aggregate consumption and the credit spread. Intuitively, the smoother allows me to "invert" the model and generate the series of TFP and credit risk shocks, $\left\{\mathcal{Z}_{t}\right\}_{t=0}^{T}$, that allow the model to replicate $\left\{C_{t} \text {, } \operatorname{spread}_{t}^{b}\right\}_{t=0}^{T}$, given $\left\{\Omega_{t}\right\}_{t=0}^{T}$. The technical and computational details for the particle filter and smoother procedures are described in Appendix B.2.

Crucially, since these shocks are measured by taking into account the fiscal policy response during this period, they are invariant to fiscal policy and hence the appropriate sequences of shocks for the purpose of studying policy counterfactuals. The smoother does not generate a single sequence for the structural shocks, but rather a sequence of densities conditional on the observables. Letting $Y^{T} \equiv\left\{C_{t}, \operatorname{spread}_{t}^{b}, \Omega_{t}\right\}_{t=0}^{T}$ stand for the sequence of observables, the particle smoother estimates $\left\{p\left(\mathcal{Z}_{t} \mid Y^{T}\right\}_{t=0}^{T}\right.$, that is, the best guess for the distribution of the structural shocks at each point in the sample given all information available over the entire sample. Since the output of the smoother is a distribution, it allows us to compute statistics and generate confidence intervals. Figure 15 plots the median of the smoothed densities for the shocks, along with 5\% confidence 

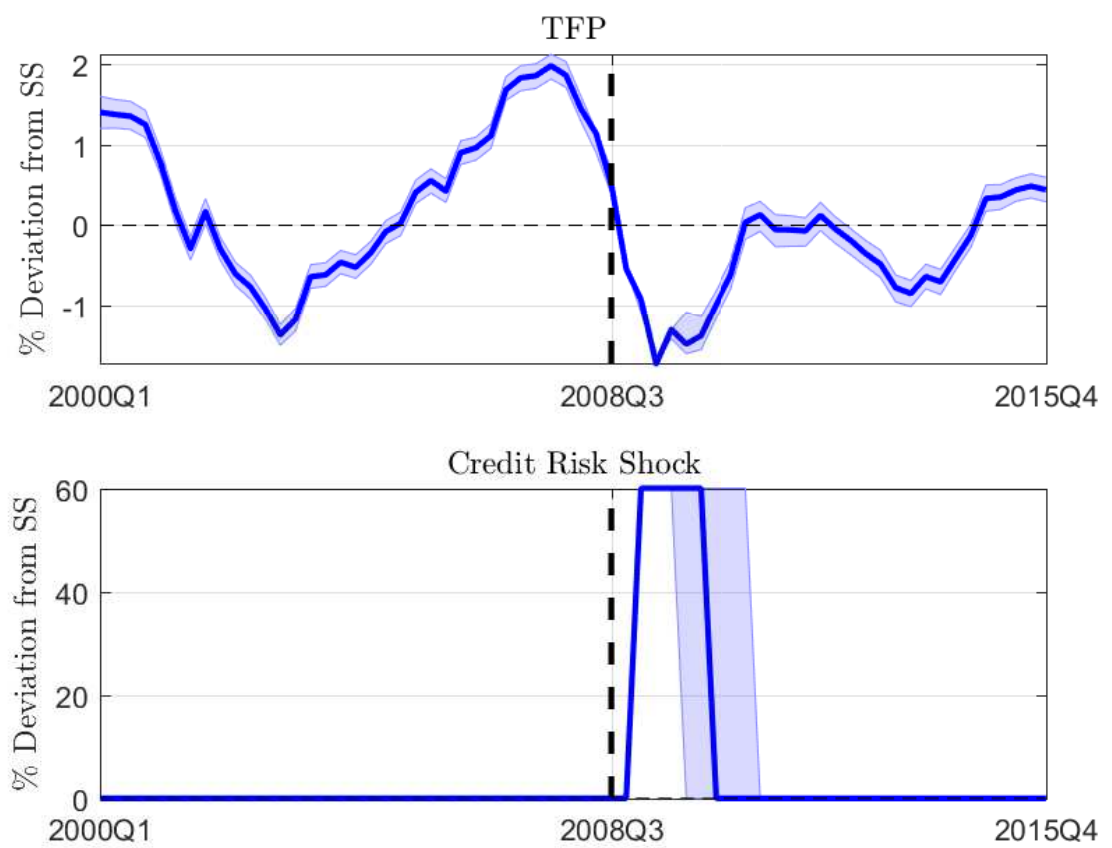

Figure 15: Smoothed series for the structural shocks, with 5\% confidence bands.

bands.

As expected, there are no significant exogenous movements in credit risk prior to the financial crisis. The smoother extracts a positive credit risk starting at the end of 2008 around the time of the Lehman shock and lasting for six quarters, until mid-2010. The overall path of the implied TFP series is very similar to that of aggregate consumption by construction: besides the policies, the smoother and the model can only fit consumption and the credit spread using two shocks. The only significant large movement in spreads takes place around the financial crisis, triggering the credit risk shock. All other variation, which includes all fluctuations in consumption before and after the Great Recession, must therefore be absorbed by movements in TFP. ${ }^{30}$

\subsection{Counterfactual: No Fiscal Policy}

Given the estimated/observed sequences of shocks, $\left\{\mathcal{Z}_{t}, \Omega_{t}\right\}_{t=0}^{T}$, I can now ask the following question: what would have the Great Recession looked like in the absence of fiscal policy response? At this stage, I have all the ingredients that are necessary to conduct this exercise: generically, the model maps $\left\{\mathcal{Z}_{t}, \Omega_{t}\right\}_{t=0}^{T}$ and a set of initial conditions for the endogenous states $X_{0}$ into a se-

\footnotetext{
${ }^{30}$ Figure A.4 in the Appendix plots the path of consumption in the data against the median of the smoothed series, with $5 \%$ confidence bands.
} 
quence of endogenous variables $\left\{Y_{t}\right\}_{t=0}^{T}=Y^{T}=f\left(\left\{\mathcal{Z}_{t}, \Omega_{t}\right\}_{t=0}^{T}, X_{0}\right)$. Since the particle smoother retrieves estimates for $\left(\{\mathcal{Z}\}_{t=0}^{T}, X_{0}\right)$, we can evaluate the counterfactual path of endogenous variables $Y^{T, C F}$ by setting $\Omega_{t}=\Omega^{\text {normal }}, \forall t \geq 0$.

Figure 16 plots the baseline path for consumption (with policy, and thus matching the data), versus the model-implied no fiscal policy counterfactual. The plots run from 2007 to the end of 2013, the period when most of the policies were active (the baseline and the counterfactual are exactly the same before any policy is active, by construction). The first panel of the figure highlights the main result of the paper, which is that the aggregate consumption would had fallen by about a third more in the absence of fiscal policy during the year of 2009. That is, instead of falling to $2 \%$ below trend, it would had fallen to $3 \%$ - and the recovery would had been slower. The total "Okun gap" for this period (2007Q1 - 2013Q4) is of 2.25\%, or 206 billion dollars of aggregate consumption. ${ }^{31}$

The second panel shows that lending spreads, the second observable series in the model, would had been significantly higher after Lehman in the absence of a policy response, almost twice as high. The remaining panels decompose the movements of aggregate consumption between borrowers and savers, and show that most of the effect of fiscal policy on aggregate consumption can be attributed to three factors: sustaining borrower consumption right before Lehman, sustaining saver consumption right after Lehman, and allowing for a faster recovery of borrower consumption in 2009. These three factors map neatly into the three large fiscal policy interventions: the ESA 2008, TARP's CPP program, and the ARRA 2009, respectively. The final panel shows that savers benefited mainly from TARP, and that the ARRA effectively transferred resources from these Ricardian savers to constrained borrowers.

This analysis is highlighted in Figure 17, which plots the difference between the counterfactual and the baseline series as a percentage of the variable's stochastic steady state. A negative value for this difference means that the variable would had taken a lower value in the absence of fiscal policy. As hinted above, the first panel shows clearly the stabilizing effects of the three main tools of fiscal policy: the ESA, TARP, and ARRA. The initial trough, before Lehman, corresponds to the stimulus under the ESA via the early 2008 Bush tax rebates. The fall right after Lehman is the no bank bailout counterfactual and, finally, the larger fall in mid-2009 corresponds to the transfer programs under the ARRA and the government purchases program. The second panel shows that TARP was essential to contain spreads, and the ARRA also played a minor role in 2009. Finally, the lower panels show, as previously explained, that the ESA and the ARRA essentially acted as transfers from savers to borrowers, while TARP played a role in boosting saver consumption.

\footnotetext{
${ }^{31}$ The "Okun gap" reported here is a back-of-the-envelope calculation that corresponds to the integral of the difference in the paths of the baseline and counterfactual lines for consumption over the 2007Q1-2013Q4 period. The dollar value is obtained by multiplying that integral by the dollar value of aggregate consumption in 2007Q1. This is the full integral, also accounting for when the counterfactual rises above the baseline.
} 

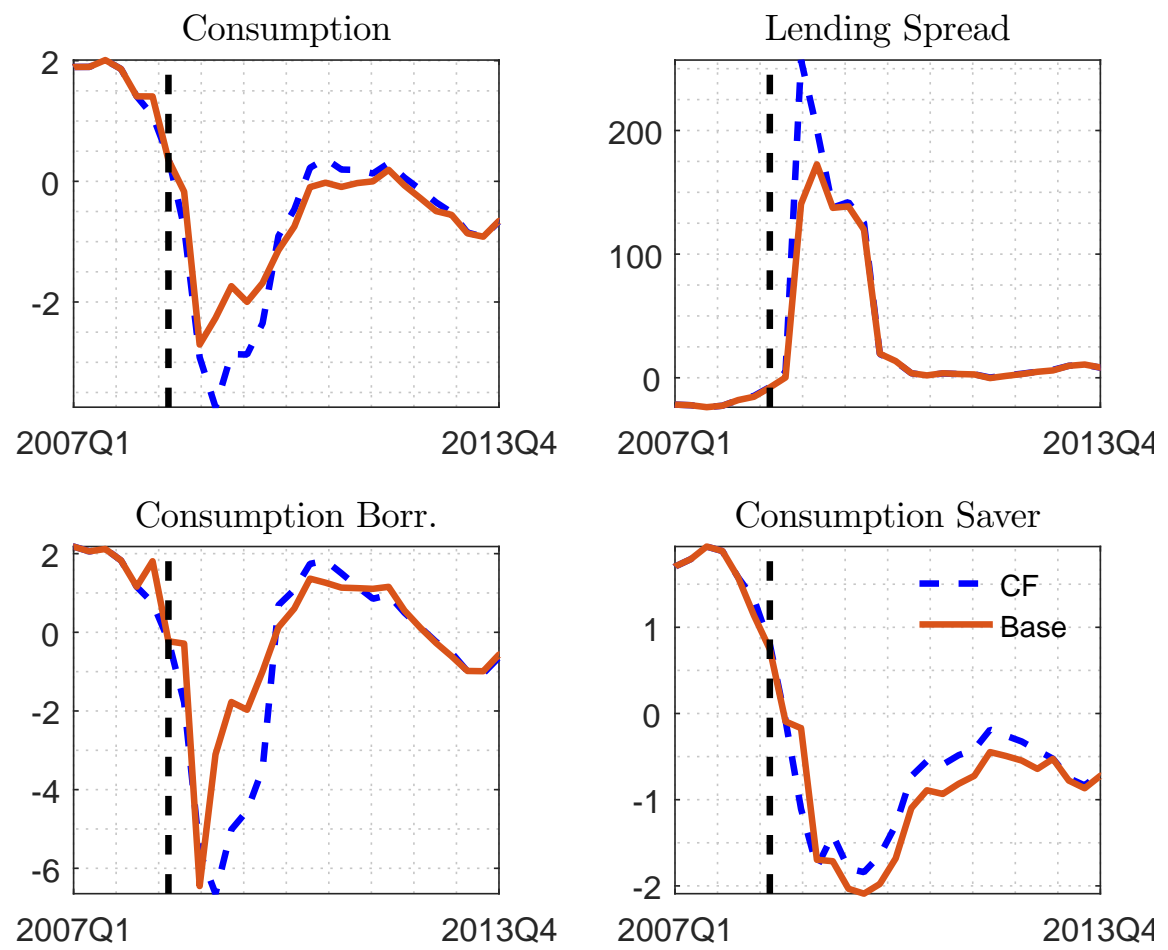

Figure 16: Baseline sequences (solid orange) vs. no fiscal policy counterfactuals (dashed blue) 

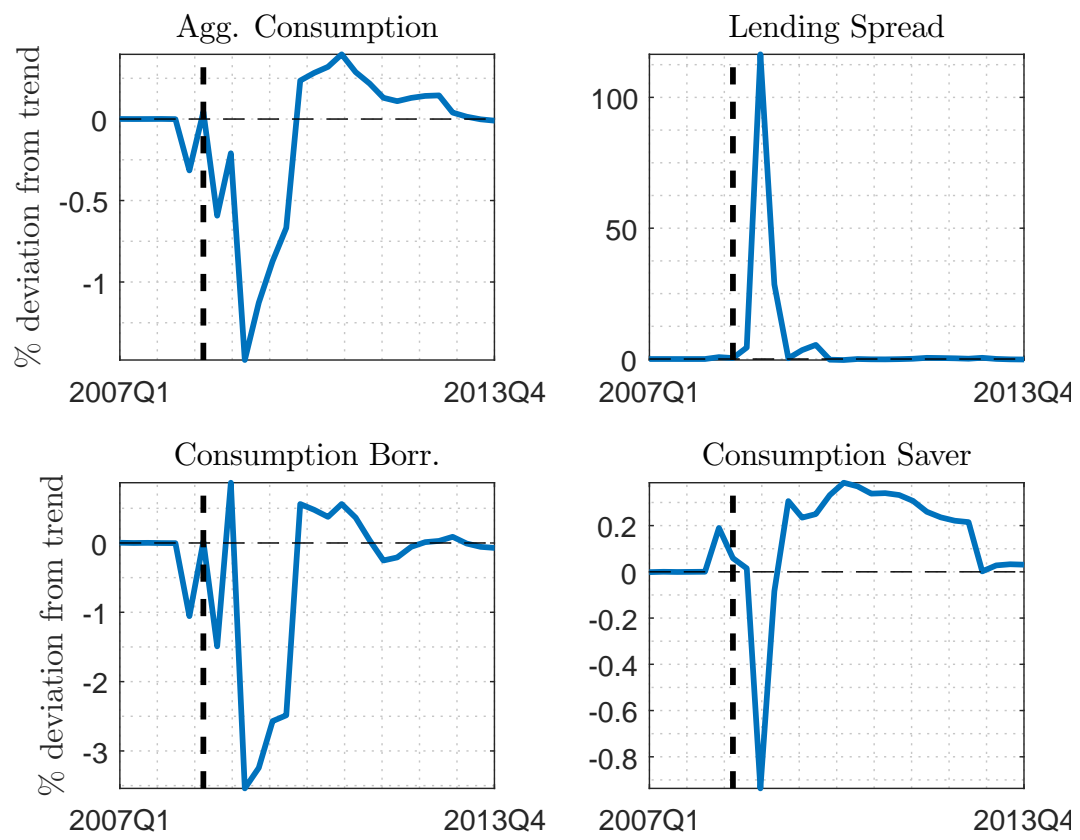

Figure 17: Difference between baseline and no policy counterfactual sequences as a percentage of the steady state for each variable. Negative (positive) values means that the counterfactual is lower (larger) than the baseline series.

\subsection{Decomposition: which policies mattered the most?}

A natural extension of the main counterfactual exercise is to ask which individual policies mattered the most. One way to conduct this decomposition is to start from the no policy counterfactual and activate one policy at a time. ${ }^{32}$ Figure 18 plots aggregate consumption in the full policy benchmark (which coincides with the data) as well as the path of aggregate consumption that is obtained by shutting off each policy at a time. The second panel plots the differences as percentages of the stochastic steady state. The figure shows that, by far, social transfers were the most important of fiscal policy stabilization during the Great Recession. Notice that, due to the nonlinear nature of the model, there is not a linear map between turning off one policy at a time and turning off all policies at a time. In fact, the no-transfer counterfactual (with other policies active) would had been slightly worse than the no policy counterfactual. The reason is that the effects of these policies interact, and can cancel each other. The figure also shows that bank recapitalizations also had a positive impact, but smaller. Government purchases seem to have had a negative impact overall, and consumption would had recovered faster in their absence.

The aggregate figure does, however, mask interesting distributional effects. An interesting

\footnotetext{
${ }^{32}$ Due to the nonlinear nature of the model this is not equivalent to starting from the full policy benchmark and turning off one policy at a time.
} 


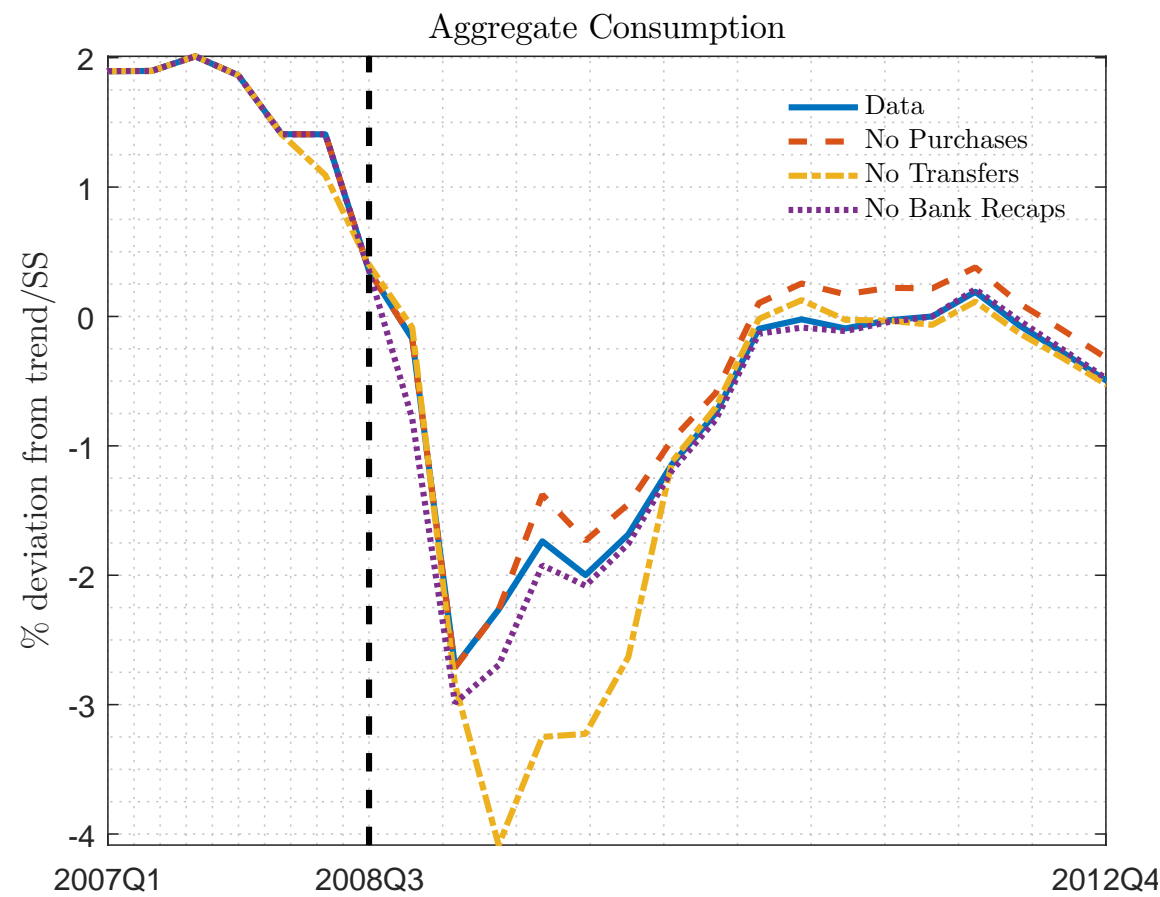

Figure 18: Counterfactual decomposition for the path of aggregate consumption. 
insight that comes from this analysis is that while transfers appear to have been the most important tool for stabilizing aggregate outcomes, bank equity injections appear to be the intervention that comes closest to being a Pareto improvement, to the extent that it benefits both borrowers and savers. Figure 19 analyzes the differential impact on borrower and saver consumption of the no transfers and no recaps counterfactuals: from the figure, it is evident that while social transfers are effectively a transfer from savers to borrowers, bank recapitalizations had a positive overall impact on the consumption of both types of agents. While they served as a direct transfers to savers, they also moderate spreads and help restore intermediation, thus helping stabilize the balance sheet of borrowers.
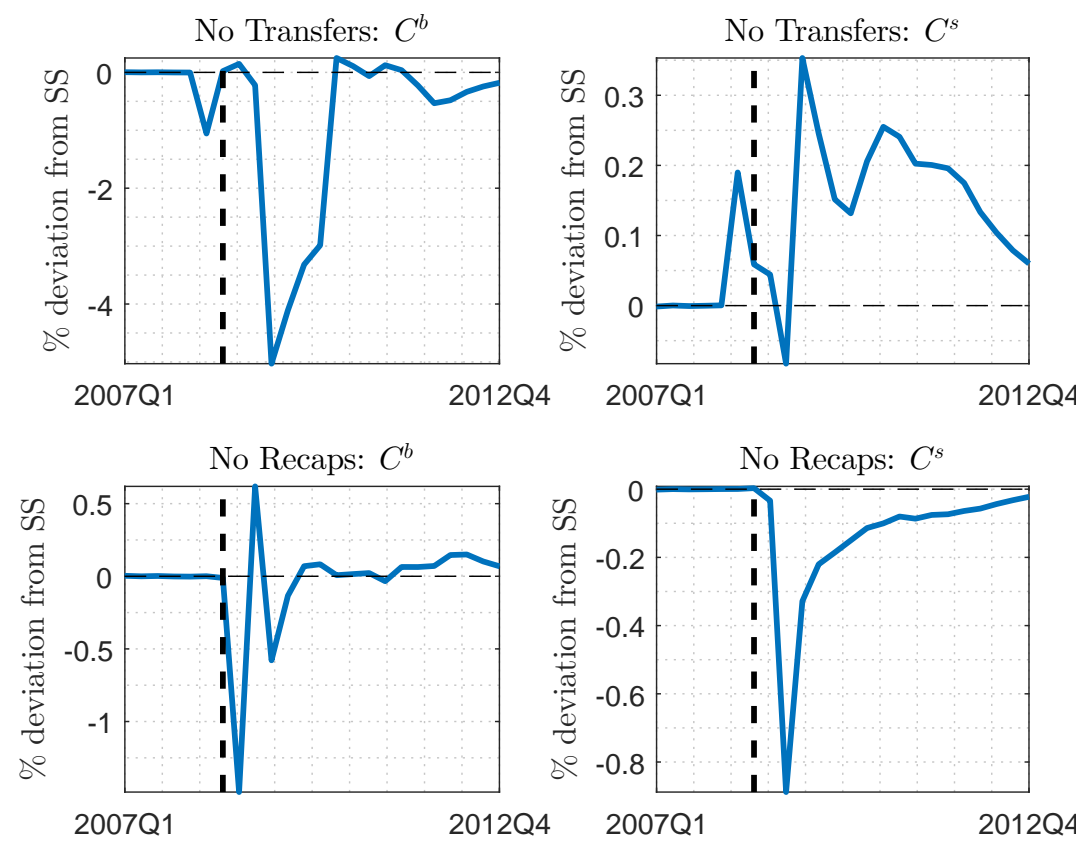

Figure 19: Counterfactual decomposition: top panels are no transfer counterfactual, bottom panels are no recap counterfactual. Left panels are borrower consumption, right panels are saver consumption. Difference between counterfactual and baseline as \% of stochastic steady state.

\subsection{Fiscal Multipliers during the Great Recession}

Since the model is nonlinear, the impact of fiscal policy depends on the state of the economy. Thus different fiscal policy tools can have a larger or smaller impact over time, depending on the combination of states experienced by the U.S. economy at each point in time. These multipliers are straightforward to compute given knowledge of these states, which is provided by the particle smoother. Figure 20 plots fiscal multipliers for each policy tool over time. For periods when the fiscal policy tool is not active, the multiplier is computed in the typical manner: by simulating a 

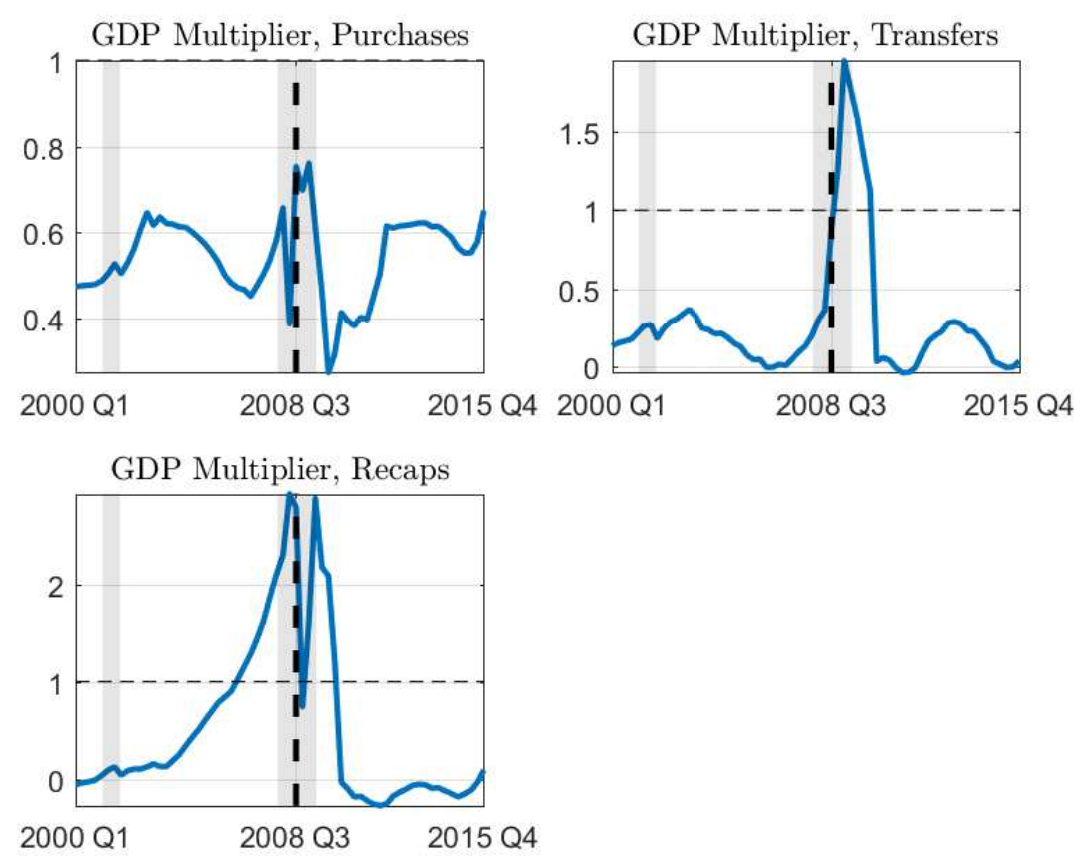

Figure 20: Estimated time series for fiscal multipliers, GDP.

counterfactual path of the economy where that policy tool is activated, given the paths for all remaining exogenous shocks. For periods when the fiscal policy is active, the multiplier is computed by comparing the equilibrium path to the counterfactual of no active policy (given the paths for all remaining exogenous shocks). ${ }^{33}$

The figure shows considerable variation over time, establishing that the state of the economy is crucial for the effectiveness of fiscal policy response. ${ }^{34}$ Multipliers rise considerably during the financial crisis, and tend to be low during other periods. Interestingly, the purchases multipliers is the most stable, and smaller than one. It only rises modestly around the Lehman event, and falls sharply during 2009 (precisely when the ARRA is implemented). The transfer multiplier is typically lower than the purchases multiplier, and is even negative during some periods of expansion. It rises considerably, above 1.5, during the financial crisis, which is consistent with the large role of transfers for stabilization. Bank recapitalizations also have fiscal multipliers that are typically negative but rise considerably during the crisis, going over 2 . These facts provide further evidence on the stabilizing role of these two fiscal policy tools during the financial crisis. Interestingly, and

\footnotetext{
${ }^{33}$ This analysis is conducted for impulses of the magnitudes estimated in the previous subsection, using the observed fiscal policy response during the financial crisis. This is important to the extent that these multipliers are also size dependent, as I have illustrated for the case of transfers.

${ }^{34}$ Sims and Wolff (2013) conduct a similar exercise, using a second-order approximation of a canonical New Keynesian model and focusing on output and welfare multipliers of government purchases.
} 
unlike government purchases, these effects are extremely state dependent as these two tools have the potential to generate negative multipliers if used during periods of expansion.

\section{Conclusion}

This paper develops a model of fiscal policy that allows for a comprehensive assessment of the policy response to the recent financial crisis and subsequent Great Recession in the United States. Importantly, it explicitly models the relationship between the balance sheets and constraints faced by the household and financial sectors. It contributes to the existing literature on fiscal policy along two main dimensions: (i) it allows for the analysis of the spillovers of conventional fiscal policy through the financial system, and (ii) it allows for the analysis of less conventional fiscal policy tools that affect the financial sector directly. In particular, I show how the interaction between borrower collateral and default and the financial system's pricing of debt securities augment traditional Keynesian effects of fiscal policy.

The nonlinear solution of the model allows us to think of how the effects of different fiscal policies vary with the state of the economy. In a quantitative application of the model to the U.S., I show that these state dependent effects are extremely important: interventions such as social transfers and bank recapitalizations can generate negative fiscal multipliers when the economy is in a expansion, but very high and positive ones when financial intermediation is constrained and aggregate demand is depressed. Using the model as a measurement device, I estimate distributions for policy-invariant structural shocks, which allow me to conduct counterfactual exercises. I find that transfers and bank recapitalizations were crucial to sustain aggregate consumption. While the aggregate effects of bank recapitalizations are smaller, they appear to be much closer to a Pareto improvement to the extent that they benefit both savers (who own the banks) and borrowers (who benefit from more borrowing and lower costs of borrowing).

The present work abstracts from other important policy interventions that occurred during this period, namely the Fed's quasi-fiscal unconventional policies and Dodd-Frank's overhaul of financial regulation. Incorporating these would require a more detailed modeling of the monetary authority and the financial system, respectively, both of which are beyond the scope of this paper. Another dimension along which the model can be extended concerns a more detailed description of public finances, and the explicit modeling of fiscal sustainability. Extended along this dimension, and in an open economy setting, the model could be used to study the experiences of Ireland or Spain, two eurozone countries that experienced a sovereign debt crisis that was either caused or aggravated by large fiscal interventions in the financial system (Martin and Philippon, 2014). These are exciting avenues for future research. 


\section{References}

Auerbach, A. J. And Y. Gorodnichenko (2012): "Measuring the Output Responses to Fiscal Policy," American Economic Journal: Economic Policy, 4, 1-27. 4, 28

Begenau, J., M. Piazzesi, And M. Schneider (2015): “Banks’ Risk Exposures,” NBER Working Papers 21334, National Bureau of Economic Research, Inc. 12

BiAnCHI, J. (2016): “Efficient Bailouts?” American Economic Review, forthcoming. 6, 31

Blinder, A. AND M. ZAndi (2015): “The Financial Crisis: Lessons for the Next One,” Tech. rep., Center on Budget and Policy Priorities. 4

Bocola, L. (2016): “The Pass-Through of Sovereign Risk," Journal of Political Economy, 124, 879-926. 62

Broda, C. And J. A. PARKer (2014): “The Economic Stimulus Payments of 2008 and the aggregate demand for consumption," Journal of Monetary Economics, 68, S20-S36. 18, 19, 67

CAmpbell, J. Y. And N. G. MAnKIW (1989): "Consumption, Income and Interest Rates: Reinterpreting the Time Series Evidence," NBER Macroeconomics Annual 1989, 4, 185-246. 5

Canzoneri, M., F. Collard, H. Dellas, and B. Diba (2016): "Fiscal Multipliers in Recessions," The Economic Journal, 126, 75-108. 5

CBO (2011): "Estimated Impact of the American Recovery and Reinvestment Act on Employment and Economic Output from April 2011 Through June 2011,' CBO report, Congressional Budget Office. 29

Chari, V. And P. J. Kehoe (2016): "Bailouts, Time Inconsistency, and Optimal Regulation," American Economic Review, 106, 2458-93. 5

Coeurdacier, N., H. Rey, And P. Winant (2011): “The Risky Steady State," American Economic Review, 101, 398-401. 21

Cogan, J. F. And J. TAYlor (2012): "What the Government Purchases Multiplier Actually Multiplied in the 2009 Stimulus Package," in Government Policies and the Delayed Economic Recovery, ed. by L. E. Ohanian, J. B. Taylor, and I. J. Wright, Hoover Institution, Stanford University, chap. 5. 66

Cúrdia, V. And M. Woodford (2010): “Credit Spreads and Monetary Policy,” Journal of Money, Credit and Banking, 42, 3-35. 6

Drautzburg, T. And H. Uhlig (2015): "Fiscal Stimulus and Distortionary Taxation," Review of Economic Dynamics, 18, 894-920. 4, 25 
Elenev, V., T. LAndvoigt, And S. VAn Nieuwerburgh (2016): "Phasing out the GSEs," Journal of Monetary Economics, 81, 111-132. 9, 19

English, W. B., S. J. VAn Den Heuvel, And E. Zakrajsek (2014): "Interest Rate Risk and Bank Equity Valuationsings," Working Papers 14-05, University of Pennsylvania, Wharton School, Weiss Center. 19

FARHI, E. AND J. TiROle (2012): “Collective Moral Hazard, Maturity Mismatch, and Systemic Bailouts," American Economic Review, 102, 60-93. 5

FERNALD, J. G. (2012): “A quarterly, utilization-adjusted series on total factor productivity," Working Paper Series 2012-19, Federal Reserve Bank of San Francisco. 20

FERnÁndeZ-VillaVerde, J. AND J. F. Rubio-RAmíRez (2007): “Estimating Macroeconomic Models: A Likelihood Approach," Review of Economic Studies, 74, 1059-1087. 43

Galí, J., J. D. LÓPEZ-S Alido, And J. VAllÉS (2007): "Understanding the Effects of Government Spending on Consumption," Journal of the European Economic Association, 5, 227-270. $2,5,26$

Garcia, C. And W. Zangwill (1981): Pathways to Solutions, Fixed Points, and Equilibria, Prentice Hall. 61

Garriga, C., F. E. Kydland, And R. Sustek (2015): "Mortgages and Monetary Policy," Working Papers 2015-33, Federal Reserve Bank of St. Louis. 15

Geithner, T. F. (2015): Stress Test: Reflections on Financial Crises, Broadway Books. 4

Gertler, M. And N. Kiyotaki (2010): "Financial Intermediation and Credit Policy in Business Cycle Analysis," in Handbook of Monetary Economics, ed. by B. M. Friedman and M. Woodford, Elsevier, vol. 3 of Handbook of Monetary Economics, chap. 11, 547-599. 12

Greenwald, D. L. (2016): “The Mortgage Credit Channel of Macroeconomic Transmission,” Unpublished, MIT Sloan. 15

Hamilton, J. D. (1989): “A New Approach to the Economic Analysis of Nonstationary Time Series and the Business Cycle," Econometrica, 57, 357-84. 42, 69

IAcoviello, M. (2015): "Financial Business Cycles," Review of Economic Dynamics, 18, 140164. 6

JeAnne, O. And A. KoRineK (2013): "Macroprudential Regulation Versus Mopping Up After the Crash," Working Paper 18675, National Bureau of Economic Research. 5 
Jeske, K., D. KRueger, And K. Mitman (2013): "Housing, mortgage bailout guarantees and the macro economy," Journal of Monetary Economics, 60, 917-935. 9

JORDÀ, O., M. SchulARICK, AND A. M. TAYLOR (2016): "The great mortgaging: housing finance, crises and business cycles," Economic Policy, 31, 107-152. 18, 20

JUDD, K. (1998): Numerical Methods in Economics, vol. 1, The MIT Press, 1 ed. 59

JudD, K., F. Kubler, AND K. SChMEDDERS (2002): “A solution method for incomplete asset markets with heterogeneous agents," Available at SSRN. 20, 61

Kaplan, G. And G. L. Violante (2014): "A Model of the Consumption Response to Fiscal Stimulus Payments," Econometrica, 82, 1199-1239. 5, 19, 26, 30

Kollmann, R., M. Ratto, W. Roeger, And J. IN'T Veld (2013): “Fiscal policy, banks and the financial crisis," Journal of Economic Dynamics and Control, 37, 387-403. 6

Landvoigt, T. (2016): "Financial Intermediation, Credit Risk, and Credit Supply during the Housing Boom," Unpublished, available at SSRN. 6, 9

Leeper, E. M., M. Plante, and N. Traum (2010): "Dynamics of fiscal financing in the United States," Journal of Econometrics, 156, 304-321. 17, 20

LuCAS, D. (2016): “Credit Policy as Fiscal Policy," Brookings Papers on Economic Activity, 52, 1-57. 4, 36

Martin, P. And T. PhilipPon (2014): "Inspecting the Mechanism: Leverage and the Great Recession in the Eurozone," NBER Working Papers 20572, National Bureau of Economic Research, Inc. 51

MCKAY, A. AND R. REIS (2016): "The Role of Automatic Stabilizers in the U.S. Business Cycle," Econometrica, 84, 141-194. 15, 26

Mehrotra, N. R. (2014): "Fiscal Policy Stabilization: Purchases or Transfers?" Unpublished, Brown University. 5, 29

Mertens, K. R. S. M. And M. O. RAvn (2014): "Fiscal Policy in an Expectations-Driven Liquidity Trap," The Review of Economic Studies, 81, 1637-1667. 5

Mian, A. And A. Sufi (2014): House of Debt: How They (and You) Caused the Great Recession, and How We Can Prevent It from Happening Again, The University of Chicago Press. 4

Mountford, A. AND H. Uhlig (2009): "What are the effects of fiscal policy shocks?" Journal of Applied Econometrics, 24, 960-992. 25 
NaKamura, E. And J. Steinsson (2014): "Fiscal Stimulus in a Monetary Union: Evidence from US Regions," American Economic Review, 104, 753-92. 26

$\mathrm{OH}, \mathrm{H}$. AND R. REIS (2012): "Targeted transfers and the fiscal response to the great recession," Journal of Monetary Economics, 59, S50-S64. 5, 29

Parker, J. A., N. S. Souleles, D. S. Johnson, and R. McClelland (2013): "Consumer Spending and the Economic Stimulus Payments of 2008," American Economic Review, 103, 2530-53. 18, 20, 67

PAUl, P. (2016): "Financial Crises \& Debt Rigidities," Unpublished, Federal Reserve Bank of San Francisco. 9

Pennings, S. (2016): "Cross-regions transfers in a monetary union: evidence from the US and implications for Europe," Unpublished, World Bank. 5

Pennings, S. And E. Giambattista (2015): "When is the government transfer multiplier large?" Unpublished, New York University. 29

PhILIPPON, T. (2010): "Debt Overhang and Recapitalization in Closed and Open Economies," IMF Economic Review, 58, 157-178. 5, 33

Prestipino, A. (2014): “Financial Crises and Policy,” Unpublished, New York University. 6, 31

Ramey, V. A. AND S. Zubairy (2016): "Government Spending Multipliers in Good Times and in Bad: Evidence from U.S. Historical Data," Unpublished, UCSD and Texas AM University. 4, 25,28

Ross, E. J. AND L. Shibut (2015): "What Drives Loss Given Default? Evidence from Commercial Real Estate Loans at Failed Banks," FDIC CFR WP 2015-03, Federal Deposit Insurance Corporation. 18

Rudebusch, G. D. And E. T. Swanson (2012): "The Bond Premium in a DSGE Model with Long-Run Real and Nominal Risks," American Economic Journal: Macroeconomics, 4, 10543. 8

Sims, E. AND J. WolfF (2013): "The Output and Welfare Effects of Government Spending Shocks over the Business Cycle," NBER Working Papers 19749, National Bureau of Economic Research, Inc. 50

Woodford, M. (2001): “Fiscal Requirements for Price Stability,” NBER Working Papers 8072, National Bureau of Economic Research, Inc. 9

(2011): "Simple Analytics of the Government Expenditure Multiplier," American Economic Journal: Macroeconomics, 3, 1-35. 2, 26 


\section{A Model Appendix}

\section{A.1 Full List of Model Conditions}

Savers,

$$
\begin{aligned}
C_{t}^{s}\left(N_{t}^{s}\right)^{\varphi} & =(1-\tau) w_{t} \\
Q_{t} & =\mathbb{E}_{t}\left[\frac{\Lambda_{t+1}^{s}}{\Pi_{t+1}}\right] \\
Q_{t}^{d} & =\mathbb{E}_{t}\left[\frac{\Lambda_{t+1}^{s}}{\prod_{t+1}} Z_{t+1}^{d}\right] \\
\Lambda_{t+1}^{s} & =\beta\left\{\frac{V_{t+1}^{s}}{\left[\mathbb{E}_{t}\left(V_{t+1}^{s}\right)^{1-\alpha^{s}}\right]^{1 /\left(1-\alpha^{s}\right)}}\right\}^{-\alpha^{s}} \frac{C_{t}^{s}}{C_{t+1}^{s}} \\
V_{t}^{s} & =\log \left(C_{t}^{s}\right)-\frac{\left(N_{t}^{s}\right)^{1+\varphi}}{1+\varphi}+\beta\left[\mathbb{E}_{t}\left(V_{t+1}^{s}\right)^{1-\alpha^{s}}\right]^{1 /\left(1-\alpha^{s}\right)}
\end{aligned}
$$

Banks,

$$
\begin{aligned}
\Pi_{t} E_{t} & =\Psi^{d}\left(u_{t}^{*}\right) Z_{t}^{b} B_{t-1}^{b}-\left[1-F^{d}\left(u_{t}^{*}\right)\right] D_{t-1}+\varpi Q_{t}^{b} B_{t-1}^{b} \\
Q_{t}^{b} B_{t}^{b} & =\left(1+s_{t}^{k}\right) \theta E_{t}+Q_{t}^{d} D_{t} \\
\kappa Q_{t}^{b} B_{t}^{b} & \leq \Phi_{t} \theta E_{t} \perp \mu_{t} \geq 0 \\
\mu_{t} \kappa & =\mathbb{E}_{t}\left\{\frac{\Lambda_{t+1}^{s}}{\Pi_{t+1}}\left(1-\theta+\theta \Phi_{t+1}\right)\left(\Psi^{d}\left(u_{t+1}^{*}\right) \frac{Z_{t+1}^{b}}{Q_{t}^{b}}-\frac{1-F^{d}\left(u_{t}^{*}\right)}{Q_{t}^{d}}\right)\right\} \\
\Phi_{t} & =\left(1+s_{t}^{k}\right) \frac{\mathbb{E}_{t}\left\{\frac{\Lambda_{t+1}^{s}}{\Pi_{t+1}}\left(1-\theta+\theta \Phi_{t+1}\right)\left[1-F^{d}\left(u_{t+1}^{*}\right)\right]\right\}}{Q_{t}^{d}\left(1-\mu_{t}\right)} \\
u_{t}^{*} & =\frac{D_{t-1}}{Z_{t}^{b} B_{t-1}^{b}}
\end{aligned}
$$




\section{Borrowers,}

$$
\begin{aligned}
C_{t}^{b}\left(N_{t}^{b}\right)^{\varphi} & =(1-\tau) w_{t} \\
B_{t}^{b}-B_{t-1}^{b} \frac{1-\gamma}{\Pi_{t}} & \leq \chi \mathrm{m} p_{t}^{h} \perp \lambda_{t}^{b} \geq 0 \\
B_{t}^{b}-B_{t-1}^{b} \frac{1-\gamma}{\Pi_{t}} \geq 0 \perp \zeta_{t}^{b} \geq 0 & \\
\nu_{t}^{*} & =\frac{B_{t-1}^{b}}{\chi \prod_{t} p_{t}^{h}} \\
p_{t}^{h} & =\frac{\xi\left(C_{t}^{b}\right)^{\sigma}+\mathbb{E}_{t} \Lambda_{t+1}^{b} p_{t+1}^{h}\left[\gamma\left(1-\Psi_{t+1}^{b}\right)+\Psi_{t+1}^{b}\right]}{1-\lambda_{t}^{b} \mathrm{~m}_{t}} \\
Q_{t}^{b} & =\mathbb{E}_{t}\left\{\frac{\Lambda_{t+1}^{b}}{\Pi_{t+1}}\left[Q_{t+1}^{b}(1-\gamma)+\gamma\left[1-F_{t+1}^{b}\left(\nu_{t+1}^{*}\right)\right]\right]\right\} \\
+ & {\left[\left(\lambda_{t}^{b}-\zeta_{t}^{b}\right)-(1-\gamma) \mathbb{E}_{t}\left\{\frac{\Lambda_{t+1}^{b}}{\Pi_{t+1}}\left(\lambda_{t+1}^{b}-\zeta_{t+1}^{b}\right)\right\}\right] } \\
(1-\tau) w_{t} N_{t}^{b}+\frac{Q_{t}^{b} B_{t}^{b}}{\chi}-T_{t}+T_{t}^{b} & =C_{t}^{b}+\frac{B_{t-1}^{b}}{\chi \prod_{t}}\left\{\gamma\left[1-F_{t}^{b}\left(\nu_{t}^{*}\right)\right]+(1-\gamma) Q_{t}^{b}\right\}+\gamma p_{t}^{h}\left(1-\Psi_{t}^{b}\right)
\end{aligned}
$$

$$
\begin{aligned}
\Lambda_{t+1}^{b} & =\beta\left\{\frac{V_{t+1}^{b}}{\left[\mathbb{E}_{t}\left(V_{t+1}^{b}\right)^{1-\alpha^{b}}\right]^{1 /\left(1-\alpha^{b}\right)}}\right\}^{-\alpha^{b}} \frac{C_{t}^{b}}{C_{t+1}^{b}} \\
V_{t}^{b} & =\log \left(C_{t}^{b}\right)-\frac{\left(N_{t}^{b}\right)^{1+\varphi}}{1+\varphi}+\beta\left[\mathbb{E}_{t}\left(V_{t+1}^{b}\right)^{1-\alpha^{b}}\right]^{1 /\left(1-\alpha^{b}\right)}
\end{aligned}
$$

Asset payoffs,

$$
\begin{aligned}
& Z_{t}^{b}=Q_{t}^{b}(1-\gamma)+\gamma\left[1-F_{t}^{b}\left(\nu_{t}^{*}\right)+\left(1-\lambda^{b}\right) \frac{1-\Psi_{t}^{b}}{\nu_{t}^{*}}\right] \\
& Z_{t}^{d}=s_{t-1}^{d}+\left(1-s_{t-1}^{d}\right)\left[1-F^{d}\left(u_{t}^{*}\right)+\left(1-\lambda^{d}\right) \frac{1-\Psi^{d}\left(u_{t}^{*}\right)}{u_{t}^{*}}\right]
\end{aligned}
$$

Phillips Curve, resource constraint, and production function

$$
\begin{aligned}
\eta \mathbb{E}_{t}\left\{\Lambda_{t+1}^{s} \frac{Y_{t+1}}{Y_{t}} \frac{\Pi_{t+1}}{\Pi}\left(\frac{\Pi_{t+1}}{\Pi}-1\right)\right\}-\varepsilon\left[\frac{\varepsilon-1}{\varepsilon}-\frac{w_{t}}{A_{t}}\right] & =\eta \frac{\Pi_{t}}{\Pi}\left(\frac{\Pi_{t}}{\Pi}-1\right) \\
C_{t}+G_{t}+\lambda^{b} \gamma \chi p_{t}^{h}\left[1-\Psi_{t}^{b}\left(\nu_{t}^{*}\right)\right]+\lambda^{d} Z_{t}^{b} \frac{B_{t-1}^{b}}{\Pi_{t}}\left[1-\Psi^{d}\left(u_{t}^{*}\right)\right] & =Y_{t}\left[1-\frac{\eta}{2}\left(\frac{\Pi_{t}}{\Pi}-1\right)^{2}\right] \\
Y_{t} & =A_{t} N_{t}
\end{aligned}
$$


Monetary and fiscal policy,

$$
\begin{aligned}
& \frac{1}{Q_{t}}=\frac{1}{\bar{Q}}\left[\frac{\Pi_{t}}{\Pi}\right]^{\phi_{\pi}}\left(\frac{Y_{t}}{\bar{Y}}\right)^{\phi_{Y}} \\
& \tau Y_{t}\left[1-d\left(\Pi_{t}\right)\right]+Q_{t} B_{t}^{g}+T_{t}=\frac{B_{t-1}^{g}}{\Pi_{t}}+G_{t}+\chi T_{t}^{b}+s_{t}^{k} \theta E_{t} \\
&+s_{t-1}^{d} \frac{D_{t-1}}{\Pi_{t}}\left[F^{d}\left(u_{t}^{*}\right)-\left(1-\lambda^{d}\right) \frac{1-\Psi^{d}\left(u_{t}^{*}\right)}{u_{t}^{*}}\right] \\
& T_{t}=\phi_{T}\left[\log B_{t-1}^{g}-\log \bar{B}^{g}\right]
\end{aligned}
$$

CDF's and partial expectations for risk shocks,

$$
\begin{aligned}
& F_{t}^{b}\left(\nu_{t}^{*}\right)=\left[\frac{\sigma_{t}^{b} \nu_{t}^{*}}{\sigma_{t}^{b}+1}\right]^{\sigma_{t}^{b}} \\
& \Psi_{t}^{b}\left(\nu_{t}^{*}\right)=1-\left[\frac{\sigma_{t}^{b} \nu_{t}^{*}}{\sigma_{t}^{b}+1}\right]^{\sigma_{t}^{b}+1} \\
& F^{d}\left(u_{t}^{*}\right)=\frac{\left(u_{t}^{*}\right)^{\sigma^{d}}-\underline{u}^{\sigma^{d}}}{\bar{u}^{\sigma^{d}}-\underline{u}^{\sigma^{d}}} \\
& \Psi^{d}\left(u_{t}^{*}\right)=\frac{\sigma^{d}}{\bar{\sigma}^{d}+1} \frac{\bar{u}^{\sigma^{d}+1}-\left(u_{t}^{*}\right)^{\sigma^{d}+1}}{\bar{u}^{\sigma^{d}}-\underline{u}^{\sigma^{d}}}
\end{aligned}
$$

\section{A.2 Price Setter's Problem and the Phillips Curve}

Given the aggregate state $\mathbb{S}_{t}$, the firm's recursive problem is

$V\left[P_{t-1}(i) ; \mathbb{S}_{t}\right]=\max _{P_{t}(i), Y_{t}(i)}\left\{P_{t}(i) Y_{t}(i)-W_{t} \frac{Y_{t}(i)}{A_{t}}-\frac{\eta}{2} P_{t} Y_{t}\left(\frac{P_{t}(i)}{\Pi P_{t-1}(i)}-1\right)^{2}+\mathbb{E}_{t} \frac{\Lambda_{t, t+1}^{s}}{\prod_{t+1}} V\left[P_{t}(i) ; \mathbb{S}_{t+1}\right]\right\}$

subject to the demand curve $Y_{t}(i)=\left(\frac{P_{t}(i)}{P_{t}}\right)^{-\varepsilon} Y_{t}$. The solution to this problem is

$$
\begin{aligned}
& \eta \frac{P_{t} Y_{t}}{\Pi P_{t-1}(i)}\left(\frac{P_{t}(i)}{\Pi P_{t-1}(i)}-1\right)+P_{t}(i)^{-\varepsilon} P_{t}^{\varepsilon} Y_{t}\left[\varepsilon-1-\varepsilon \frac{W_{t}}{A_{t}} \frac{1}{P_{t}(i)}\right] \\
= & \mathbb{E}_{t} \frac{\Lambda_{t, t+1}^{s}}{\prod_{t+1}} \eta \frac{P_{t+1} P_{t+1}(i) Y_{t+1}}{\Pi P_{t}(i)^{2}}\left(\frac{P_{t+1}(i)}{\Pi P_{t}(i)}-1\right)
\end{aligned}
$$

In a symmetric equilibrium, all firms choose the same price $P_{t}(i)=P_{t}$. Thus the above condition becomes a Phillips Curve,

$$
\eta \frac{\Pi_{t}}{\Pi}\left(\frac{\Pi_{t}}{\Pi}-1\right)+\varepsilon\left[\frac{\varepsilon-1}{\varepsilon}-\frac{w_{t}}{A_{t}}\right]=\eta \mathbb{E}_{t} \Lambda_{t, t+1}^{s} \frac{Y_{t+1}}{Y_{t}} \frac{\Pi_{t+1}}{\Pi}\left(\frac{\Pi_{t+1}}{\Pi}-1\right)
$$




\section{A.3 Solution to the Bank's Problem}

To solve the bank's problem, we start by writing the bank's franchise value as

$$
\begin{aligned}
\Phi_{j, t}\left(e_{j, t}\right) & \equiv \mathbb{E}_{t} \int_{u_{j, t+1}^{*}}^{\infty} \Lambda_{t, t+1} V_{j, t+1}\left(e_{j, t+1}\right) \mathrm{d} F_{t+1}^{d} \\
& =\mathbb{E}_{t} \int_{u_{j, t+1}^{*}}^{\infty} \Lambda_{t, t+1}\left[(1-\theta) e_{j, t+1}\left(u_{j, t+1}\right)+\Phi_{j, t+1}\left(e_{j, t+1}\right)\right] \mathrm{d} F_{t+1}^{d}
\end{aligned}
$$

We now guess, to later verify, that the bank's franchise value is linear in current earnings,

$$
\Phi_{j, t}\left(e_{j, t}\right)=\Phi_{j, t} \theta e_{j, t}
$$

Under this assumption, we can reformulate the bank's problem as

$$
\Phi_{j, t} \theta e_{j, t}=\max _{b_{j, t}, d_{j, t}} \mathbb{E}_{t} \int_{u_{j, t+1}^{*}}^{\infty} \Lambda_{t, t+1}\left(1-\theta+\theta \Phi_{j, t+1}\right) e_{j, t+1}\left(u_{j, t+1}\right) \mathrm{d} F_{t+1}^{d}
$$

subject the law of motion for earnings, the balance sheet constraint and the leverage constraint. Replacing for the first two, we can write the bank's Lagrangian as

$$
\begin{aligned}
& \Phi_{j, t} \theta e_{j, t} \\
&=\max _{b_{j, t}} \mathbb{E}_{t} \int_{u_{j, t+1}^{*}}^{\infty} \Lambda_{t+1}\left(1-\theta+\theta \Phi_{j, t+1}\right)\left[\left(u_{j, t+1} \frac{Z_{t+1}^{b}}{Q_{t}^{b}}-\frac{1}{Q_{t}^{d}}\right) Q_{t}^{b} b_{j, t}^{b}+\frac{\theta e_{j, t}}{Q_{t}^{d}}\right] \mathrm{d} F_{t+1}^{d} \\
& \quad+\mu_{j, t}\left[\Phi_{j, t} \theta e_{j, t}-\kappa Q_{t}^{b} b_{j, t}^{b}\right]
\end{aligned}
$$

The first order condition with respect to $b_{j, t}$ is then

$$
\mathbb{E}_{t} \int_{u_{j, t+1}^{*}}^{\infty} \Lambda_{t, t+1}\left(1-\theta+\theta \Phi_{j, t+1}\right)\left(u_{j, t+1} \frac{Z_{t+1}^{b}}{Q_{t}^{b}}-\frac{1}{Q_{t}^{d}}\right) \mathrm{d} F_{t+1}^{d}=\mu_{j, t} \kappa
$$

Applying the envelope theorem then yields

$$
\Phi_{j, t}=\frac{\mathbb{E}_{t}\left\{\frac{\Lambda_{t, t+1}^{s}}{\Pi_{t+1}}\left(1-\theta+\theta \Phi_{j, t+1}\right)\left[1-F^{d}\left(u_{j, t+1}^{*}\right)\right]\right\}}{Q_{t}^{d}\left(1-\mu_{j, t}\right)}
$$

thus confirming our conjecture that the value was linear in earnings.

\section{B Computational Appendix}

\section{B.1 Model Solution}

I adopt a global solution method that combines time iteration (Judd, 1998) and multilinear interpolation. Given a vector of state variables $\mathbb{S}_{t-1}$ and innovations $\epsilon_{t}$, one can use the equilibrium 
conditions described in Appendix A to compute the values of all endogenous variables $\mathcal{Y}_{t}$ in the current period,

$$
\mathcal{Y}_{t}=f\left(\mathbb{S}_{t-1}, \epsilon_{t}\right)
$$

The procedure consists on approximating $f$ (an infinite-dimensional object) using a finite approximation $\hat{f}$ chosen from some space of functions. The approximation is obtained by solving for $\hat{f}$ exactly at a finite number of grid points, and interpolating between these when evaluating the equilibrium at points of the state space that do not belong to the grid.

In practice, it is not needed to approximate all elements of $\mathcal{Y}_{t}$. Given knowledge of the states and innovations $\left(\mathbb{S}_{t-1}, \epsilon_{t}\right)$, as well as of a restricted set of endogenous variables $\mathcal{X}_{t} \subset \mathcal{Y}_{t}$ (the "policies"), one can use the model's static equilibrium conditions to back out the remaining elements of $\mathcal{Y}_{t}$. For the specific case of my model, we have that

$$
\mathcal{S}_{t} \equiv\left(\mathbb{S}_{t-1}, \epsilon_{t}\right)=\left(D_{t-1}, B_{t-1}^{b}, B_{t-1}^{g}, A_{t}, \sigma_{t}^{b}, \Omega_{t}\right)
$$

Policies $\mathcal{X}_{t}$ are typically variables that either appear inside expectations term (and so we need to be able to evaluate them for different values of $\mathbb{S}_{t+1}$ ), and/or variables that cannot be determined statically without solving a nonlinear equation. Using these as the main criteria, I choose as policies the following set of variables

$$
\mathcal{X}_{t}=\left(C_{t}^{s}, N_{t}^{s}, p_{t}^{h}, Q_{t}^{d}, Q_{t}^{b}, \Pi_{t}, \mu_{t}, \lambda_{t}^{b}, \zeta_{t}^{b}, V_{t}^{s}, V_{t}^{b}\right)
$$

The algorithm then proceeds as follows,

1. Generate a discrete grid for the state variables, $\left\{g_{i}\right\}_{i=1}^{N}=\mathbb{G}=G_{D} \times G_{B} \times G_{A} \times G_{\sigma} \times G_{\Omega}$.

2. Approximate $\mathcal{X}_{t}$ over $\mathbb{G}$ by choosing an initial guess and a functional space to define the approximant. As the initial guess, I use the model's non-stochastic steady state. This means that I can guess a value for each variable $X_{t} \in \mathcal{X}_{t}$ at each grid point. Call this set of values $X^{0}=\left\{x_{i}^{0}\right\}_{i=1}^{N}$. As an approximant, I use piecewise linear functions (multilinear interpolation). The approximant allows me to evaluate $X^{0}$ outside of the grid points, at any combination of values for the states.

3. Given this initial guess for the policies $\mathcal{X}^{0}$, solve the model by using time iteration. Set $\mathcal{X}^{\tau}=\mathcal{X}^{0}$

(a) For each point in the grid, $g_{i}$, solve a system of residual equations for the value of the policies at that grid point. Evaluate expectations using quadrature methods, and use the approximant $\mathcal{X}^{\tau}$ to evaluate the policies inside of the expectation terms. Obtain a series of values for the policies at each point in the grid $\left\{\mathcal{X}_{i}^{\text {new }}\right\}_{i=1}^{N}$.

(b) Given values for these points, compute a convergence criterion for each element of $\mathcal{X}$ as

$$
\max _{i}\left\|X_{i}^{\text {new }}-X_{i}^{\tau}\right\|
$$


(c) If the criterion is smaller than some defined tolerance, stop. Otherwise, update the guess for each point in the grid

$$
X_{i}^{\tau+1}=\lambda X_{i}^{\text {new }}+(1-\lambda) X_{i}^{\tau}
$$

Reevaluate (update) the approximant, and return to step (a).

Intuitively, time iteration works by guessing some functional form for the endogenous variables inside of the expectations terms, and iterating backwards until today's policies are consistent with the expected future policies at each point in the state space. Solving models with this method is particularly challenging, since very few convergence results exist (unlike, for example, value function iteration methods).

Occasionally Binding Constraints To deal with occasionally binding constraints, I apply the procedure described in Garcia and Zangwill (1981) and used by Judd et al. (2002). This involves rewriting inequality conditions and redefining Lagrange multipliers such that equilibrium conditions can be written as a system of equalities, and standard methods for solving nonlinear systems of equations can be applied. As a concrete example, take the bank's leverage constraint and the associated Lagrange multiplier $\mu_{t} \geq 0$. I define an auxiliary variable $\mu_{t}^{\text {aux }} \in \mathbb{R}$, such that

$$
\mu_{t}=\max \left(0, \mu_{t}^{\mathrm{aux}}\right)^{2}
$$

and the inequality to which the complementarity condition $\mu_{t} \geq 0$ is associated reads

$$
\Phi_{t} \theta E_{t}=\kappa Q_{t}^{b} B_{t}+\max \left(0,-\mu_{t}^{\mathrm{aux}}\right)^{2}
$$

Notice then that whenever $\mu_{t}^{\text {aux }} \geq 0$, the inequality holds as an equality, and $\mu_{t} \geq 0$. On the other hand, when we have that $\mu_{t}^{\text {aux }}<0$, this variable becomes the residual for the inequality, which implies that $\Phi_{t} \theta E_{t}>\kappa Q_{t} B_{t}$, and $\mu_{t}=0$. Defining this auxiliary variable as the square of a max operator ensures that the system is differentiable with respect to this variable, which is helpful when using Newton-based methods to solve the nonlinear system of equilibrium conditions.

Grid Construction For each endogenous variable grid limits are chosen to minimize extrapolation. Given the nonlinear nature of the model, grids are constructed manually and made denser wherever strong nonlinearities are present (i.e. when constraints start binding). Given that bank and household debt are very positively correlated, using rectangular grids is computationally costly, since it involves solving the model for many points that will never be visited during stochastic simulations. One approach to deal with this issue is to use grid rotations based on singular value decompositions. Since my grid is constructed manually, I instead opt for redefining the state variables. In particular, I use $\operatorname{lev}_{t-1}=\frac{D_{t-1}}{B_{t-1}^{b}}$ instead of $D_{t-1}$ as a state. The bounds of the grid are chosen so as to prevent extrapolation (a concern since the approximant is linear). The distribution 
of the endogenous states bank leverage and household debt after a long simulation is shown in A.5. Blue unfilled circles are periods of low credit risk, while orange filled squares correspond to periods of high credit risk. The solid red dot is the stochastic steady state of the model.

Accuracy of the Solution To evaluate the accuracy of the model solution, I run a long simulation of the model and report the Euler equation residuals in decimal log base. The histogram for this errors is in Figure A.6, where the dashed red line reports the median. The magnitude of these errors is in line with what is considered acceptable in the literature (see, for example, Bocola, 2016).

\section{B.2 Particle Filter and Smoother}

In this section, I describe the particle filter and smoother used to extract the sequences of structural shocks from the data.

Nonlinear State Space Model The first step to write the particle filter is to write the model in nonlinear state space form. The general structure of these models is comprised of two blocks: a state transition function $f$ and an observations function $g$

$$
\begin{aligned}
x_{t} & =f\left(x_{t-1}, \epsilon_{t} ; \gamma\right) \\
y_{t} & =g\left(x_{t} ; \gamma\right)+\eta_{t}
\end{aligned}
$$

where $\gamma$ is a vector of structural parameters, $x_{t}$ is a vector of state variables, $y_{t}$ is a vector of observable variables, $\epsilon_{t}$ are structural shocks, and $\eta_{t}$ are measurement errors. The structural shocks follow some distribution with density function $f$, and measurement errors are assumed to be additive and Gaussian,

$$
\eta_{t} \sim \mathcal{N}(\mathbf{0}, \mathbf{\Sigma})
$$

For the current model, we have

$$
\begin{aligned}
& x_{t}=\left(\operatorname{lev}_{t}, B_{t}^{b}, B_{t}^{g}, A_{t}, \sigma_{t}^{b}, \Omega_{t}\right) \\
& y_{t}=\left(C_{t}, \operatorname{spread}_{t}, \Omega_{t}\right)
\end{aligned}
$$

The structural shocks are the innovations to $\left(A_{t}, \sigma_{t}^{b}, \Omega_{t}\right)$, and all variables are observed with some measurement error that is Gaussian and uncorrelated across variables. For the endogenous observables, $\left(C_{t}\right.$, spread $\left._{t}\right)$, I set the standard deviation of the measurement error equal to $10 \%$ of the standard deviation of the data series. For the policies, $\Omega_{t}$, I set the standard deviation of the measurement error to be $1 \%$ of the standard deviation of the data series. 
Likelihood Function Given a sample of observables $y^{T}=\left\{y_{t}\right\}_{t=0}^{T}$, we can apply the typical factorization and write the likelihood given parameters $\gamma$ as

$$
\mathcal{L}\left(y^{T} ; \gamma\right)=\prod_{t=1}^{T} p\left(y_{t} \mid y^{t-1} ; \gamma\right)
$$

We can further decompose the period-by-period conditional density $p\left(y_{t} \mid y^{t-1} ; \gamma\right)$ as

$$
\mathcal{L}\left(y^{T} ; \gamma\right)=\prod_{t=1}^{T} \int p\left(y_{t} \mid x_{t} ; \gamma\right) p\left(x_{t} \mid y^{t-1} ; \gamma\right) \mathrm{d} x_{t}
$$

The first term is easy to evaluate: $p\left(y_{t} \mid x_{t} ; \gamma\right)$ comes from the observation equation and the density for the measurement error. Given the assumption that measurement error is additive and Gaussian, $\eta_{t} \sim \mathcal{N}(0, \Sigma)$, we can simply evaluate

$$
p\left(y_{t} \mid x_{t} ; \gamma\right)=\phi\left[y_{t}-g\left(x_{t} ; \gamma\right)\right]
$$

where $\phi$ is the (multivariate) standard normal density.

The problem comes from evaluating the second term, $p\left(x_{t} \mid y^{t-1} ; \gamma\right)$, which is a complicated function of the states. This is where the particle filter is helpful, since it allows us to compute this conditional density by simulation.

Bootstrap Filter Our goal is to evaluate $p\left(x_{t} \mid y^{t-1} ; \gamma\right)$ at each $t$. The particle filter is a way of obtaining a sequence of state densities conditional on past observations, $\left\{p\left(x_{t} \mid y^{t-1} ; \gamma\right)\right\}_{t=0}^{T}$. Throughout the procedure, we will have to keep track of a sequence of sampling weights, $\left\{\left\{\pi_{t}^{i}\right\}_{i=1}^{N}\right\}_{t=0}^{T}$

It proceeds as follows,

1. Initialization, set $t=1$ and initialize $\left\{x_{0}^{i}, \pi_{0}^{i}\right\}_{i=1}^{N}$ by taking $N$ draws from the model's ergodic distribution and set $\pi_{0}^{i}=\frac{1}{N}, \forall i$.

2. Prediction, for each particle $i$, draw $x_{t \mid t-1}^{i}$ from the proposal density $h\left(x_{t} \mid y^{t}, x_{t-1}^{i}\right)$. This involves randomly drawing one vector of structural innovations $\epsilon_{t}^{i}$, and computing

$$
x_{t \mid t-1}^{i}=g\left(x_{t-1}^{i}, \epsilon_{t}^{i}\right)
$$

3. Filtering, assign to each draw $x_{t \mid t-1}^{i}$ a particle weight given by

$$
\pi_{t}^{i}=\frac{p\left(y_{t} \mid x_{t \mid t-1}^{i} ; \gamma\right) p\left(x_{t} \mid x_{t \mid t-1}^{i} ; \gamma\right)}{h\left(x_{t} \mid y^{t}, x_{t-1}^{i}\right)}
$$

Noting that

$$
p\left(y_{t} \mid x_{t \mid t-1}^{i} ; \gamma\right)=\phi\left(y_{t}-g\left(x_{t \mid t-1}^{i} ; \gamma\right)\right)
$$


We can compute each particle weight as

$$
\pi_{t}^{i}=\frac{p\left(y_{t} \mid x_{t \mid t-1}^{i} ; \gamma\right)}{\sum_{i=1}^{N} p\left(y_{t} \mid x_{t \mid t-1}^{i} ; \gamma\right)}
$$

This generates a swarm of particle weights that add up to one, $\left\{\pi_{t}^{i}\right\}_{i=1}^{N}$.

4. Sampling, sample $N$ values for the state vector with replacement, from $\left\{x_{t \mid t-1}^{i}\right\}_{i=1}^{N}$ using the weights $\left\{\pi_{t}^{i}\right\}_{i=1}^{N}$. Call this set of draws $\left\{x_{t}^{i}\right\}_{i=1}^{N}$, and set the weights back to $\pi_{t}^{i}=\frac{1}{N}, \forall i$.

These steps generate a sequence of $\left\{\left\{x_{t \mid t-1}^{i}\right\}_{i=1}^{N}\right\}_{t=0}^{T}$, which can then be used to generate $\left\{\left\{p\left(y_{t} \mid x_{t \mid t-1}^{i} ; \gamma\right)\right\}_{i=1}^{N}\right\}_{t=0}^{T}$. This then allows us to evaluate the likelihood as

$$
\mathcal{L}\left(y^{T} ; \gamma\right) \simeq \prod_{t=1}^{T} \frac{1}{N} \sum_{i=1}^{N} p\left(y_{t} \mid x_{t \mid t-1}^{i} ; \gamma\right)
$$

Filtered States At the end of the process, we have a sequence of simulated swarms of particles for each time period $\left\{\left\{x_{t}^{i}\right\}_{i=1}^{N}\right\}_{t=0}^{T}$. These can be treated as empirical conditional densities for the state, given the observed data until $t$, or $y^{t}$. For the purpose of our exercise, we can do better by obtaining the conditional densities of the states given the entire sample, or $y^{T}$. For that, we can use the output of the particle filter to run a particle smoother.

Particle Smoother Running the particle filter gives us the model's best estimates of the states at each point in time given data until that point in time. Given a sample $y^{T}$, the particle smoother provides a better estimate of the state at each point in time, since it uses not only information up to that period, but also future information (that was not available in that period). Thus, unlike the filter, we cannot run the smoother "in real time", but only historically. In other words, the smoother requires more information than the filter, but also provides more accurate estimates for the conditional densities of the state.

Formally, the particle filter gives us $\left\{p\left(x_{t} \mid y^{t} ; \gamma\right)\right\}_{t=0}^{T}$, while the particle smoother gives us $\left\{p\left(x_{t} \mid y^{T} ; \gamma\right)\right\}_{t=0}^{T}$. To obtain these conditional densities, we factorize the state's conditional density "backwards", as

$$
p\left(x^{T} \mid y^{t} ; \gamma\right)=p\left(x_{T} \mid y^{T}\right) \prod_{t=1}^{T-1} p\left(x_{t} \mid x_{t+1}, y^{T}\right)
$$

The procedure is as follows: first, we run the particle filter and get $\left\{p\left(x_{t} \mid y^{t} ; \gamma\right)\right\}_{t=0}^{T}$. The particle filter gives us sequences $\left\{x_{t}^{i}, \pi_{t}^{i}\right\}_{i=1, t=0}^{N, T}$. We want to obtain a distribution of smoothed states, $\left\{\tilde{x}_{t}^{i}\right\}_{t=1}^{T}$. 
1. To initialize the smoother, draw a particle swarm from the density of the final state, $\left\{x_{T}^{i}, \pi_{T}^{i}\right\}_{i=1}^{N}$. Set $\left\{\tilde{x}_{T}^{i}\right\}_{i=1}^{N}=\left\{x_{T}^{i}\right\}_{i=1}^{N}$. I sample uniformly from the last period's density.

2. Given $\left\{\tilde{x}_{t}^{i}\right\}_{i=1}^{N}$, for each $i$, draw with replacement $\left\{x_{t-1 \mid t}^{i, j}\right\}_{j=1}^{M}$ using uniform weights.

3. For each particle in this new swarm, compute weights $\left\{w_{t-1 \mid t}^{i, j}\right\}_{j=1}^{M}$ as

$$
w_{t-1 \mid t}^{i, j}=\frac{p\left(\tilde{x}_{t}^{i} \mid x_{t-1 \mid t}^{i, j}\right)}{\sum_{j=1}^{M} p\left(\tilde{x}_{t}^{i} \mid x_{t-1 \mid t}^{i, j}\right)}
$$

In practice, this is the probability of observing $x_{t-1 \mid t}^{i, j}$ in the previous period, given $\tilde{x}_{t}^{i}$ in the current period. Taking advantage of the fact that the structural innovations are uncorrelated across structural shocks, we can compute this number by using (i) the relevant transition probability in the transition matrices, (ii) using the fact that TFP innovations are standard normal, (iii) taking the product of all these probabilities. We then normalize the weights to ensure that they sum to one.

4. Using these weights, draw exactly one element from $\left\{x_{t-1 \mid t}^{i, j}\right\}_{j=1}^{M}$. Call it $\tilde{x}_{t-1}^{i}$.

5. Repeat this process for all $i$, obtain $\left\{\tilde{x}_{t-1}^{i}\right\}_{i=1}^{N}$ for each $t$.

6. Repeat this process for all $t$, obtain $\left\{\tilde{x}_{t}^{i}\right\}_{i=1, t=0}^{N, T}$, a sequence of densities for the smoothed states.

Other Details I use a swarm of 15,000 particles to run the filter and the smoother. To initialize the filter, I obtain the initial conditions for the states by running a long simulation of the model, shown in figure A.5, and drawing $\left\{x_{0}^{i}\right\}_{i=1}^{N}$ by sampling uniformly from that simulation.

\section{B.3 Generalized Impulse Response Functions}

In the context of a nonlinear stochastic model, Impulse Response Functions do not have as a straightforward interpretation. In linear models, certainty equivalence holds and shocks are additive. This means that we can study the response of macroeconomic variables to a shock with respect to a trivial benchmark: the path of those variables in the absence of shocks, i.e. the deterministic steady state. This is no longer the case in a nonlinear stochastic model, since the economy may respond to a shock differently depending on its initial state, and the impact of shocks is not linearly additive.

To define a benchmark against which the path of the economy should be compared, we therefore need to take a stance on two aspects: first, where to start the simulation in the state space, since the economy may react to the same shock differently depending on its initial states, and, second, what to compare the simulation against. I compute Generalized Impulse Response Functions 
(GIRF) as follows: let $Y_{t}=f\left(Y_{t-1}, \epsilon_{t}\right)$ denote the equilibrium of the model at time $t$, as a function of state variables $Y_{t-1}$ as well as innovations $\epsilon_{t}$. First, I simulate the model for a large number of periods without any shocks in order to obtain its stochastic steady state, which I use as a starting point for all exercises unless otherwise noted.

I draw $R$ different sequences of shocks of length $T,\left\{\epsilon_{r, t}\right\}_{t=1, r=1}^{T, R}$, and simulate the model $R$ times, starting from the stochastic steady state. This gives me $R$ different sequences of simulated endogenous variables, $\left\{Y_{r, t}^{\text {base }}\right\}_{t=1, r=1}^{T, R}$. Using the exact same sequences of innovations, I re-simulate the model $R$ times, but adding a $1 \%$ positive (negative) shock to the TFP process in the first period of the simulation. This generates "shocked" sequences $\left\{Y_{r, t}^{\text {shock }}\right\}_{t=1, r=1}^{T, R}$ Then, for each period $t$ and variable $Y$, I take the difference between the average behavior of that variable under the shocked sequences and the base sequences. The GIRF is thus formally defined as

$$
G I R F_{t}(Y)=\frac{\frac{1}{R} \sum_{r=1}^{R} Y_{r, t}^{\text {shocked }}-\frac{1}{R} \sum_{r=1}^{R} Y_{r, t}^{\text {base }}}{Y^{\text {stoch. SS }}}
$$

The only difference between the sequences of base and shocked innovations is that $\epsilon_{r, t}^{\text {shocked,TFP }}=$ $\epsilon_{r, t}^{\mathrm{base}, \mathrm{TFP}}+x \%$, where $x$ is the magnitude of the shock.

\section{Fiscal Policy Data}

In this appendix, I describe the collection and construction of the discretionary fiscal policy series in greater detail.

Government Purchases The only discretionary fiscal policy measure that included government purchases of goods and services was the ARRA - and even then, these were far from being the bulk of the package: by mid-2010, it was estimated that only $2 \%$ of the total outlays of this program were associated with direct purchases by the Federal Government as estimated by Cogan and Taylor (2012). I rely on these authors' methodology to estimate a quarterly time series of government purchases. The Bureau of Economic Analysis (BEA) has estimated the dollar impact of the ARRA on federal government sector transactions in the national income and product accounts (NIPA), the national accounting system of the United States. I rely on the BEA's estimates to measure a quarterly time series of discretionary government purchases of goods and services for the Federal Government. These estimates are available from 2009Q1, the beginning of the program, through 2013Q1. In particular, I take the sum of Consumption expenditures and Gross investment as the measure of federal purchases undertaken under the ARRA.

Estimating purchases by states and local governments is not as straightforward. A significant portion of the ARRA consisted of transfers and grants to state and local governments, which could then potentially be used for purchases of goods and services (grants for school and infrastructure construction, for example). The bulk of these grants is allocated to Medicaid, which is effectively 
a transfer to households. I use the residual of these transfers (total transfers minus Medicaid) as a proxy for state and local government purchases, adding it to the measure of Federal purchases. ${ }^{35}$

Transfers to Households Several types of policies involved transfers to households, either explicitly or implicitly. I aggregate a relatively wide range of policies into this measure, which are broadly of three types: (a) tax cuts and rebates, (b) social transfers (i.e. unemployment benefits, Medicaid), and (c) homeowner/borrower relief.

The ARRA included several tax credit and social transfer policies, as well as the aforementioned Medicaid transfers to state and local governments. Again, I use the BEA estimates to compute total transfers made under ARRA programs. I take (minus) revenue losses on Current Tax Receipts (these include tax benefits given as part of programs such as "Making Work Pay"), plus Current Transfer Payments, plus Grants to state and local governments minus the residual that I classified as purchases above. ${ }^{36}$

Another large tool of US discretionary fiscal policy in the Great Recession were the tax rebates included in the Economic Stimulus Act of 2008. This consisted, primarily, of tax rebates targeted at low and middle-income households. The impact of these tax rebates on household and aggregate consumption and demand has been studied by Parker et al. (2013) and Broda and Parker (2014). The program was nominally allocated $\$ 106$ bn, with the Department of Treasury disbursing $\$ 79$ bn in the second quarter of 2008 and an additional \$15 bn in the third quarter.

Finally, the TARP included a host of programs aimed at helping homeowners in need. Many of these programs involved government-sponsored debt restructuring through incentive payments to mortgage lenders. For simplicity, and given that these programs involve implicit transfers of wealth to borrowers (who are also the homeowners in the model), I classify them as transfers. I collect data on amounts allocated and effectively disbursed under TARP programs from the website of the U.S. Treasury.I consider three TARP programs as transfers: Making Home Affordable (MHA), Federal Housing Agency Refinance Program (FHA-RP), and the Hardest Hit Fund (HHF). The MHA, through its main pillar, the Home Affordable Modification Program (HAMP), provided mortgage lenders with incentive payments to restructure or refinance mortgages, and/or give temporary forbearance so as to avoid foreclosure. The MHA was allocated $\$ 30 \mathrm{bn}$, of which about half was actually disbursed. The FHA-RE was targeted at homeowners who were current on their payments, but underwater. The FHA would help these homeowners to refinance their mortgages with new ones that were adjusted for lower house values. While the FHA-RE was allocated over $\$ 1$ bn, less than $\$ 60 \mathrm{M}$ had actually been disbursed by 2016. Finally, the HHF consisted of extra funds made available by the Treasury to the state housing agencies in those states that were hardest hit by unemployment. They were mostly channeled towards foreclosure prevention, and many of the policy tools and effects thus overlap with those of HAMP. The HHF was allocated $\$ 9.6 \mathrm{bn}$, of

\footnotetext{
${ }^{35}$ This is likely to be an underestimate, however, since higher Federal Medicaid transfers from the federal government may in turn lead state governments to allocate less of their own funds to Medicaid, and more funds to purchases.

${ }^{36}$ This leaves, effectively, the categories Medicaid and Education.
} 
which $\$ 6.5$ bn were actually disbursed.

Equity Injections and Transfers to the Financial Sector Equity injections in financial institutions were arguably the most visible face of TARP. They were conducted through several programs, most notably through the Capital Purchase Program (CPP), which involved the purchase of preferred stock and warrants of commercial and investment banks, and let to total disbursements of $\$ 245$ bn. A similar but considerably smaller program, the Community Development Capital Initiative (CDCI), was also launched for credit unions. Additional programs that involved direct equity purchases of financial firms by the government were also launched for institutions that were deemed systemic (the Treasury Investment Program, targeted at Bank of America and Citigroup), for AIG, and for the government-sponsored enterprises Fannie Mae and Freddie Mac. I collect data on fund attribution under all of these programs from the website of the US Department of Treasury.

Credit and Asset Guarantees In this category, I include not only direct credit and asset guarantee programs, but more broadly any lender-of-last-resort (LOLR) interventions that were deployed by the US Treasury and the FDIC. The important distinguishing feature of this type of interventions is that they involve, in one way or another, the creation of a contingent liability for the public agency.

The only large guarantee program financed directly by the Treasury was the aptly named Asset Guarantee Program, through which the Treasury provided a \$5 bn asset guarantee to Citigroup. ${ }^{37}$ Additionally, the Treasury committed $\$ 100 \mathrm{M}$ to the Term Asset-Backed Securities Loan Facility of the Federal Reserve. None of these guarantees were ever triggered.

Indirectly, the Treasury was also responsible by the Temporary Liquidity Guarantee Program operated by the FDIC, which guaranteed all transaction accounts and some unsecured senior debt issued by participating banks. The program was initiated in late 2008 and, at its peak, over $\$ 340$ bn of bank debt was guaranteed under this program.

I collect data on funds committed and maturity of the guarantees for all the programs mentioned above. For the purpose of the model, the relevant metric are not funds disbursed, but rather funds committed as a percentage of outstanding financial debt.

\section{Discretization of Fiscal Policy Series}

As stated in the main text, I assume that each fiscal policy series $\omega_{t}$ follows a two-state Markov process described by

$$
\omega_{t}=\left[\omega^{\text {normal }}, \omega^{\text {crisis }}\right]^{T} \quad \text { and } \quad \mathbf{P}^{\omega}=\left[\begin{array}{cc}
.995 & .005 \\
1-p^{\omega} & p^{\omega}
\end{array}\right]
$$

\footnotetext{
${ }^{37}$ A $\$ 7.5$ bn asset guarantee was also negotiated with Bank of America, but never implemented.
} 
our goal is to estimate $\theta=\left(\omega^{\text {crisis }}, p^{\omega}\right)$ given the observed path of the policy over the sample $\left\{\omega_{t}\right\}_{t=0}^{T} \equiv \omega^{T}$. Since this is basically a hidden Markov model, I use the so-called Hamilton filter (Hamilton, 1989) to construct the likelihood function and estimate these parameters using maximum likelihood.

To do this, let $x_{t}$ denote the "hidden state", which is the policy discretization, and assume that the policy is observed subject to some measurement error,

$$
\omega_{t}=x_{t}+\epsilon_{t}
$$

where $\epsilon_{t} \sim \mathcal{N}(0, \sigma)$, and $x_{t}$ follows the two-state Markov chain described above. I set $\sigma$, the standard deviation of measurement error, to be equal to $10 \%$ of the standard deviation of the data series. We want to solve

$$
\max _{\theta} \mathcal{L}\left(\omega^{T} ; \theta\right)
$$

which requires constructing the likelihood function. Generically,

$$
\mathcal{L}\left(\omega^{T} ; \theta\right)=\prod_{t=1}^{T} \operatorname{Pr}\left(\omega_{t} \mid \omega_{t-1} ; \theta\right)
$$

and we can write

$$
\operatorname{Pr}\left(\omega_{t} \mid \omega_{t-1} ; \theta\right)=\int \operatorname{Pr}\left(\omega_{t} \mid x_{t} ; \theta\right) \operatorname{Pr}\left(x_{t} \mid \omega_{t-1} ; \theta\right) \mathrm{d} x_{t}
$$

Since we assume $x_{t}$ to be a discrete process with values $\left\{x_{1}, \ldots, x_{j}, \ldots, x_{N}\right\}$, the conditional density is simply

$$
\operatorname{Pr}\left(\omega_{t} \mid \omega_{t-1} ; \theta\right)=\sum_{j=1}^{N} \operatorname{Pr}\left(\omega_{t} \mid x_{t}=j ; \theta\right) \operatorname{Pr}\left(x_{t}=j \mid \omega_{t-1} ; \theta\right)
$$

The first term is easy to evaluate for any $j$, since it comes from the measurement error equation. The second term is trickier, for which the filter is helpful. Let $\xi_{t \mid t}$ be a $N \times 1$ vector of conditional probabilities $\left[\operatorname{Pr}\left(x_{t}=j \mid \omega^{t} ; \theta\right)\right]_{j=1}^{N}$, and let $\xi_{t+1 \mid t}$ be the vector of $\operatorname{Pr}\left(x_{t+1}=j \mid \omega^{t} ; \theta\right)$. Then, we have that

$$
\xi_{t+1 \mid t}=\left(\mathbf{P}^{\omega}\right)^{T} \xi_{t \mid t}
$$

and the filtering step is given by

$$
\xi_{t+1 \mid t+1}=\frac{\operatorname{Pr}\left(\omega_{t+1} \mid x_{t+1}, \omega^{t} ; \gamma\right) \odot \xi_{t+1 \mid t}}{\sum_{j=1}^{N} \operatorname{Pr}\left(\omega_{t+1} \mid x_{t+1}=j, \omega^{t} ; \gamma\right) \odot \xi_{t+1 \mid t}(j)}
$$

where $\odot$ is the Hadamard product (element-wise multiplication). Given an initial condition $\xi_{0 \mid 0}$, this filtering procedure allows us to easily construct the likelihood function. The likelihood function can then be maximized with respect to the parameters using standard procedures. 
As the initial condition, I set $\xi_{0 \mid 0}=[1,0]^{T}$, since the first period of the sample is 2000Q1, when no discretionary policy was in place. To estimate the sequence of states $\left\{x_{t}\right\}_{t=0}^{T}$, I use the backward sampler that works as follows: draw $x_{T}$ from $\xi_{T \mid T}$. Given $x_{T}=k$, compute

$$
\xi_{T-1 \mid T}(j)=\operatorname{Pr}\left(x_{T}=k \mid x_{T-1}=j\right) \times \frac{\xi_{T-1 \mid T-1}(j)}{\xi_{T \mid T-1}(k)}
$$

Sample $x_{T-1}$ using $\xi_{T-1 \mid T}$. Then, repeat the process and iterate backwards until $x_{1}$.

\section{E Additional Figures}
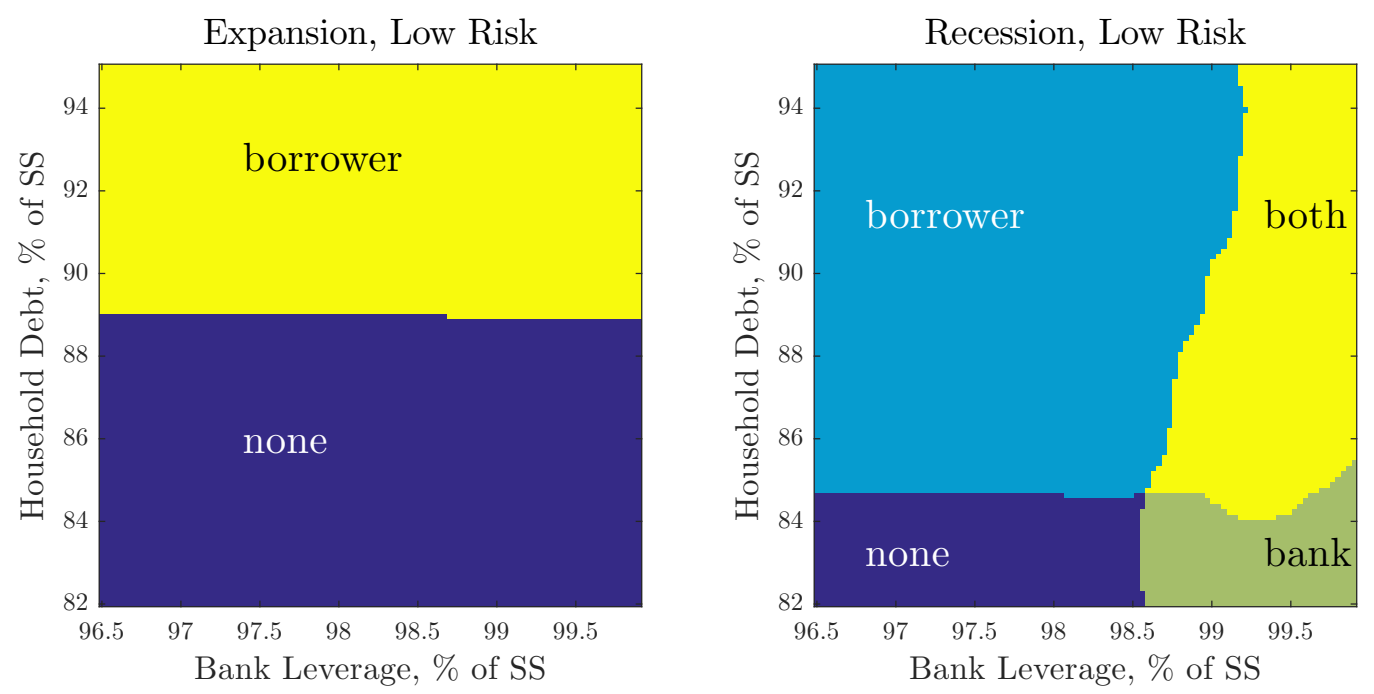

Figure A.1: Binding Constraints over the State Space, TFP Expansion vs. Recession. 

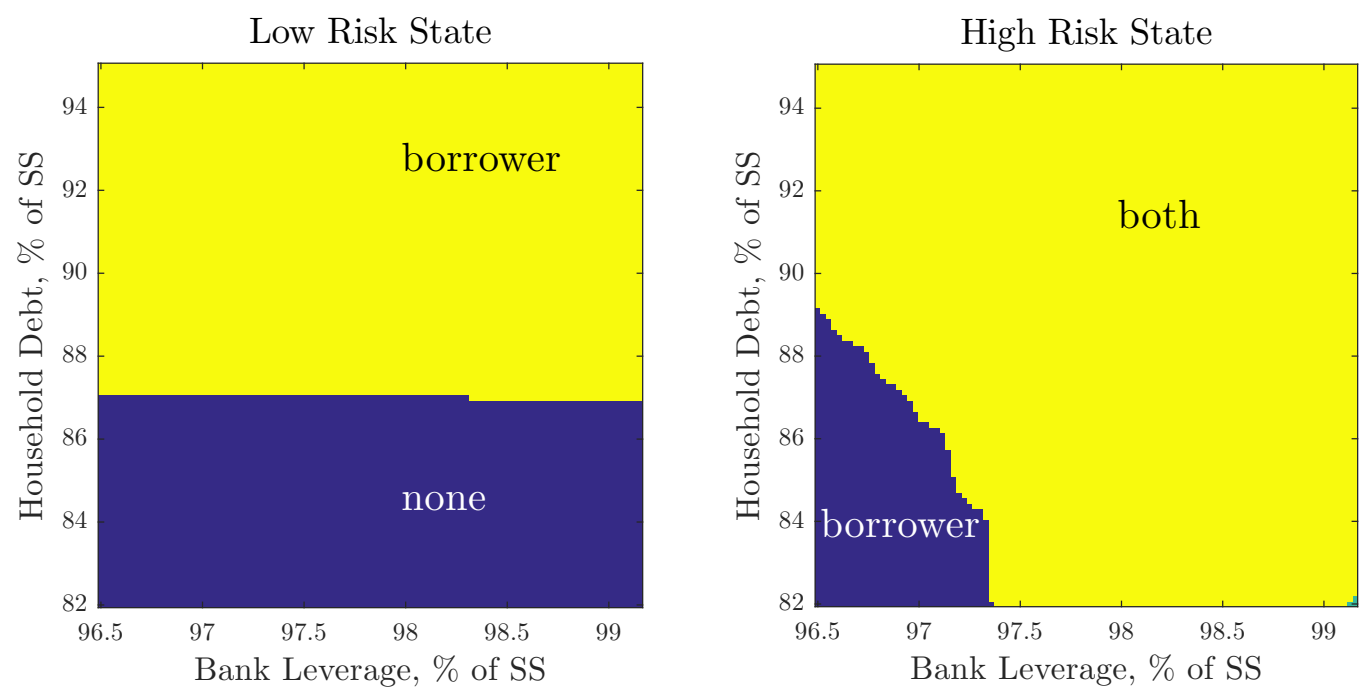

Figure A.2: Binding Constraints over the State Space, Low vs. High Risk States.
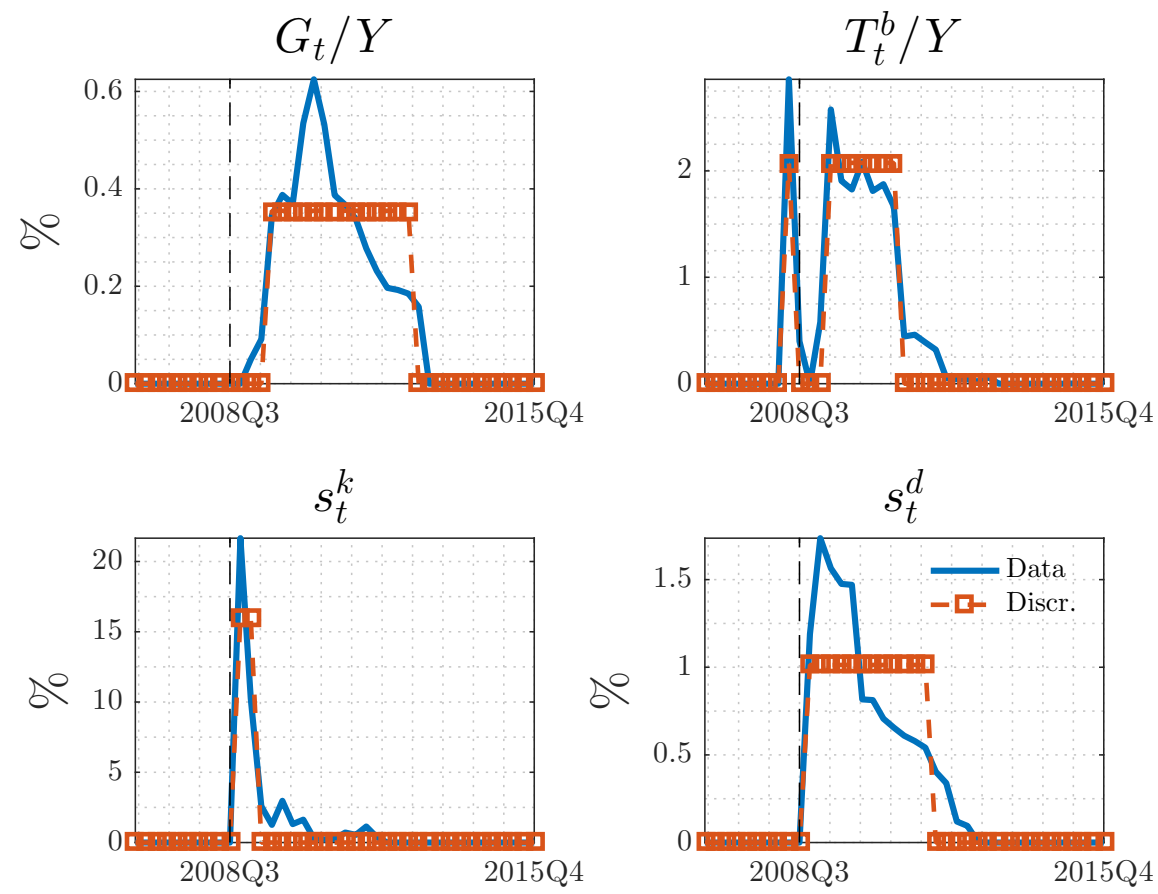

Figure A.3: Implied series for discretionary fiscal policy in the model (solid blue) and discretized series (orange squares). 


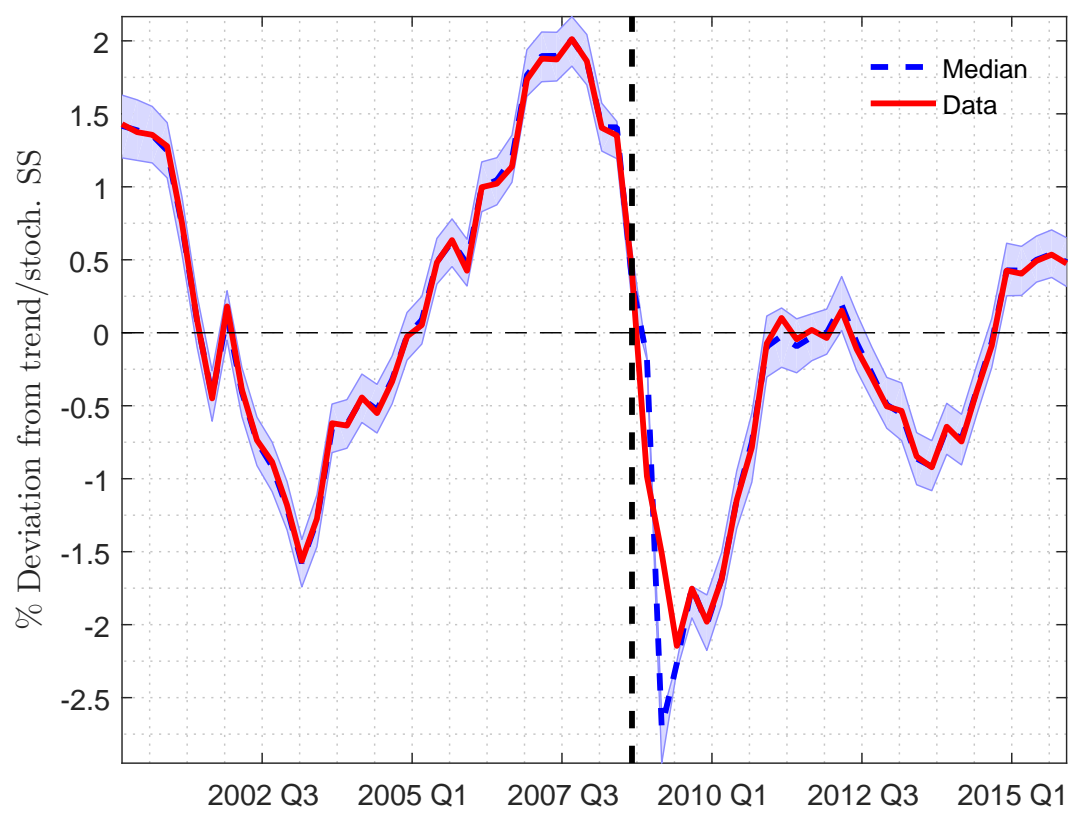

Figure A.4: Consumption: data (solid red) vs. median of smoothed series (dashed blue) and 5\% confidence bands

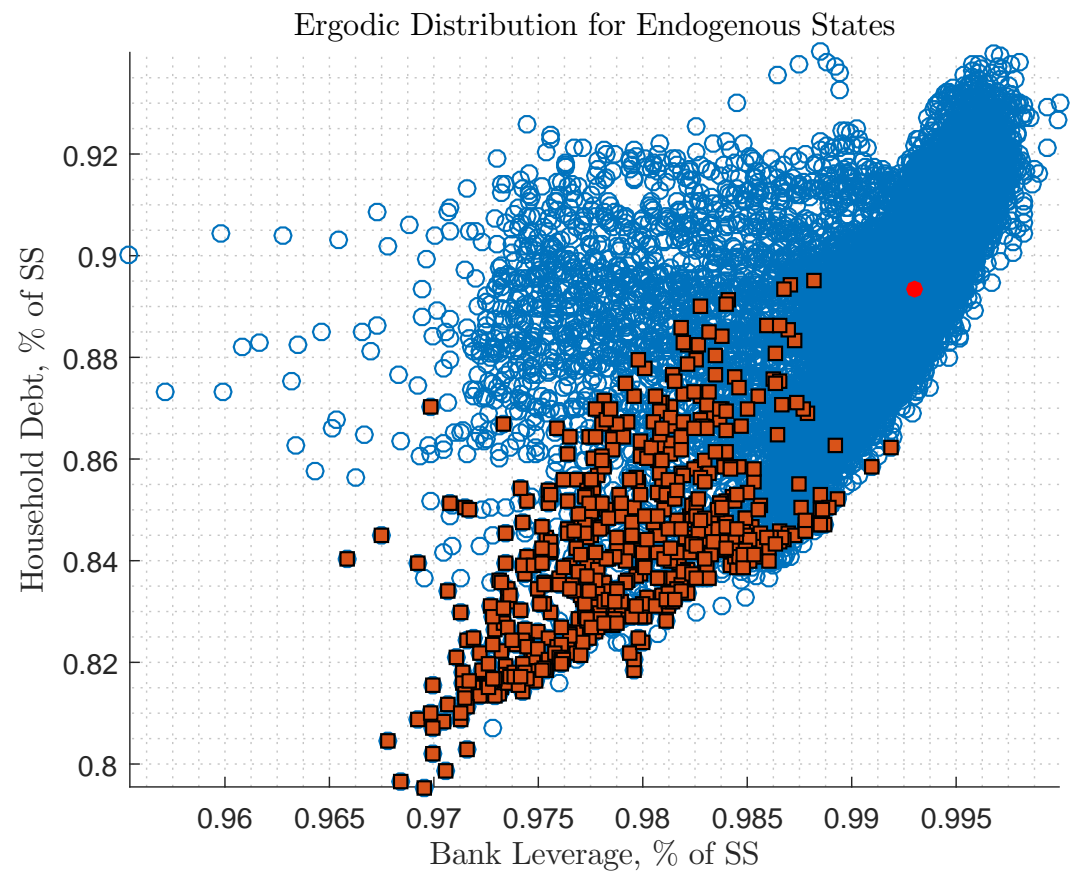

Figure A.5: Distribution of endogenous states over the bank leverage - household debt space. Filled orange squares are realizations with high risk. The solid red dot is the stochastic steady state. 

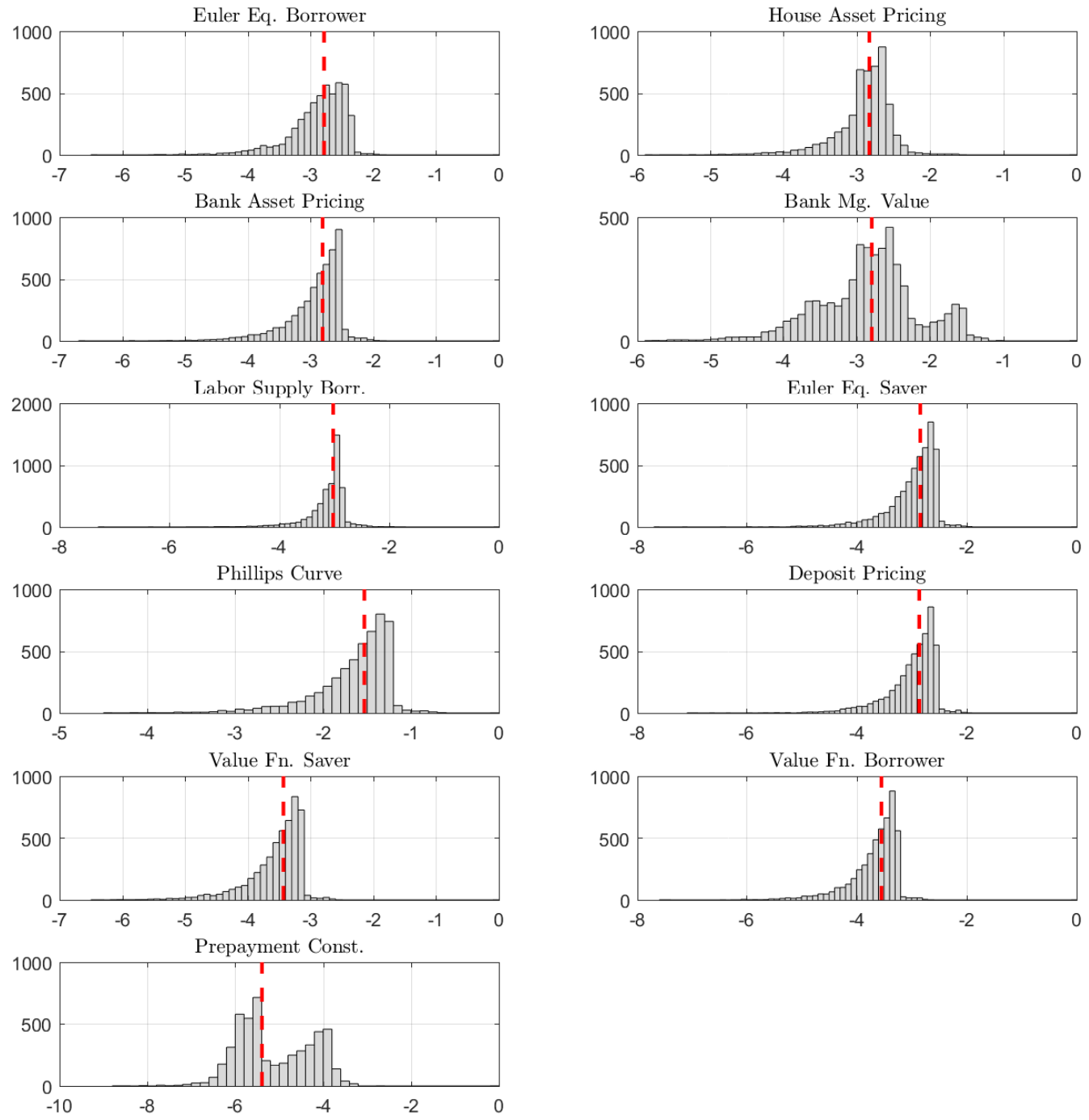

Figure A.6: Simulation Euler Equation Residuals, decimal log base 